Colloid-Facilitated Radionuclide Transport in Fractured Carbonate Rock from Yucca Flat, Nevada National Security Site

M. Zavarin, S.K. Roberts, M.R. Johnson, Q. Hu, B.A. Powell, P. Zhao, A.B. Kersting, R.E. Lindvall, R.J. Pletcher

February 19, 2013 
This document was prepared as an account of work sponsored by an agency of the United States government. Neither the United States government nor Lawrence Livermore National Security, LLC, nor any of their employees makes any warranty, expressed or implied, or assumes any legal liability or responsibility for the accuracy, completeness, or usefulness of any information, apparatus, product, or process disclosed, or represents that its use would not infringe privately owned rights. Reference herein to any specific commercial product, process, or service by trade name, trademark, manufacturer, or otherwise does not necessarily constitute or imply its endorsement, recommendation, or favoring by the United States government or Lawrence Livermore National Security, LLC. The views and opinions of authors expressed herein do not necessarily state or reflect those of the United States government or Lawrence Livermore National Security, LLC, and shall not be used for advertising or product endorsement purposes.

This work performed under the auspices of the U.S. Department of Energy by Lawrence Livermore National Laboratory under Contract DE-AC52-07NA27344. 


\title{
Colloid-Facilitated Radionuclide Transport in Fractured Carbonate Rock from Yucca Flat, Nevada National Security Site
}

\author{
Mavrik Zavarin ${ }^{1}$, Sarah K. Roberts ${ }^{2}$, Mackenzie R. Johnson ${ }^{3}$, \\ Qinhong Hu${ }^{1}$, Brian A. Powell ${ }^{1}$, Pihong Zhao ${ }^{1}$, Annie B. Kersting ${ }^{1}$, Rachel E. Lindvall ${ }^{1}$, and \\ Ronald J. Pletcher ${ }^{2}$ \\ ${ }^{1}$ Chemistry, Materials, and Life Sciences Directorate* \\ ${ }^{2}$ Energy and Environment Directorate* \\ ${ }^{3}$ Engineering Directorate* \\ Lawrence Livermore National Laboratory \\ Livermore, California \\ Prepared for the Underground Test Area Project \\ U. S. Department of Energy \\ National Nuclear Security Administration \\ Nevada Field Office
}

May, 2013

* Directorates are identified as they existed when experiments were conducted (2006). 


\section{TABLE OF CONTENTS}

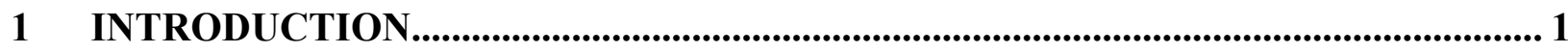

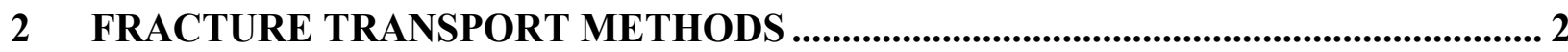

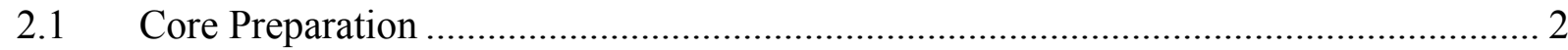

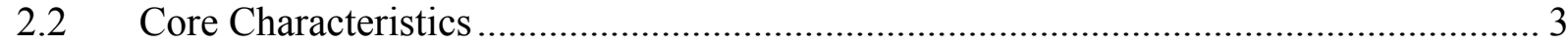

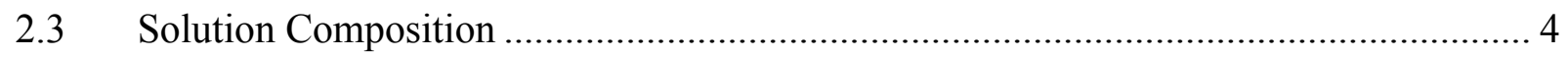

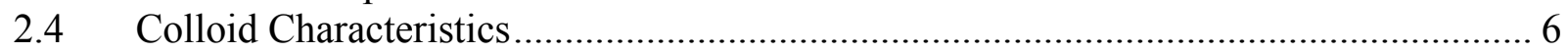

2.5 Flowthrough Experiment Apparatus...................................................................... 7

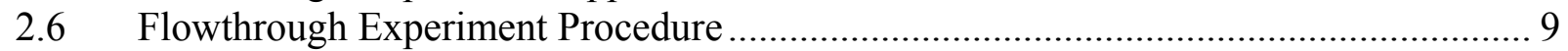

2.7 Effluent and Post-Test Core Characterization ............................................................ 9

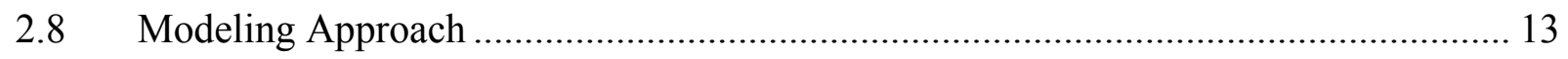

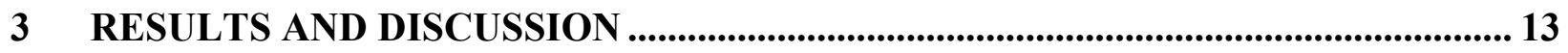

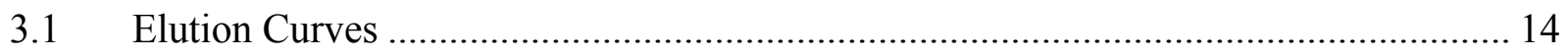

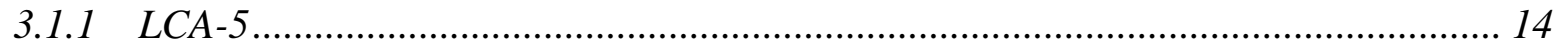

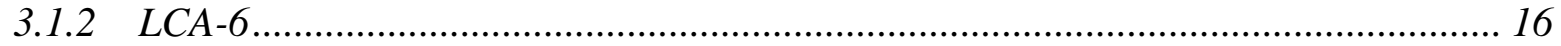

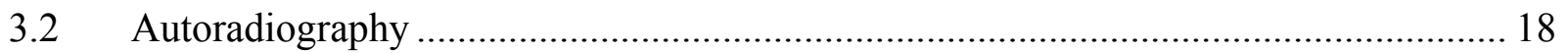

3.2.1 LCA 5 -

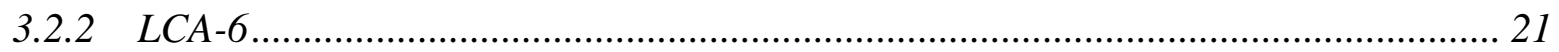

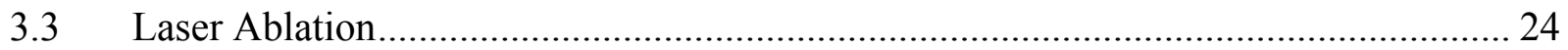

4 REACTIVE TRANSPORT MODELING ..................................................................... 29

5 CONCLUSIONS AND RECOMMENDATIONS........................................................... 35

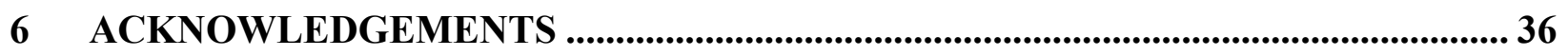

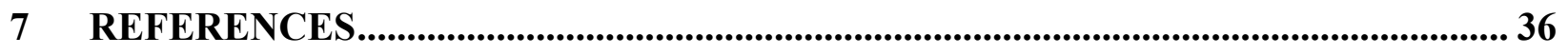

8 APPENDIX ......................................................................................................................... 39 


\section{LIST OF FIGURES}

Figure 2.1 Photograph of experimental set-up showing membrane sealed core in flowthrough reactor. Gradient HPLC pump that controlled flow rate is behind the flowthrough reactor, and the fraction collector for outflow solutions is seen at right

Figure 2.2 Fracture flow experiment diagram where sketches (a) to (e) show steps in experiment preparation (slotted fractures). Sample core (a) has reference flats ground on end surfaces and at relative azimuths of 0,90 , and $180^{\circ}$ on the cylindrical surface (b); core is cut in half (c); is laid open and a 500 or $50 \mu \mathrm{m}$ wide slot is ground into one side (d); finally it is reassembled (e) for experiments. (Images (a)-(e) from Durham et al. (2001)) ..................... 8

Figure 2.3 Examples of signal responses for elements from laser ablation on the LCA-6 sample. "Bkgd" represents instrument background. ...................................................................... 11

Figure 2.4 Instrumental signal responses for internal standards during laser ablation sampling for LCA-5.

Figure 2.5 Elemental signal responses from NIST Standard Reference Material glasses (SRM $610,612,614$, and 616).

Figure 2.6 Calibration curves using NIST Standard Reference Material glasses (SRM 610, 612, 614, and 616). Y-axis is the dimensionless response (such as these in Y-axis of Figure 2.3) of each isotope divided by that of ${ }^{44} \mathrm{Ca}$.

Figure 3.1 LCA-5 breakthrough plot (log scale y-axis). The two vertical lines represent the beginning and end of the sorption pulse.

Figure 3.2 LCA-5 breakthrough plot (linear scale y-axis). Sorption pulse timeframe magnified. The two vertical lines represent the beginning and end of the sorption pulse...................... 16

Figure 3.3 LCA-6 breakthrough plot (log scale y-axis). The two vertical lines represent the beginning and end of the sorption pulse.

Figure 3.4 LCA-6 breakthrough plot (linear scale y-axis). Sorption pulse timeframe magnified.

The two vertical lines represent the beginning and end of the sorption pulse.

Figure 3.5 One-half of LCA-5 core (top right) and developed radiography plates (bottom right). Image of developed film is overlain on the core (left) and the arrow is noting direction of flow during the flowthrough experiment. Dark spots on the radiography plates indicate regions of concentrated alpha activity. Expanded inset of LCA-5 core outlet is shown in top left position.

Figure 3.6 One-half of LCA-6 core (top right) and developed radiography plates (bottom right). Image of developed film is overlain on the core (left) and the arrow is noting direction of flow during the flowthrough experiment. Dark spots on the radiography plates indicate regions of concentrated alpha activity. Areas noted A, B, and C (left) show areas of interest as discussed in the text.

Figure 3.7 Digital image of precipitates/colloids and synthetic fibers observed in region B of Figure 3.6. 23

Figure 3.8 Digital image of region C from Figure 3.6. Scale markings represent $1 \mathrm{~mm}$........... 24 Figure 3.9 Distribution of isotopes obtained from surface profiling in LCA-5 core using LA/ICP-MS. Symbols represent data; lines represent background intensity ratios (average \pm standard deviation). The distribution of intrinsic Mg-26 is also shown. 
Figure 3.10 Distribution of several isotopes obtained from depth profiling in LCA-5 core sample using LA/ICP-MS at two locations near the core inlet. Symbols represent data; lines represent background intensity ratios (average \pm standard deviation).

Figure 3.11 Distribution of isotopes obtained from surface profiling in LCA-6 core using LA/ICP-MS. Symbols represent data; lines represent background intensity ratios (average \pm standard deviation).

Figure 3.12 Distribution of Fe and Pu on LCA-6 fracture surface using LA/ICP-MS. Strong correlation is indicative of the preferential sorption of $\mathrm{Pu}$ to iron oxide vs. calcite. 29

Figure 4.1 Model fits to LCA-5 (A) and LCA-6 (B) non-sorbing tracer elution data. 31

Figure 4.2 LCA-5 model of aqueous tracer radionuclide distribution at end of flowthrough experiment.

Figure 4.3 Model fits to LCA-5 (A) and LCA-6 (B) U(VI) elution data. 31

Figure 4.4 Model fits to LCA-5 (A) and LCA-6 (B) Sm(III) elution data. .............................. 32

Figure 4.5 LCA-5 model of sorbed radionuclide distribution for $\mathrm{U}, \mathrm{Sm}, \mathrm{Pu}(\mathrm{IV})$, and $\mathrm{Pu}(\mathrm{V})$ at end of flowthrough experiment.

Figure 4.6 Model fits to LCA-5 (A) and LCA-6 (B) Pu elution data. Model results also include transport behavior of $\mathrm{Pu}(\mathrm{IV})$ and $\mathrm{Pu}(\mathrm{V})$.

Figure 4.7 LCA-6 model of sorbed radionuclide distribution at end of flowthrough experiment.

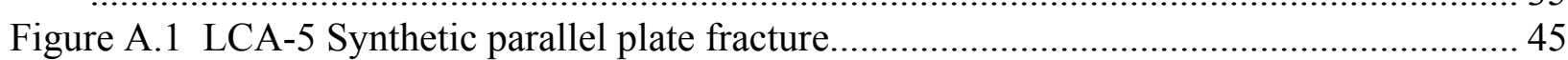

Figure A.2 LCA-6 Synthetic parallel plate fracture .......................................................... 45 


\section{LIST OF TABLES}

Table 2.1 Core parameters. ............................................................................................... 2

Table 2.2 Composition of background solutions used in flowthrough experiments. ................... 4

Table 2.3 Composition of LCA waters in Yucca Flat. .............................................................. 5

Table 2.4 Radionuclide composition of solutions used in flowthrough experiments.................. 5

Table 2.5 Percentage of $\mathrm{Pu}$ associated with colloids. ${ }^{\mathrm{a}}$.............................................................. 7

Table 2.6 Duration (in days) of each experimental stage for the individual cores. .................... 9

Table 3.1 Fraction of radionuclides eluted over the timeframe of each experiment. ................ 14

Table 3.2 Exposure times for $\alpha$-radiography on the rock cores.......................................... 18

Table 4.1 Predicted and fitted radionuclide retardation and diffusion parameters for carbonate

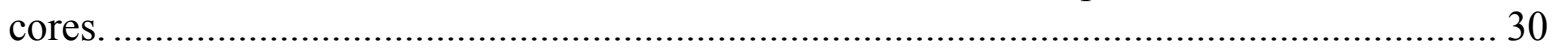

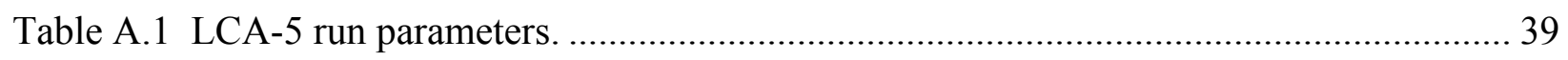

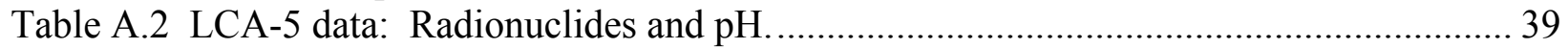

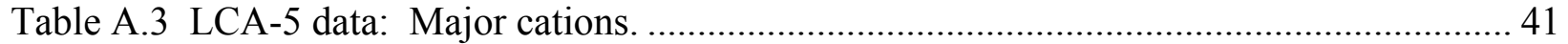

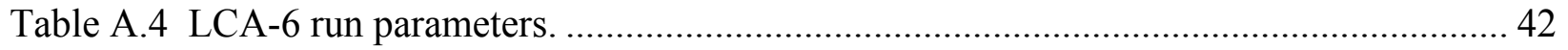

Table A.5 LCA-6 data: Radionuclides and pH.............................................................. 42

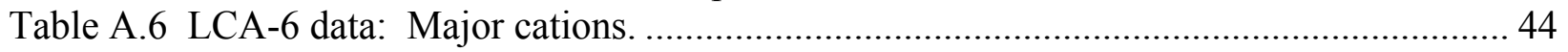




\section{INTRODUCTION}

In the Yucca Flat basin of the Nevada National Security Site (NNSS), 750 nuclear detonations were conducted, primarily within the tuff confining unit (TCU) and the overlying alluvium. The regional carbonate aquifer (lower carbonate aquifer) is located below the TCU and is the most likely pathway for radionuclide migration off the NNSS. The regional carbonate aquifer underlies most of the NNSS and is known to be highly transmissive. Two principal pathways for LCA contamination exist in Yucca Flat. The first is composed of shortcuts (e.g. fractures) through the TCU which may provide a radionuclide transport pathway from tests conducted in the overlying alluvium and volcanics. The second is the release and migration of radionuclides from a small number (four) of tests conducted directly in the carbonate rock. Two of those tests were located near the saturated zone (Nash and Bourbon).

Understanding the migration behavior of radionuclides once they reach the fractured LCA is the subject of this report. Because the LCA is the regional aquifer unit and a potentially important radionuclide transport pathway, in FY2005, LLNL conducted a set of laboratory experiments to examine radionuclide transport in carbonate fractures (Zavarin et al., 2005). A complimentary experimental effort was conducted by LANL (Ware et al., 2005) and a summary report has been issued (Zavarin et al., 2006). Absent from these experiments was an examination of the role of colloids in radionuclide transport in carbonate rock. This report summarizes experiments that evaluated the role of colloids in radionuclide transport in fractured carbonate rock. Colloidfacilitated transport has be identified as an important transport mechanisms in fractured tuff (Kersting et al., 1999). It is likely to be similarly important in fractured carbonate.

Carbonate cores were prepared from archived ER-6-1 core obtained from the USGS Core Library, Mercury, Nevada. The core was originally collected in 1994 and placed in boxes without any attempt to preserve natural water contents. Flowthrough experiments were performed using smooth parallel-plate fractures synthesized from the solid core. Smooth parallel-plate fractures were used to better control the processes affecting transport. Natural fractures contain variable apertures and heterogeneously distributed fracture lining minerals which complicate data interpretation. Previous data have shown that transport behavior observed in synthetic parallel-plate fractures is comparable to natural fractures; differences can be attributed largely to the role of fracture lining minerals. Parallel-plate (slotted) fractures were synthesized with apertures of 500 and 50 micrometers. The transport of non-sorbing ${ }^{3} \mathrm{H}$ and $\mathrm{Re}(\mathrm{VII})$, and sorbing $\mathrm{Sm}(\mathrm{III}), \mathrm{U}(\mathrm{VI}), \mathrm{Pu}(\mathrm{IV})$, and $\mathrm{Pu}(\mathrm{V})$ was examined by introducing a short pulse of tracers into the synthetic fracture at a constant flow rate and measuring their breakthrough (i.e. a flowthrough experiment). The tracers ${ }^{3} \mathrm{H}$ and $\mathrm{ReO}_{4}{ }^{-}$are non-sorbing; their transport behavior will be controlled by their diffusivity from the fracture into the carbonate matrix. Samarium(III) is expected to sorb very strongly to both colloids and the carbonate matrix; its transport will be governed by colloid-facilitated transport. Samarium behaves similar to other trivalent radionuclides that have been deposited in the subsurface of the NNSS as a result of underground nuclear testing. (e.g. ${ }^{244} \mathrm{Cm},{ }^{243} \mathrm{Am},{ }^{241} \mathrm{Am},{ }^{150} \mathrm{Eu},{ }^{152} \mathrm{Eu},{ }^{154} \mathrm{Eu},{ }^{166} \mathrm{Ho}$ ). Uranium(VI) sorption to aluminosilicate colloids and carbonate rock is weak. It is expected to migrate as an aqueous species and only slightly retarded by its interaction with the carbonate 
matrix. Plutonium(IV) is expected to sorb strongly to both colloids and the carbonate matrix. However, as $\mathrm{Pu}(\mathrm{V})$, plutonium is a weak sorber and may migrate as an aqueous species.

During the flowthrough experiments, radionuclide concentrations in the effluent were measured. At the conclusion of the experiments, the distribution of radioactive components that were not transported entirely through the column was examined using autoradiography and laser ablation inductively coupled plasma mass spectrometry (LA/ICP-MS). These data were used to evaluate the accessibility of the rock matrix to tracer diffusion and sorption. At the conclusion of all effluent and post-test core analyses, the reactive transport of radionuclides in the fractures was modeled. Data were modeled using the CRUNCH code (Steefel and Yabusaki, 1995) combined with our surface complexation and ion exchange sorption database (Zavarin and Bruton, 2004a; Zavarin and Bruton, 2004b). Data were also modeled using the RELAP (REactive transport LAPlace transform inversion computer code) code. This code solves a semi-analytical dualporosity transport model of fracture transport. RELAP is described in detail in Reimus and Haga, (1999), Reimus et al. (2003), and Reimus et al. (2002). RELAP/RETRAN solves Laplace transformed versions of the 1-D dual-porosity transport equations using a Laplace-to-time domain inversion algorithm. One of the solutions included in the RELAP model is the parallel plate, infinite matrix, equilibrium sorption fracture transport solution of Tang et al. (1981). However, RELAP/RETRAN may also account for finite matrices, rate-limited sorption, and radial flow. All data and modeling results are compared to earlier carbonate fracture transport experiments in the absence of colloids.

\section{FRACTURE TRANSPORT METHODS}

\subsection{Core Preparation}

Fracture flowthrough experiment core characteristics are listed in Table 2.1. The carbonate cores had an original diameter of $83 \mathrm{~mm}$ (3.25 inches) and were sub-cored to a diameter of $70 \mathrm{~mm}$ using a diamond impregnated water-cooled core barrel. The ends of each core were ground with a precision grinding machine to the size designated for each of the two flowthrough reactors. The Appendix contains photographs of the prepared cores used in the flowthrough tests.

Table 2.1 Core parameters.

\begin{tabular}{cccccccccccc}
\hline Exp\# & Well and depth & Mass & Length & Diam & Aperture & Porosity & Permeability & $\begin{array}{c}\text { Bulk } \\
\text { Density }\end{array}$ & $\begin{array}{c}\text { Inflow } \\
\text { Tube Vol. }\end{array}$ & $\begin{array}{c}\text { Outflow } \\
\text { Tube Vol. }\end{array}$ & $\begin{array}{c}\text { Flow } \\
\text { Rate }\end{array}$ \\
& feet & $\mathrm{g}$ & $\mathrm{mm}$ & $\mathrm{mm}$ & $\mu \mathrm{m}$ & $\%$ & $\mathrm{md}^{1}$ & $\mathrm{~g} / \mathrm{cm}^{3}$ & $\mathrm{~mL}$ & $\mathrm{~mL}$ & $\mathrm{~mL} / \mathrm{min}$ \\
\hline LCA-5 & $\begin{array}{c}\text { ER-6-1 } \\
\begin{array}{c}2601.7-2602.8 \\
\text { ER-6-1 }\end{array}\end{array}$ & 1204 & 113 & 70 & 500 & 1.0 & $1.9 \mathrm{E}-3$ & 2.80 & 1.42 & 0.59 & 0.02 \\
LCA-6 & $2619.0-2620.0$ & $\sim 1200$ & 128 & 70 & 50 & 4.9 & 6.0 & 2.70 & 1.84 & 0.68 & 0.02 \\
\hline
\end{tabular}

${ }^{1}$ Units of permeability are presented as millidarcy $(\mathrm{md}) .1$ Darcy $=9.87 \times 10^{-13} \mathrm{~m}^{2}$.

The subcores were sawed in half and opposing faces of the core were ground flat and parallel to the saw-cut (used for orientation purposes during grinding). The two inner faces were then ground flat with a fine-grained diamond impregnated grinding wheel. The same machine was used to grind a trench in one of the surfaces such that when the two halves were re-joined, there 
would be a synthetic fracture (a "slot") with a known aperture with a width equal to the depth of the trench (see Figures 2.1 and 2.2). The depth of this trench was 500 and $50 \mu \mathrm{m}$ for LCA-5 and LCA-6, respectively. After both ends of the core had been ground flat (and thus perpendicular to the length of the core), the halves were placed in an ultrasonic bath of deionized water for five minutes to remove any fine-grained particles from the pores that were trapped during the machining. The cores were then placed in a $50^{\circ} \mathrm{C}$ oven for 48 hours. Finally, the two halves were glued together by applying Devcon ${ }^{\circledR}$ Flexane quick-drying, chemically-resistant rubber epoxy to the external edges of the synthetic fracture. The cores were then placed in a flowthrough apparatus.

\subsection{Core Characteristics}

The porosity, density, and permeability of each core are reported in Table 2.1. Measurements were made by sub-coring one inch diameter $(2.54 \mathrm{~cm})$ plugs from rock adjacent vertically to the prepared fractured cores and shipping the plugs to Core Laboratories Inc. (Aurora, CO) for analysis. Specific physical properties (length, diameter, weight, and bulk volume) of each plug sample were measured and recorded. Samples were dried in an oven for 24 hours at $180^{\circ} \mathrm{F}$ $\left(80^{\circ} \mathrm{C}\right)$ before permeability and porosity measurements were recorded. Permeability (using nitrogen) and porosity (using helium) were measured for each sample according to standard procedures (API RP 27, 1952; API RP 40, 1960).

For porosity, samples were placed into a Coberly-Stevens Boyle's Law porosimeter and injected with helium at approximately $100 \mathrm{psig}$. Corresponding pressures and volumes were measured and Boyle's Law was used to calculate sample grain volume. Pore volume was determined by subtracting the calculated grain volume from the measured bulk volume. Grain density and bulk density values were calculated from these measurements. Importantly, rock porosities can vary substantially over very short distances. Thus, the reported porosities may not be equivalent to those of the synthetically fractured cores used in flowthrough experiments. Nevertheless, it is quite clear that the porosity of these rocks is quite low.

For permeability, samples were placed into a Hassler-Sleeve core holder. The annulus of the core holder was pressurized to a pre-determined value (400 psig minimum) to seal the sample. Nitrogen gas was forced through the sample at a given pressure under steady-state conditions. The flow rate was measured and permeability to air was calculated. A Klinkenberg-corrected permeability value was obtained using these values.

The mineralogy of the carbonate cores was determined by $\mathrm{x}$-ray diffraction (XRD). X-ray scans were collected using a Scintag PAD-V generator equipped with a $\mathrm{Cu}$ x-ray tube operated at 45 $\mathrm{kV}$ and $35 \mathrm{~mA}$, and a Sieffert goniometer with a solid-state detector. Diffraction patterns were collected in step scan mode at 4 seconds per $0.02^{\circ} 2 \theta$. Collimation was provide by a $1^{\circ}$ divergence and $2^{\circ}$ scatter slit on the $\mathrm{x}$-ray tube and a $0.3 \mathrm{~mm}$ scatter and $0.2 \mathrm{~mm}$ registration slit on the detector. Samples were scanned from 2 to $72^{\circ} 2 \theta$.

Quantitative mineralogic analyses were performed using the Rietveld method. Phase identification was accomplished using an XRD pattern processing software program (Jade, version 3.0, Materials Data, Inc., Livermore, CA), which utilizes data from the Joint Committee 
on Powder Diffraction Standards Powder Diffraction File (JCPDS-PDF). The Rietveld least squares refinement was performed using a quantitative XRD software program (Siroquant, version 2.0, Sietronics, Australia). Both cores were composed of essentially pure dolomite. Quartz was the only other mineral identified in LCA-5 at $1.6 \%$.

\subsection{Solution Composition}

The background solution composition used in the carbonate flowthrough experiments (Table 2.2) was based on measured concentrations of major ions in groundwaters sampled from the LCA (Table 2.3), culled from the UGTA geochemistry database (Stoller-Navarro, 2004). Sulfate, nitrate, and fluoride were omitted from the background solution because their role in radionuclide retardation is expected to be minimal. The calcium concentration was adjusted by equilibrating background solutions with calcite to minimize calcite dissolution/precipitation during flowthrough experiments. The LCA experiment solution was prepared at equilibrium with atmospheric $\mathrm{CO}_{2}(\mathrm{~g})$ (higher $\mathrm{pH}$ and lower carbonate alkalinity than measured LCA groundwater composition) to improve solution composition stability. Sensitivity calculations suggest that the difference in groundwater composition may increase the experiment $\mathrm{Kd}$ by as much as $0.5 \log$ units for Pu but significantly less for other radionuclides when compared to average LCA groundwater chemistry.

Table 2.2 Composition of background solutions used in flowthrough experiments.

\begin{tabular}{|c|c|c|c|c|c|}
\hline Exp\# & pH & $\mathbf{N a}$ & Mg & $\bar{K}$ & $\mathbf{C a}$ \\
\hline & 70 & $11 \times 10^{-3}$ & $0.1 \times 10^{-4}$ & $\mathrm{~L}-$ & $77 \times 10^{-4}$ \\
\hline LCA-6 & 7.8 & $3.8 \times 10^{-3}$ & $8.8 \times 10^{-4}$ & $2.3 \times 10^{-3}$ & $8.6 \times 10^{-4}$ \\
\hline
\end{tabular}

Radionuclides used in the flowthrough experiments were chosen because they represent a range of transport behavior. Table 2.4 summarizes the radionuclide composition of these solutions. The solutions were prepared by spiking the prepared background solutions with the appropriate amount of each radionuclide. The concentration of each radionuclide was chosen based on a combination of instrument detection limits, expected background concentrations in equilibrium with LCA rock, solubility limits, and sorption linearity.

For $\mathrm{Pu}$, two stock solutions were used to provide an appropriate ${ }^{238} \mathrm{Pu}$ alpha signal for Liquid Scintillation Counting (LSC) and post-test characterization and ${ }^{242} \mathrm{Pu}$ signal for ICP-MS analysis. Both Pu stock solutions were purified using TEVA resin (Eichrom Technologies, Inc.) columns and diluted into $1 \mathrm{~mol} / \mathrm{L} \mathrm{HNO}_{3}$. 
Table 2.3 Composition of LCA waters in Yucca Flat.

\begin{tabular}{|c|c|c|c|c|c|c|c|c|c|c|c|c|}
\hline \multirow{2}{*}{ SITE_ID } & Sample Date & $\begin{array}{l}\text { Water } \\
\text { Temp }\end{array}$ & $\mathrm{pH}$ & $\mathrm{Ca}$ & $\mathrm{Mg}$ & $\mathrm{Na}$ & K & ${ }^{1} \mathrm{HCO}_{3}$ & $\mathrm{Cl}$ & $\mathrm{SO}_{4}$ & $\mathrm{NO}_{3}$ & $\mathrm{~F}$ \\
\hline & & ${ }^{\circ} \mathrm{C}$ & & & & & & 110 & & & & \\
\hline USGS Water Well C & 9/11/1990 & 36 & 7.3 & 74.5 & 28.2 & 126 & 13.2 & 584 & 33.2 & 65 & n.d. & 1.1 \\
\hline Water Well C-1 & $9 / 25 / 1996$ & 37 & 6.7 & 73 & 27 & 120 & 14 & 580 & 33 & 66 & n.d. & 1.1 \\
\hline ER-6-1 & 10/9/1992 & 43.7 & 7.87 & 33.4 & 12.2 & 47 & 8.32 & 237 & 11.8 & 32.1 & 0.58 & 0.68 \\
\hline ER-6-1 \#2 & $1 / 16 / 2003$ & 39.9 & 7.6 & 33.6 & 14 & 47.1 & 6.3 & 256 & 10 & 34 & 1.1 & 0.8 \\
\hline ER-3-1 & 10/16/1996 & 37.8 & 6.69 & 94.9 & 35.1 & 143 & 19 & 741 & 43.4 & 68.1 & $<0.05$ & 1.38 \\
\hline U-3cn \#5 & $1 / 29 / 1997$ & 42.4 & 7.21 & 39.6 & 16.7 & 53.4 & 7.9 & 262 & 29.5 & 36.2 & $<0.05$ & 0.87 \\
\hline UE-1h (651 m depth) & $5 / 26 / 1993$ & 25.3 & 8.2 & 15.3 & 7.5 & 102 & 25 & 276 & 43.6 & 25 & n.d. & 0.7 \\
\hline UE-1c & $8 / 31 / 1988$ & 26 & 7.98 & 34.1 & 13.2 & 33.7 & 12.7 & 238 & 6.7 & 34.1 & 2.4 & 0.5 \\
\hline UE-1q & 7/10/1992 & 31.5 & 7.8 & 29.4 & 15.3 & 31.2 & 4.6 & 199 & 5.3 & n.d. & n.d. & n.d. \\
\hline UE-10j (765-773 m depth) & 3/17/1997 & 32.7 & 6.43 & 101 & 42.3 & 64 & 12.3 & 504 & 24 & 83 & n.d. & 0.3 \\
\hline UE-10j (732-740 m depth) & $3 / 20 / 1997$ & 32.3 & 6.73 & 68 & 30 & 43 & 8.3 & 403 & 16 & 67 & n.d. & 0.3 \\
\hline UE-10j (691-699 m depth) & $3 / 24 / 1997$ & 32.1 & 6.96 & 56 & 25.4 & 35 & 6.9 & 349 & 12.5 & 60.8 & n.d. & 0.3 \\
\hline Average & & & 7.3 & 51 & 21 & 60 & 11 & 368 & 20 & 49 & $<1.4$ & 0.7 \\
\hline Standard deviation & & & 0.6 & 29 & 11 & 36 & 6 & 173 & 14 & 21 & & 0.4 \\
\hline Average & & & & $1.3 \mathrm{E}-3$ & 8.7E-4 & $2.6 \mathrm{E}-3$ & $2.8 \mathrm{E}-4$ & $6.0 \mathrm{E}-3$ & $5.7 \mathrm{E}-4$ & $5.1 \mathrm{E}-4$ & $<2.2 \mathrm{E}-5$ & $3.8 \mathrm{E}-5$ \\
\hline Standard Deviation & & & & $7.2 \mathrm{E}-4$ & $4.7 \mathrm{E}-4$ & $1.6 \mathrm{E}-3$ & $1.6 \mathrm{E}-4$ & $2.8 \mathrm{E}-3$ & 4.0E-4 & $2.2 \mathrm{E}-4$ & & $1.9 \mathrm{E}-5$ \\
\hline
\end{tabular}

Table 2.4 Radionuclide composition of solutions used in flowthrough experiments.

\begin{tabular}{ccccccc}
\hline Sample \# & $\begin{array}{c}{ }^{3} \mathbf{H} \\
\text { cnts/min }\end{array}$ & Sm & Re & $\begin{array}{c}\text { U } \\
\text { mol/L }\end{array}$ & ${ }^{242}$ Pu stock $^{\mathbf{2}}{ }^{238}$ Pu stock $^{\mathbf{a}}$ \\
& $3.88 \times 10^{2}$ & $9.28 \times 10^{-7}$ & $1.01 \times 10^{-6}$ & $5.04 \times 10^{-6}$ & $1.96 \times 10^{-9}$ & $3.0 \times 10^{-9}$ \\
\hline LCA-5 & $3.60 \times 10^{2}$ & $7.22 \times 10^{-7}$ & $1.03 \times 10^{-6}$ & $9.74 \times 10^{-7}$ & $2.11 \times 10^{-9}$ & $3.0 \times 10^{-9}$ \\
LCA-6 & 3
\end{tabular}

${ }^{a}$ Concentrations refer to the total $\mathrm{Pu}$ concentration in these stock solutions and not the concentration of any particular isotope. See text for the percentages of ${ }^{238} \mathrm{Pu},{ }^{239} \mathrm{Pu},{ }^{240} \mathrm{Pu},{ }^{241} \mathrm{Pu}$, and ${ }^{242} \mathrm{Pu}$ in the stock solution

The first Pu stock solution (referred to as Pu-242 stock) contained $0.0098 \%{ }^{238} \mathrm{Pu}, 0.0040 \%$ ${ }^{239} \mathrm{Pu}, 0.104 \%{ }^{240} \mathrm{Pu}, 0.047 \%{ }^{241} \mathrm{Pu}$, and $99.84 \%{ }^{242} \mathrm{Pu}$ by mass. The stock Pu was reduced to $\mathrm{Pu}(\mathrm{IV})$ and the oxidation state tested using a Guided Wave Model 260 Fiber Optic spectrophotometer. However, $\mathrm{Pu}(\mathrm{IV})$ is inherently unstable in this solution and oxidized with time. At the start of the experiments, the solution was $\sim 40 \% \mathrm{Pu}(\mathrm{V} / \mathrm{VI})$ and $\sim 60 \% \mathrm{Pu}(\mathrm{IV})$.

The isotopic contents of the second Pu stock solution (referred as Pu-238 stock) were 7.03\% ${ }^{238} \mathrm{Pu}, 87.19 \%{ }^{239} \mathrm{Pu}, 5.57 \%{ }^{240} \mathrm{Pu}, 0.15 \%{ }^{241} \mathrm{Pu}$ and $0.05 \%{ }^{242} \mathrm{Pu}$ by mass as determined by $\alpha-$ spectrometry. The stock $\mathrm{Pu}$ was reduced to $\mathrm{Pu}(\mathrm{IV})$ and the oxidation state confirmed using solvent extraction with 4-Benzoyl-3-methyl-1-phenyl-2-pyrozolln-5-one (PMBP). The extraction results showed that $>90 \pm 5 \%$ was $\mathrm{Pu}(\mathrm{IV})$. As in the other stock solution, by the start of the experiments, a significant fraction of the Pu had reoxidized; the starting solution was $\sim 95 \%$ $\mathrm{Pu}(\mathrm{V} / \mathrm{VI})$ and $\sim 5 \% \mathrm{Pu}(\mathrm{IV})$. 
It should be noted that the stability of $\mathrm{Pu}(\mathrm{IV})$ in solution increases in the presence of sorbing mineral surfaces (e.g. colloids). Thus, when stock solutions were added to the colloid-containing sorption solutions, it is likely that some of the $\mathrm{Pu}(\mathrm{V} / \mathrm{VI})$ began slowly reducing to $\mathrm{Pu}(\mathrm{IV})$. Thus, the oxidation state of $\mathrm{Pu}$ in the stock solutions is not likely to be a very accurate representation of the oxidation state of the sorption solution over time.

Of the radionuclides included in the sorption solution, ${ }^{3} \mathrm{H}$ and $\mathrm{ReO}_{4}{ }^{-}$will behave as non-sorbing tracers. The only difference in their transport behavior will result from the lower diffusivity of $\mathrm{ReO}_{4}{ }^{-}$and possible charge exclusion effects due to the negative charge on the $\mathrm{ReO}_{4}{ }^{-}$anion. At $25^{\circ} \mathrm{C}$, the diffusivity of $\mathrm{ReO}_{4}{ }^{-}$in water is significantly less than that of ${ }^{3} \mathrm{H}\left(1.5 \times 10^{-9}\right.$ (Lide, 2000) and $2.2 \times 10^{-9} \mathrm{~m}^{2} / \mathrm{sec}$ (Mills, 1973), respectively). The tracer $\mathrm{ReO}_{4}{ }^{-}$was used as an analog to $\mathrm{TcO}_{4}{ }^{-}$. Divergence in the breakthrough profile of these two non-sorbing tracers is an indication that matrix diffusion is occurring.

The Sm(III), U(VI), and Pu radionuclides can form a variety of aqueous complexes with $\mathrm{CO}_{3}{ }^{2-}$, $\mathrm{OH}^{-}$, or both under the experimental solution conditions. Sm(III) will complex with $\mathrm{CO}_{3}{ }^{2-}$ to form $\mathrm{SmCO}_{3}{ }^{+}$and $\mathrm{Sm}\left(\mathrm{CO}_{3}\right)_{2}{ }^{-}$at our experimental solution conditions. The formation of $\mathrm{Sm}\left(\mathrm{CO}_{3}\right)_{2}{ }^{-}$will tend to reduce sorption because the negative charge of most mineral surfaces at $\mathrm{pH} \sim 8.5$ will result in electrostatic repulsion. Nevertheless, the strong affinity of Sm for most mineral surfaces is expected to result in minimal Sm transport in carbonate fractures in the absence of colloids (Zavarin et al., 2005). Pu(IV) is expected to be in solution as the hydroxide complex, $\mathrm{Pu}(\mathrm{OH})_{4}{ }^{0}$, and as the hydroxycarbonate complex, $\mathrm{Pu}(\mathrm{OH})_{2}\left(\mathrm{CO}_{3}\right)_{2}{ }^{2-}$. As for other radionuclides, the formation of negatively-charged aqueous species will tend to reduce sorption. This was observed in sorption experiments reported in (Kersting et al., 2003). Nevertheless, $\mathrm{Pu}(\mathrm{IV})$ expresses a moderate affinity for calcite surfaces and aluminosilicate colloids. Unlike $\mathrm{Pu}(\mathrm{IV}), \mathrm{Pu}(\mathrm{V})$ sorption to both calcite and aluminosilicate surfaces is quite weak (Zavarin and Bruton, 2004b; Zavarin et al., 2005). Thus, the transport behavior of Pu will be controlled in large part, by the oxidation state speciation of $\mathrm{Pu}$ in groundwater. This will become quite evident in the flowthrough experiments described below.

\subsection{Colloid Characteristics}

Both LLNL and LANL have investigated radionuclide transport in fractured carbonate core (Ware et al., 2005; Zavarin et al., 2005; Zavarin et al., 2006). However, those experiments did not (intentionally) examine the role of colloids in facilitating radionuclide transport in the LCA. To examine the role of colloids, column experiments were prepared so as to achieve a steadystate colloid load in the fracture fluid. This is expected to be representative of field conditions where colloid generation and filtration rates have likely reached steady state. To achieve steadystate conditions, the radionuclide sorption cocktail and the background solution for each experiment included colloids. Prior to injection of radionuclides, sufficient background colloidcontaining solution was injected to reach a steady state colloid load in the fracture fluid. For the LCA-5 experiment, the heulandite colloid concentration in the column in-flow and out-flow was 63.2 and $63.1 \mathrm{mg} / \mathrm{L}$, respectively. In LCA-6, a steady state silica colloid load of $1000 \mathrm{mg} / \mathrm{L}$ was used. These colloid concentrations are substantially higher that observed in the field. Thus, their filtration behavior may be an artifact that is not representative of field conditions. As a result, caution needs to be exercised when extrapolating these results directly into a field transport 
model. Nevertheless, these colloid facilitated transport experiments are intended to provide qualitative insight into the potential colloid-facilitated transport of certain radionuclides in fractured carbonate rock.

For LCA-5, $63 \mathrm{mg} / \mathrm{L}$ colloidal heulandite (153 nm average particle size) was used ${ }^{1}$. The heulandite particles were the product of pulverizing a single heulandite crystal in an agate mortar and pestle followed by particle size segregation using centrifugation. Initial examination of LCA-5 column breakthrough indicated that less $\mathrm{Pu}$ was recovered than expected. The fraction of ${ }^{238} \mathrm{Pu}$ sorbed onto the colloids in the spike solution was analyzed and found to be relatively small (Table 2.5), most likely due the oxidized state of $\mathrm{Pu}$ in solution. For LCA-6, very high surface area silica colloids were used to increase $\mathrm{Pu}$ association with colloids. The silica colloids were obtained by washing a commercial colloidal silica solution (Ludox HS-30) to remove excess sodium. The $22.4 \mathrm{~nm}$ silica colloids sorbed $>99$ percent of the ${ }^{238} \mathrm{Pu}$ when a colloid load of 1000 $\mathrm{mg} / \mathrm{L}$ was used. Sorption was measured in the spike solution prior to injections by centrifugation and scintillation counting.

Table 2.5 Percentage of $\mathrm{Pu}$ associated with colloids. $^{a}$

\begin{tabular}{lcc}
\hline & $\begin{array}{c}\text { Analysis } \\
\text { date }\end{array}$ & ${ }^{238} \mathrm{Pu}$ \\
\hline LCA-5 (with zeolite colloids) & $5 / 5 / 06$ & $14 \%$ \\
LCA-6 (with silica colloids) & $7 / 25 / 06$ & $99 \%$ \\
\hline a Only the association of ${ }^{238} \mathrm{Pu}$ with colloids was \\
measured. The association of ${ }^{242} \mathrm{Pu}$ with colloids is not \\
known.
\end{tabular}

\subsection{Flowthrough Experiment Apparatus}

An existing flowthrough reactor was used to perform the transport experiments. A photograph of the core apparatus is shown in Figure 2.1, and a schematic of the apparatus is shown in Figure 2.2. The core is sealed on the outside with flexible tubular membranes. The entire core is subjected to external pressure to squeeze the membrane against the outside of the core to prevent fluid flow along the core wall. Water was used as the confining pressure medium and was controlled by a gradient HPLC pump (Gilson 305) at a flow rate that produced a constant pressure of 10 PSI. Fluid flow through the core was also controlled by a gradient HPLC pump (Gilson 305) set to a rate of $0.02 \mathrm{~mL} / \mathrm{min}$.

\footnotetext{
${ }^{1}$ All reported colloid sizes were measured using a Brookhaven Instruments, Inc., particle size analyzer which uses the principles of dynamic light scattering to estimate particle size.
} 


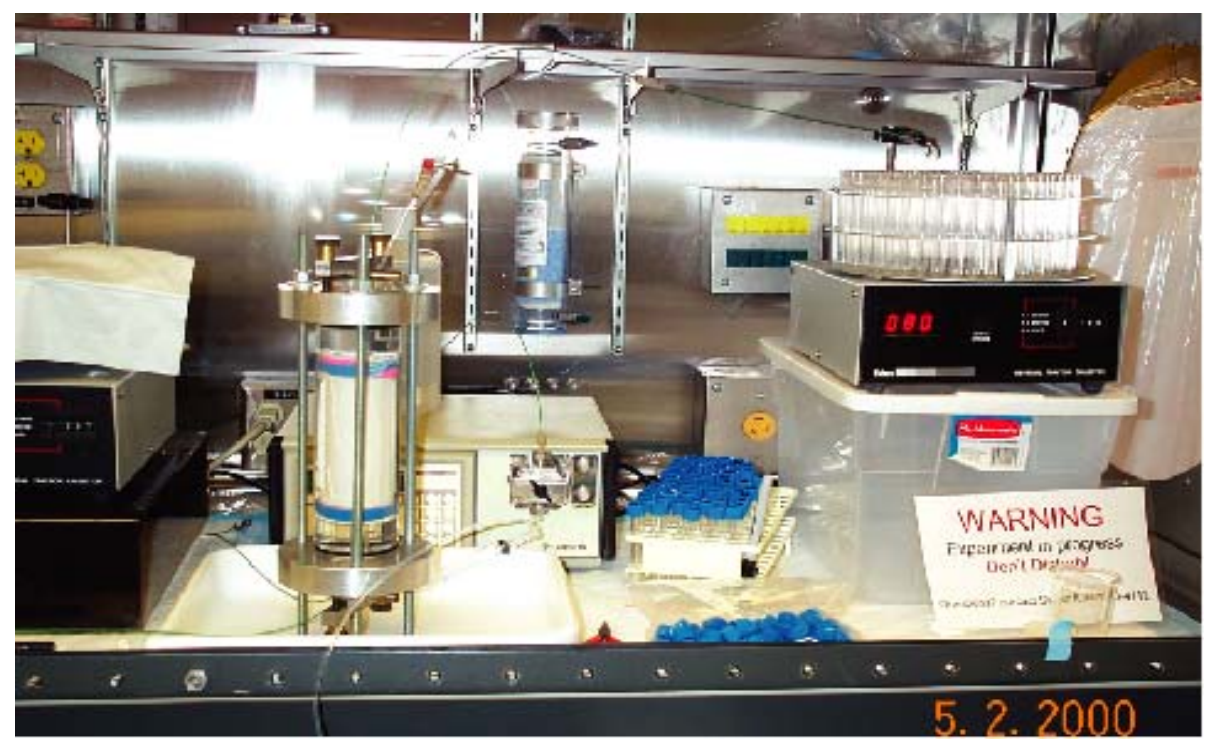

Figure 2.1 Photograph of experimental set-up showing membrane sealed core in flowthrough reactor. Gradient HPLC pump that controlled flow rate is behind the flowthrough reactor, and the fraction collector for outflow solutions is seen at right.

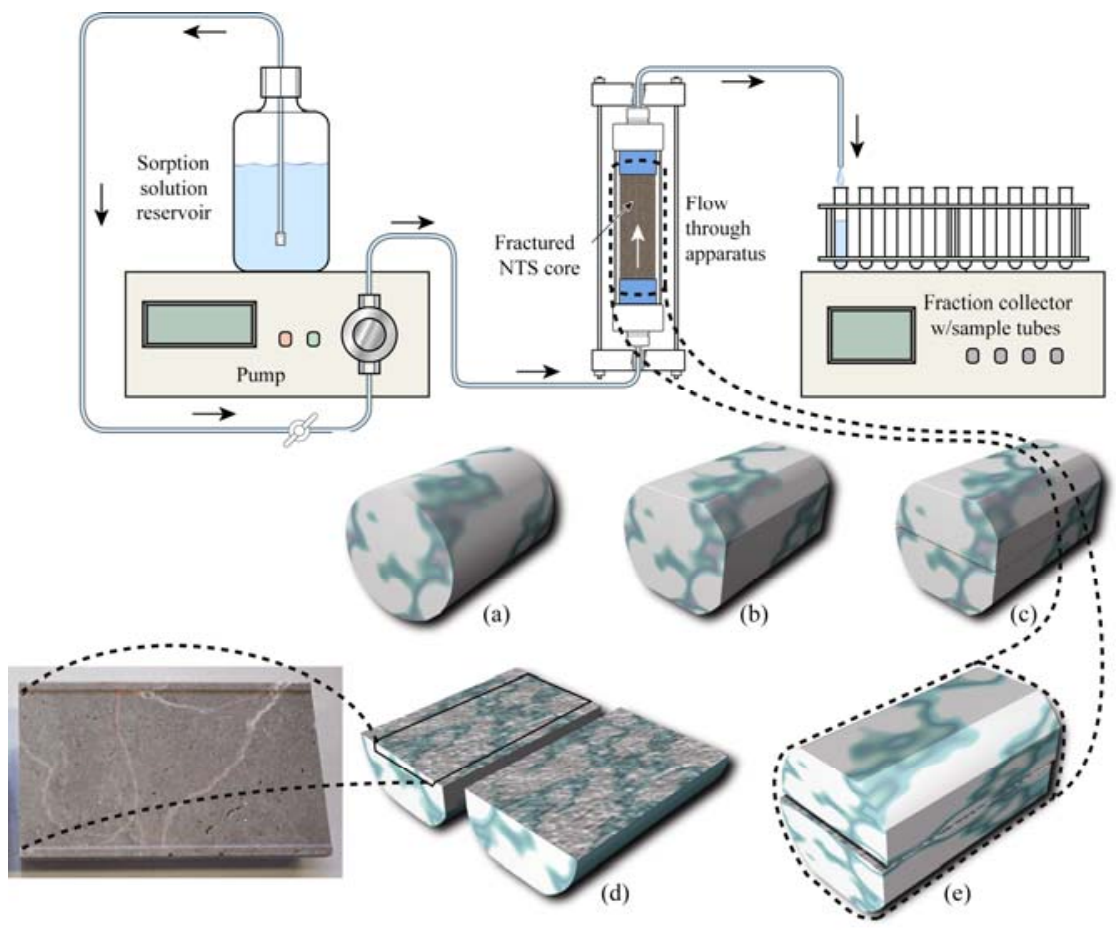

Figure 2.2 Fracture flow experiment diagram where sketches (a) to (e) show steps in experiment preparation (slotted fractures). Sample core (a) has reference flats ground on end surfaces and at relative azimuths of 0,90 , and $180^{\circ}$ on the cylindrical surface (b); core is cut in half (c); is laid open and a 500 or $50 \mu \mathrm{m}$ wide slot is ground into one side (d); finally it is reassembled (e) for experiments. (Images (a)-(e) from Durham et al. (2001)). 


\subsection{Flowthrough Experiment Procedure}

Each of the flowthrough experiments occurred in four steps: $\mathrm{a}_{2}$ (g) flush, core saturation (initially without colloids, then with colloids), a sorption pulse, and a desorption stage. Table 2.6 provides a summary of the stage durations for each experiment.

Table 2.6 Duration (in days) of each experimental stage for the individual cores.

\begin{tabular}{lcc}
\hline & LCA-5 & LCA-6 \\
\hline $\mathbf{C O}_{2}$ (g) & 1.08 & 0.71 \\
Core Saturation & 6.00 & 13.20 \\
Sorption & 0.66 & 0.71 \\
Desorption & 8.98 & 9.11 \\
\hline
\end{tabular}

To ensure full saturation of the core, it was necessary to remove air from the core. One method used to ensure core saturation is to apply a vacuum to the core followed by introduction of water. Alternatively, carbon dioxide can be flushed through the core. Unlike the air it replaces, $\mathrm{CO}_{2}(\mathrm{~g})$ will readily dissolve in water. As the $\mathrm{CO}_{2}$ (g) dissolves, it is replaced by the water that is introduced into the core. For the present set of experiments, $\mathrm{CO}_{2}(\mathrm{~g})$ was pumped through the core overnight.

After the $\mathrm{CO}_{2}$ (g) flush, a background solution was pumped through the core for a period of 6 to 13 days. Flushing the core with background solution provided reasonable confidence that the core was fully saturated, the $\mathrm{CO}_{2}$ (g) had dissolved, and the core was at equilibrium with the background solution prior to the addition of radionuclides.

The sorption solution pulse was typically pumped through the core for 16 to 17 hours. Data collection began simultaneously with the introduction of the sorption solution, and continued for a period lasting up to 10 days to capture the effects of desorption and diffusion. The sorption pulse is delineated by the vertical black lines on the breakthrough plots that are presented in Sections 3.1 and 3.2 .

\subsection{Effluent and Post-Test Core Characterization}

Effluent U, Pu, Re, and Sm concentration were analyzed on either a Agilent HP4500 ICP-MS or a Thermo X7 ICP-MS. Major cations ( $\mathrm{Na}, \mathrm{Ca}, \mathrm{K}$, and $\mathrm{Mg}$ ) were measured on the ICP-MS as well. Typically, samples were diluted 100 times with $2 \%$ nitric acid; an internal standard was always included. A Tri-Carb 2500 Liquid Scintillation analyzer from Packard Instrument Company was used for liquid scintillation counting of ${ }^{238} \mathrm{Pu}$ and ${ }^{3} \mathrm{H}$. Following the flowthrough experiments, $\alpha$-radiography and LA/ICP-MS were used to determine the location of radionuclides in the cores. 
Alpha-radiography is an in-situ, non-destructive technique based upon the decay properties of $\alpha$ emitting radionuclides to visualize their spatial distribution. Plutonium isotopes used in the flowthrough experiments are $\alpha$-emitters, and hence can be detected by using CR-39 film, a polymer of polyallyl diglycol carbonate plastic produced by Track Analysis Systems, Ltd. in Bristol, U.K. The film has a high sensitivity toward $1 \mathrm{MeV}$ protons, $6 \mathrm{MeV} \alpha$-emissions, and an excellent optical quality making it ideal for identification of nuclear material (Cartwright et al., 1978). For these experiments, $100 \mathrm{~mm} \times 100 \mathrm{~mm}$ pieces of the CR-39 film were placed in direct contact with the flat core surface. The film was exposed to the LCA-5 and LCA-6 cores for 4 and 5 days, respectively. During the exposure process, $\alpha$ particles are released from their source on the core and strike the film, forming an indentation. Following exposure, the $\alpha$-tracks were etched by heating the plates for 5 hours at $75^{\circ} \mathrm{C}$ in a $6.3 \mathrm{~N} \mathrm{NaOH}$ solution. The plates were scanned using a Mictrotek Scanmaker i700 digital scanner. One radiography plate was left on the benchtop near the core as a positive control and no significant $\alpha$-tracks were observed. Specific regions of each core were inspected using an optical microscope equipped with a digital camera (Polaroid Model DMC 1 digital camera and Wild Makroskop M420 microscope).

Laser ablation refers to the process in which an intense burst of energy delivered by short laser pulses is used to vaporize a minute (in the range of nanograms) sample from a specific location. The chemical composition of the vaporized sample is then analyzed by ICP-MS. Since 1985, LA/ICP-MS has evolved as a powerful analytical tool for solid sampling and analysis (e.g., (Russo et al., 2000; Russo et al., 2002). LA/ICP-MS can determine simultaneously a large number of chemical elements at low detection limits, typically in the range of nanograms to lowmicrograms per gram.

We used a laser ablation system (CETAC LSX-200, CETAC Technologies, Omaha, NE), with spot-size options ranging from $10 \mu \mathrm{m}$ to $300 \mu \mathrm{m}$, interfaced with an ICP-MS (X-Series ICP-MS, Thermo Electron Corporation, West Palm Beach, FL). During data acquisition, signal intensities (counts per second, cps) were recorded for a number of elements, including introduced chemicals/radionuclides $\left({ }^{147} \mathrm{Sm},{ }^{185} \mathrm{Re},{ }^{238} \mathrm{U}\right.$, and $\left.{ }^{242} \mathrm{Pu}\right)$ and other elements intrinsic to the rock (e.g., ${ }^{26} \mathrm{Mg},{ }^{44} \mathrm{Ca},{ }^{85} \mathrm{Rb}$ ). Examples of signal response from LA/ICP-MS are shown in Figure 2.3; about 10 seconds after ablation from laser firing, elements are detected by the ICP-MS. Signal intensity in the $y$-axis indicates the signal response measured by the ICP-MS for the laser-ablated mass. The signal intensity measured during the initial 10 second period is used to determine the instrument background for each element. When the sample reaches the detector, there is a sharp rise in signal intensity, followed by a gradual decrease in intensity to near-background levels within several minutes after laser firing. After the background is subtracted from the sample signal, integrating under the curve provides the sample signal intensity. Differences in the integrated signal intensity for different elements reflect their differences in concentration in the sample matrix. 


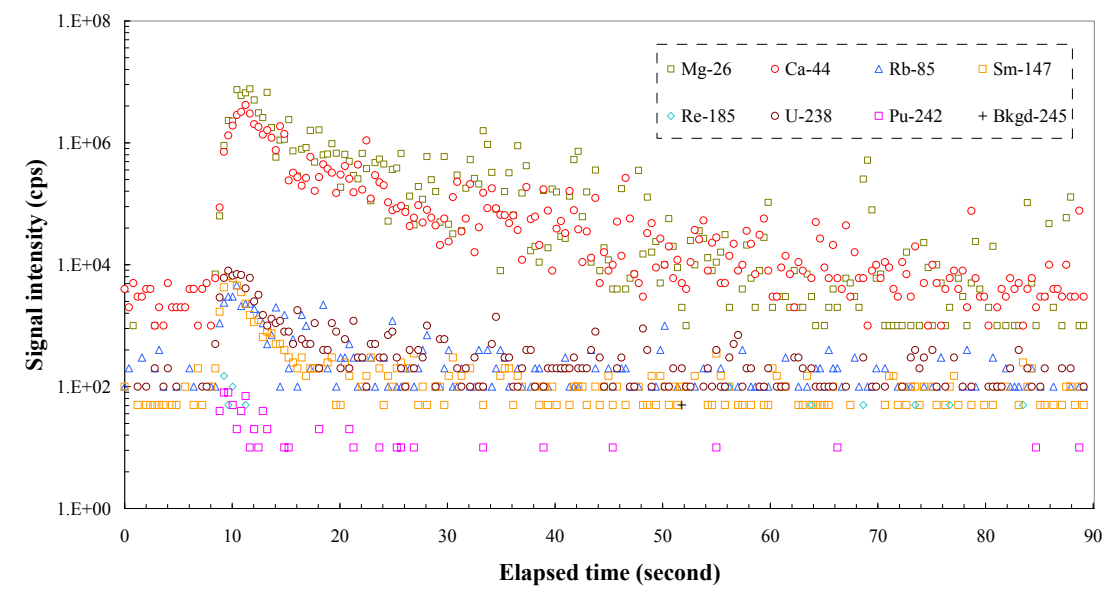

Figure 2.3 Examples of signal responses for elements from laser ablation on the LCA-6 sample. "Bkgd" represents instrument background.

We have adopted a robust method to monitor and correct the ICP-MS instrumental drift during a run period, by continuously sampling a $5 \mathrm{ppb}$ solution with isotopes $\left({ }^{6} \mathrm{Li},{ }^{45} \mathrm{Sc},{ }^{115} \mathrm{In}\right.$, and $\left.{ }^{208} \mathrm{Bi}\right)$ that are not normally encountered in geologic samples. These isotopes are commonly used as the internal standards in the liquid sample analyses using ICP-MS. Figure 2.4 shows the good stability in the sensitivity of ICP-MS during a run period of 9 hours. The signal response for an element from each laser ablation sampling location is corrected from the liquid ${ }^{115}$ In response when the laser sampling was conducted. By doing this, any instrumental drift is corrected. Figure 2.5 presents the elemental signal responses in four NIST standard glasses, with a concentration range of about 0.02 to $500 \mathrm{mg} / \mathrm{kg}$ for many elements. Note that the $\mathrm{Si}$ and Ca concentration is the same in all of the four standard materials, with the value of 336,551 and $85,763 \mathrm{mg} / \mathrm{kg}$, respectively. The $\mathrm{Y}$-axis is the signal response for each isotope (total counts divided by the ${ }^{115} \mathrm{I}$ counts per ppt). In essence, Figure 2.5 shows the dimensionless signal per unit laser pulse for each isotope of interest.

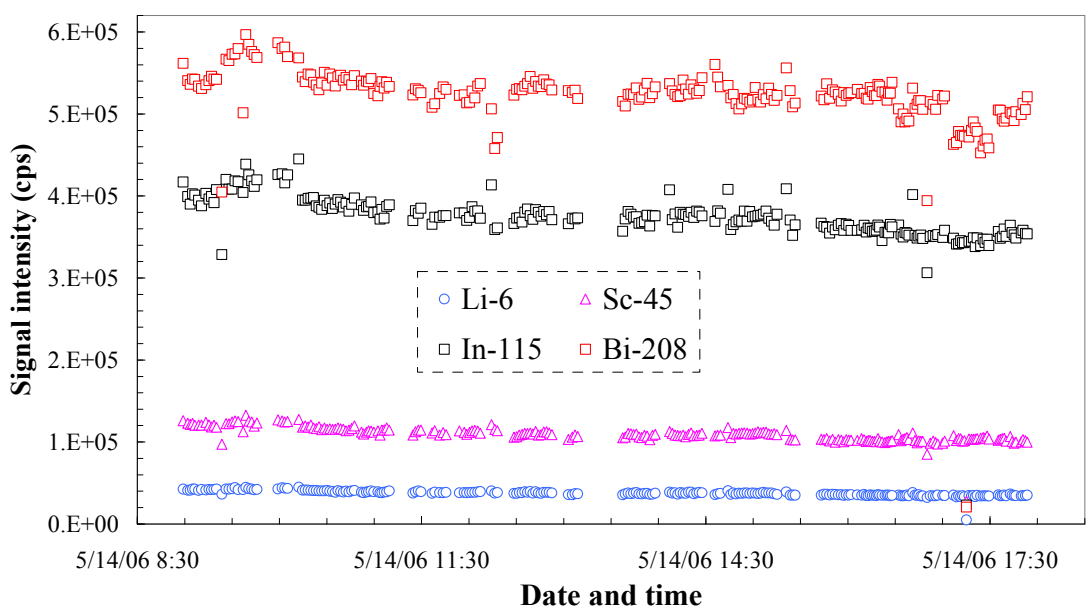

Figure 2.4 Instrumental signal responses for internal standards during laser ablation sampling for LCA-5. 


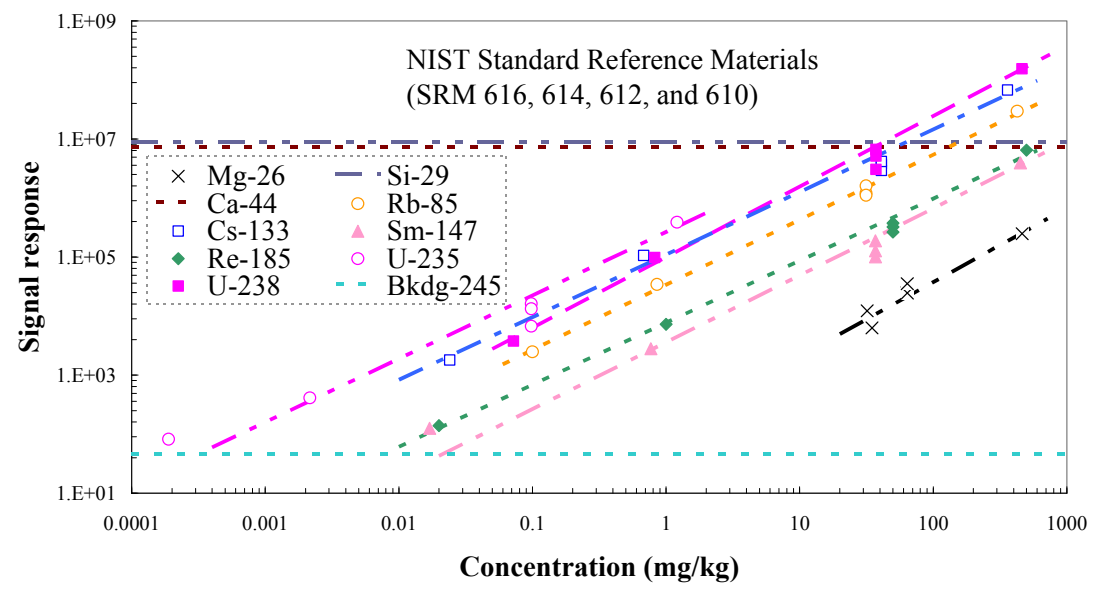

Figure 2.5 Elemental signal responses from NIST Standard Reference Material glasses (SRM 610, 612,614 , and 616).

Quantitative measurement has been one of the major challenges in LA/ICP-MS analyses because of a lack of matrix matching calibration. However, the concentration of an analysis can be calculated from a normalized ratio of both unknown and reference samples (Ghazi et al., 2000; Russo et al., 2002). The method of a single element internal standard calibration strategy is effective for overcoming the potential quantification problems of the LA/ICP-MS. One of the major element constituents of the sample and reference matrix is chosen (such as ${ }^{44} \mathrm{Ca}$ for dolomite samples) as the reference element. The normalized ratio of analyte to internal standard from the LA/ICP-MS analysis of both the sample and reference standard is then used to calculate the analyte concentration. The calibration curves are obtained from four NIST glasses. Figure 2.6 shows example calibration curves for several isotopes of interest in this study. It is evident that the calibration curves are linear down to $0.01 \mathrm{mg} / \mathrm{kg}$ levels for middle-range masses and $<0.001 \mathrm{mg} / \mathrm{kg}$ for higher masses wherein interferences are less. During depth profiling, normalization accounts for the reduced signal as a function of depth and distinguishes it from a true decrease in the relative element concentration. Normalization during surface profiling also helps to improve data accuracy by considering potential laser performance, e.g., less tracer signal is associated with less ${ }^{44} \mathrm{Ca}$ signal. In summary, data quality is improved from using the liquid internal standard to correct the ICP-MS drift, and from normalizing methodology to correct laser ablation processes. We assume that the two LCA samples used in the present colloidal transport studies are predominantly comprised of dolomite $\left(\mathrm{CaMg}\left(\mathrm{CO}_{3}\right)_{2}\right)$. We use ${ }^{44} \mathrm{Ca}$ as the internal standard. 


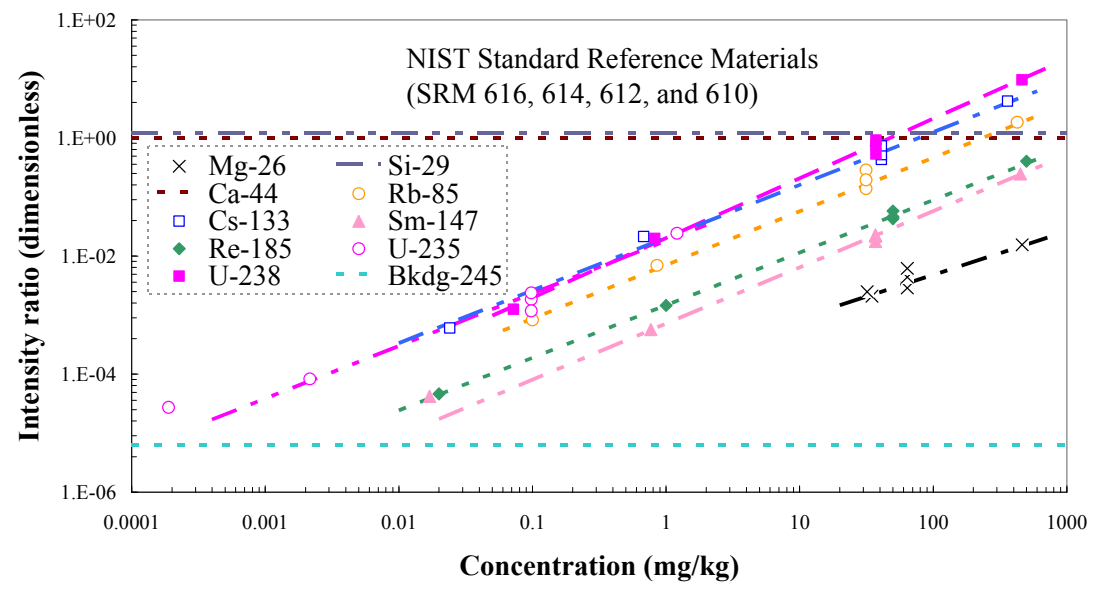

Figure 2.6 Calibration curves using NIST Standard Reference Material glasses (SRM 610, 612, 614, and 616). Y-axis is the dimensionless response (such as these in Y-axis of Figure 2.3) of each isotope divided by that of ${ }^{44} \mathrm{Ca}$.

\subsection{Modeling Approach}

Modeling fracture transport was simulated in 2 dimensions using the CRUNCH code (Steefel and Yabusaki, 1995). The modeling strategy is discussed in detail in (Zavarin et al., 2005) and will not be repeated here. Sorption to matrix minerals (calcite/dolomite) and aqueous speciation was accomplished directly in the CRUNCH code based on surface complexation, ion exchange, and aqueous speciation thermodynamic parameters and mineral characteristics reported in (Zavarin and Bruton, 2004a; Zavarin and Bruton, 2004b; Zavarin et al., 2004). Sorption to colloids was implemented using colloid characteristics combined with surface complexation reactions. In essence, colloids were simulated as mobile mineral surfaces with no colloid filtration. Given the simple geometry, short length of our cores, and relatively wide and smooth synthetic apertures, colloid filtration was assumed to be negligible. Diffusion of colloids and colloid-bound radionuclides into the matrix was not allowed. Simulations were run with 2 nodes in the fracture and 12 nodes in the matrix; the core length was divided into 20 nodes for a total of 280 nodes. Matrix diffusion coefficients were based on recent experimental efforts of Reimus et al., (2002) for tuffs and Hershey et al., (2003) for carbonate rock, as will be described in the following section.

\section{RESULTS AND DISCUSSION}

The two synthetic parallel-plate fracture experiments were conducted. Both used carbonate core sampled from the Nevada National Security Site (ER-6-1). Both cores had similar diameters, lengths, and mineralogy (see Tables 2.1 and 2.2). Both cores used a similar background and sorption solution composition. However, there were two key differences between the two experiments. First, LCA-5 had a fracture aperture of $500 \mu \mathrm{m}$ which was ten times wider than the aperture of LCA-6. Second, heulandite colloids were used in LCA-5 whereas silica colloids were used in LCA-6. 


\subsection{Elution Curves}

Table 3.1 lists the fraction of each radionuclide that eluted from the column over the timeframe of the flowthrough experiment. The elution of ${ }^{238} \mathrm{Pu}$ and ${ }^{242} \mathrm{Pu}$ is not identical due to their difference in initial oxidation state. For both experiments, the non-sorbing elements eluted quantitatively. In LCA-5, the amount of ${ }^{3} \mathrm{H}$ and $\mathrm{ReO}_{4}{ }^{-}$eluted was greater than the calculated amount that was injected into the column. The error is the result of a combination of sample evaporation and uncertainty in the initial concentration for these elements. Given that the major element concentrations did not indicate drastic evapoconcentration of samples, the error lies primarily with the uncertainty in initial concentration. However, some sample evaporation was observed as well. In LCA-6, the autosampler device was encased in a humidified chamber to reduce the potential for sample evaporation. This change, combined with stricter control of flow rates and sorption solution composition resulted in much better quantitation.

Table 3.1 Fraction of radionuclides eluted over the timeframe of each experiment.

\begin{tabular}{lcccccc}
\hline & ${ }^{3} \mathrm{H}$ & $\mathrm{Re}$ & $\mathrm{U}$ & $\begin{array}{c}{ }^{238} \mathrm{Pu} \\
(\mathrm{LSC})\end{array}$ & $\begin{array}{l}{ }^{242} \mathrm{Pu} \\
(\mathrm{ICP})\end{array}$ & $\mathrm{Sm}$ \\
\hline LCA-5 & $1.40^{\mathrm{a}}$ & $1.60^{\mathrm{a}}$ & 0.87 & 0.50 & 0.44 & 0.19 \\
LCA-6 & 0.96 & 1.08 & 1.01 & 0.47 & 0.72 & 0.23 \\
\hline a Value $>1$ is an artifact of sample evaporation during the \\
experiment and uncertainty in the initial concentration of these \\
radionuclides. Evaporation problem was corrected in experiment \\
LCA-6 by enclosing auto-sampler in humidified chamber.
\end{tabular}

\subsubsection{LCA-5}

Elution of all radionuclides is presented in Figures 3.1 and 3.2. Based on ${ }^{3} \mathrm{H}$ and Re breakthrough profiles, diffusion into the carbonate matrix is very slow. However, the long tailing of both these species is indicative of a combination of matrix diffusion and dispersion. The very close match in the tailing of these two non-sorbing tracers suggests that dispersion is the dominant component controlling the tailing behavior observed in LCA-5.

$\mathrm{Sm}, \mathrm{U}$, and $\mathrm{Pu}$ are all retarded, though their breakthrough is observed. Sm breakthrough is predominantly in the form of an attenuated pulse breakthrough coincident with the non-sorbing tracer breakthrough. We attribute this transport behavior to that of colloid-facilitated transport. In the absence of colloids (Zavarin et al., 2005), no Sm was observed in the effluent. The affinity of Sm for calcite is very high (Zavarin et al., 2005) and its transport is expected to be drastically retarded in the absence of colloids. Importantly, less than $20 \%$ of Sm was recovered from the column effluent. The loss of Sm from the eluent can be attributed to a combination of desorption of Sm from colloids and sorption to the carbonate matrix and colloid filtration. The size of the synthetic aperture and its geometry was expected to minimize the role of filtration in these experiments. However, as will be shown later, deposition of colloids on the fracture surfaces was unavoidable.

Nearly all the U introduced into the column was recovered in the effluent. Based on the observed transport behavior and its very weak affinity for aluminosilicate minerals, colloids did not play a role in $\mathrm{U}$ transport. Though $\mathrm{U}(\mathrm{VI})$ sorption to calcite is quite weak (Zavarin and 
Bruton, 2004a), trace quantities of iron oxides and/or silicates (1.6\% quartz detected by XRD) may have contributed to $\mathrm{U}$ retardation.

$\mathrm{Pu}$ breakthrough has been plotted for both ${ }^{238} \mathrm{Pu}$ and ${ }^{242} \mathrm{Pu}$. The ${ }^{238} \mathrm{Pu}$ was measured by LSC and the stock solution was composed of 95:5 $\mathrm{Pu}(\mathrm{V} / \mathrm{VI})$ :(IV). The ${ }^{242} \mathrm{Pu}$ was measured by ICP-MS and the stock solution was composed of 40:60 Pu(V/VI):(IV). The difference in their breakthrough can be attributed to the difference in initial oxidation state. For example the small peak in ${ }^{242} \mathrm{Pu}$ that coincides with $\mathrm{Sm}(\mathrm{III})$ breakthrough can be attributed to colloid-facilitated $\mathrm{Pu}(\mathrm{IV})$ transport. $\mathrm{As} \mathrm{Pu}(\mathrm{V})$ is a relatively weak sorber on aluminosilicates, colloid-facilitated transport of $\mathrm{Pu}(\mathrm{V})$ is unlikely. Instead, the broad breakthrough peak observed for ${ }^{238} \mathrm{Pu}$ can be attributed to retardation of aqueous $\mathrm{Pu}(\mathrm{V})$ on the rock matrix. Importantly, it should not be assumed that the $\mathrm{Pu}$ oxidation states in these experiments are invariant with time. In fact, we expect $\mathrm{Pu}(\mathrm{V})$ to reduce and sorb to both the calcite matrix and the aluminosilicate colloids with time (Zavarin et al., 2005). At field spatial and temporal scales, sorbed Pu will be predominantly in the +4 state while the aqueous phase may be in the +5 state (Powell et al., 2006). Nevertheless, the results from LCA- 5 suggest that Pu transport will be governed by a combination of colloid-facilitated and aqueous transport mechanisms that will evolve with time and depend on the oxidation-state of $\mathrm{Pu}$.

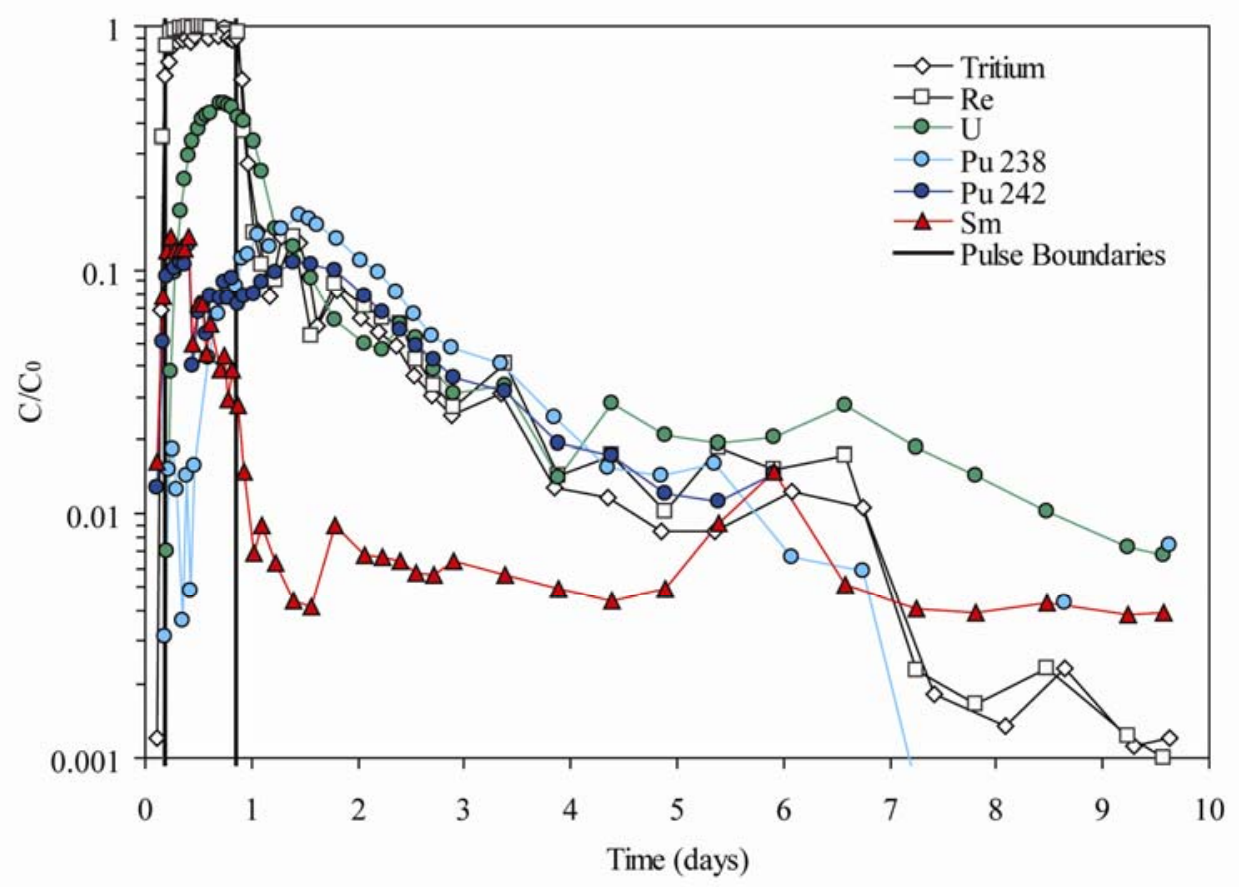

Figure 3.1 LCA-5 breakthrough plot (log scale y-axis). The two vertical lines represent the beginning and end of the sorption pulse. 


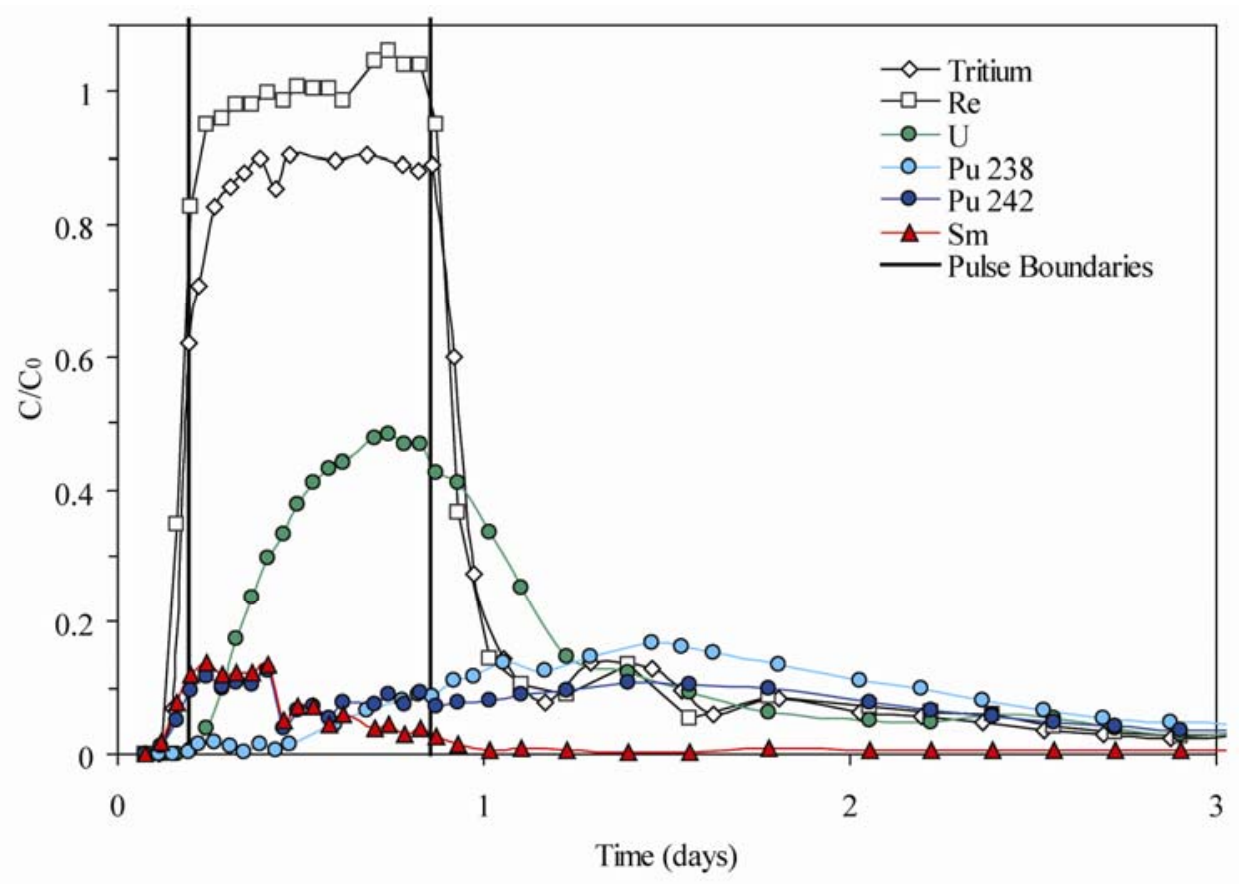

Figure 3.2 LCA-5 breakthrough plot (linear scale y-axis). Sorption pulse timeframe magnified. The two vertical lines represent the beginning and end of the sorption pulse.

\subsubsection{LCA-6}

Elution of all radionuclides is presented in Figures 3.3 and 3.4. Matrix diffusion of ${ }^{3} \mathrm{H}$ and Re is more pronounced than LCA-5 due to the small aperture of the LCA- 6 fracture $(0.050 \mathrm{~mm})$. The long tailing of both these species is indicative of a combination of diffusion-controlled retardation and dispersion. The divergent breakthrough of Re and $3 \mathrm{HHO}$ in the tailing is indicative of matrix diffusion, which appears to be slow at the scale of these experimental conditions.

$\mathrm{Sm}, \mathrm{U}$, and $\mathrm{Pu}$ are all less retarded than in LCA-5. This is, in part, due to the shorter residence time of these radionuclides in the fracture. Sm breakthrough is predominantly in the form of an attenuated pulse coincident with the non-sorbing tracer. However, some tailing exists as well. The unretarded breakthrough of Sm is indicative of colloid-facilitated transport. However, as in LCA-5, only a fraction of Sm was recovered from the column effluent. Thus, a substantial fraction of the $\mathrm{Sm}$ is lost to the carbonate core along the flow path.

All the $\mathrm{U}$ introduced into the column was recovered in the effluent and very little retardation was observed. U breakthrough followed the profile on the non-sorbing tracers. There are no mineralogic or geochemical parameter that can explain the lower sorption in this experiment compared to LCA-5.

$\mathrm{Pu}$ breakthrough has been plotted for both ${ }^{238} \mathrm{Pu}$ and ${ }^{242} \mathrm{Pu}$. The ${ }^{238} \mathrm{Pu}$ breakthrough (95:5 $\mathrm{Pu}(\mathrm{V} / \mathrm{VI}):(\mathrm{IV}))$ is somewhat more attenuated than ${ }^{242} \mathrm{Pu}(40: 60 \mathrm{Pu}(\mathrm{V} / \mathrm{VI}):(\mathrm{IV}))$. In this core, $\mathrm{Pu}(\mathrm{V})$ sorption is quite weak and much of the breakthrough is coincident with the non-sorbing tracers. Transport of $\mathrm{Pu}(\mathrm{V})$ is expected to be predominantly as an aqueous phase. The ${ }^{242} \mathrm{Pu}$ breakthrough can be attributed to a combination of aqueous $\mathrm{Pu}(\mathrm{V})$ transport and colloid- 
facilitated $\mathrm{Pu}(\mathrm{IV})$ transport. Colloid-facilitated $\mathrm{Sm}$ (III) transport coincides with the increased breakthrough of ${ }^{242} \mathrm{Pu}$ versus ${ }^{238} \mathrm{Pu}$. As in LCA-5, it should not be assumed that the Pu oxidation states in these experiments are invariant with time. However, ${ }^{242} \mathrm{Pu}$ will certainly be more reduced that ${ }^{238} \mathrm{Pu}$.

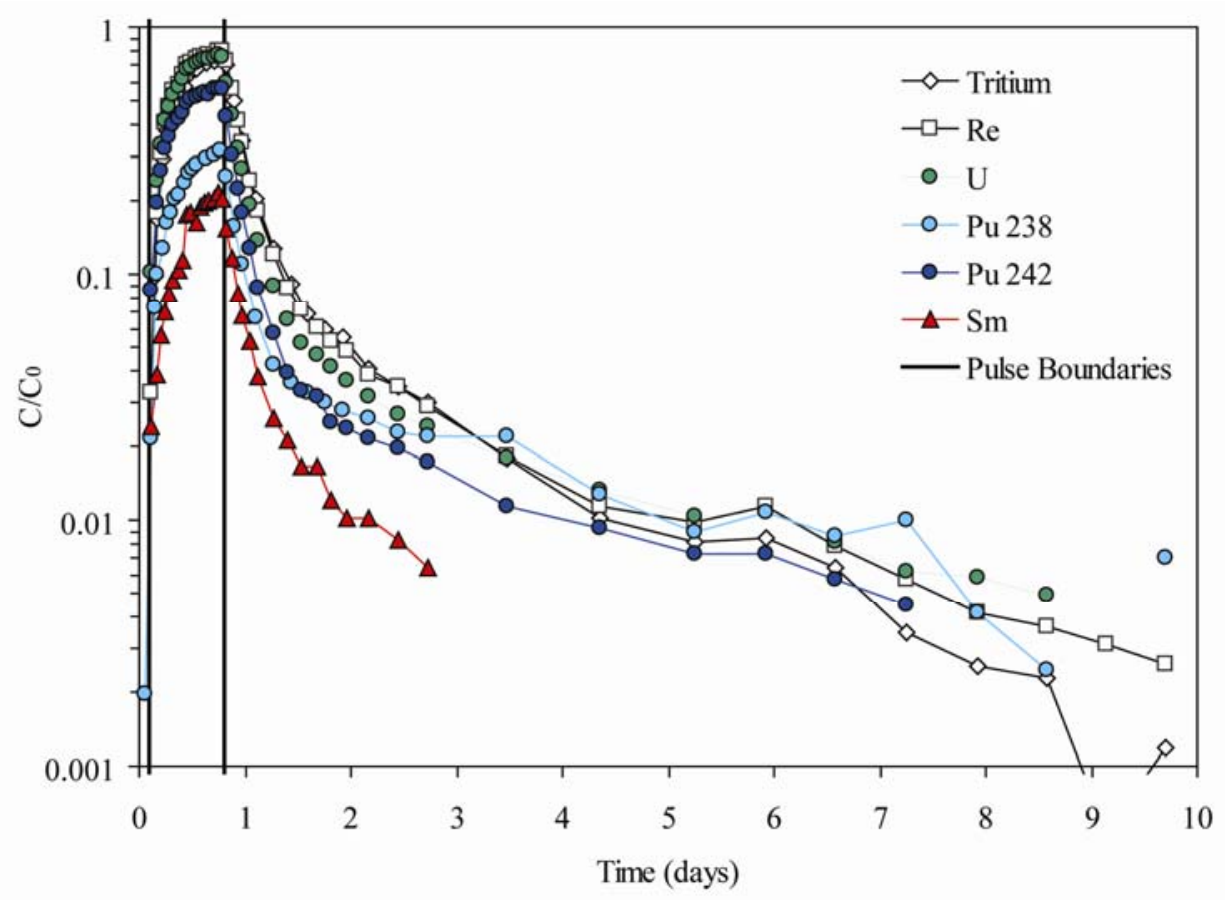

Figure 3.3 LCA-6 breakthrough plot (log scale y-axis). The two vertical lines represent the beginning and end of the sorption pulse. 


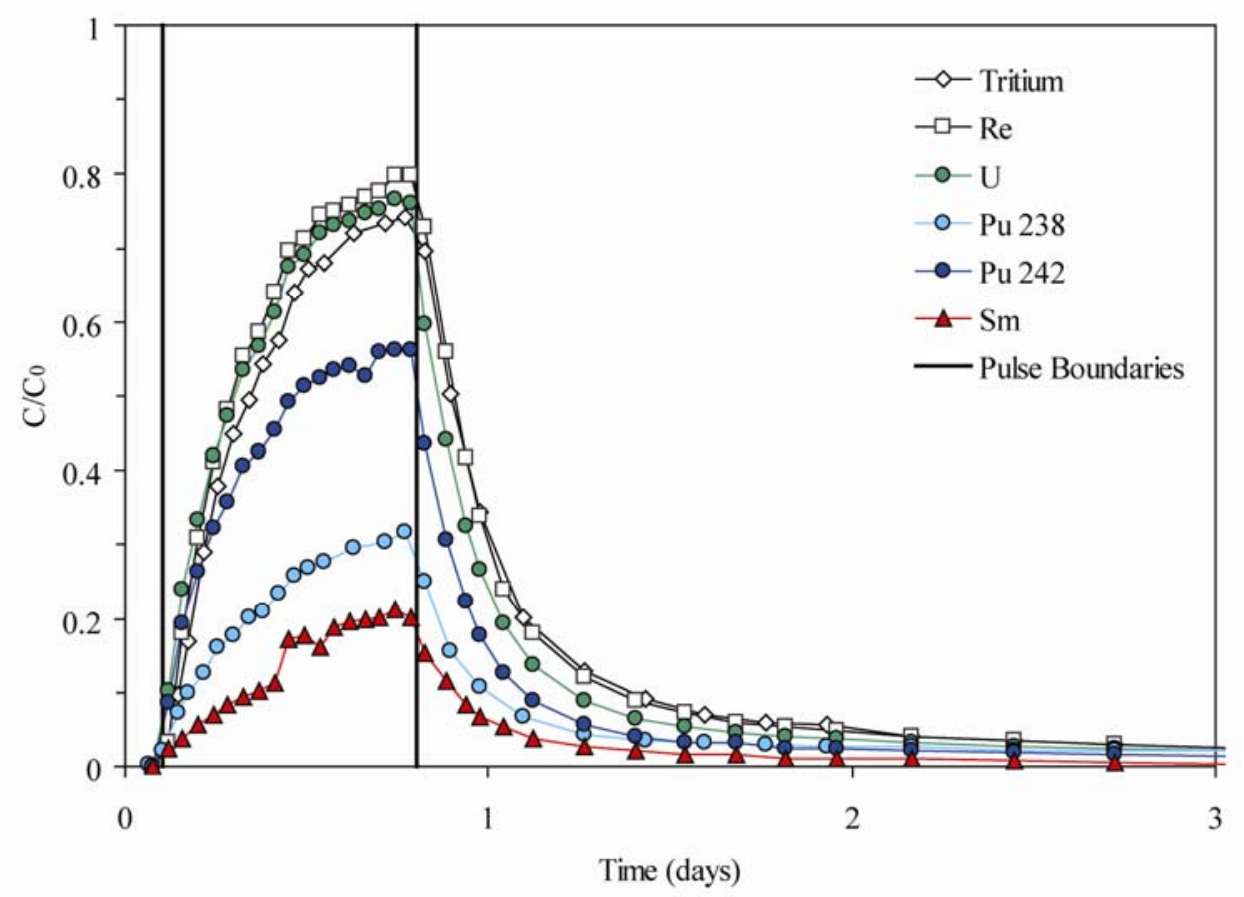

Figure 3.4 LCA-6 breakthrough plot (linear scale y-axis). Sorption pulse timeframe magnified. The two vertical lines represent the beginning and end of the sorption pulse.

\subsection{Autoradiography}

\subsubsection{LCA-5}

Autoradiography was performed on both cores. The exposure times varied for each of the cores and are shown in Table 3.2. The LCA-5 core did not contain as many occlusions and rough surfaces as the LCA-6 core and there were no visible iron oxide regions. One of the plates used for alpha radiography of LCA-5 was slightly warped and created a thin air layer (capable of attenuating alpha particles) between the core surface and the plate. The location of the air layer corresponds to the region of low alpha activity shown in the center of the core in Figure 3.5. Therefore, the extent of alpha activity in this region cannot be accurately determined. In regions where there was minimal separation between the plate and the core surface, alpha activity was widely distributed throughout the core. There are regions of higher activity near the edges of the fracture that may indicate preferential flow-paths. However, activity observed at both the inlet and outlet ports demonstrates that alpha emitting radionuclides $\left({ }^{238} \mathrm{Pu}\right)$ reached the outlet port of the column. This is consistent with the observed ${ }^{238} \mathrm{Pu}$ in the effluent.

Table 3.2 Exposure times for $\alpha$-radiography on the rock cores.

\begin{tabular}{cc}
\hline Core & Exposure Time (days) \\
\hline LCA-5 & 6.75 \\
LCA-6 & 5.75 \\
\hline
\end{tabular}


Under microscopic observation, the fracture surface was coated with intertwined, needle-like white solids. The morphology of the white solids is significantly different than the surrounding core. Small amounts of this material were collected and placed in acid; little or no strong effervescence was observed. Thus, it is likely that a significant fraction of this material is colloidal heulandite. A high concentration of this material was observed near the core outlet (inset Figure 3.5) near an exposed cavity along with a relatively high concentration of alpha activity. Based upon their observed co-association, the material appears to significantly control the distribution of alpha emitting radionuclides within the core. Furthermore, they suggest that colloid filtration may have attenuated the breakthrough of alpha-emitting radionuclides (e.g. $\left.{ }^{238} \mathrm{Pu}\right)$.

In addition to the white solids, several yellow and blue fibers were observed which appear to be synthetic. A large grouping of these fibers associated with the white material was observed in LCA-6. Intertwinement of the fibers with the white material indicates that the fibers were introduced before or during the experiment and are not an artifact of post-experiment sample processing. The identity of the fibers has not been ascertained. With the exception of one area, the fibers and white material appeared to be widely dispersed over the LCA-5 core surface. The synthetic fibers within LCA-5 did not appear to be correlated with alpha activity. 


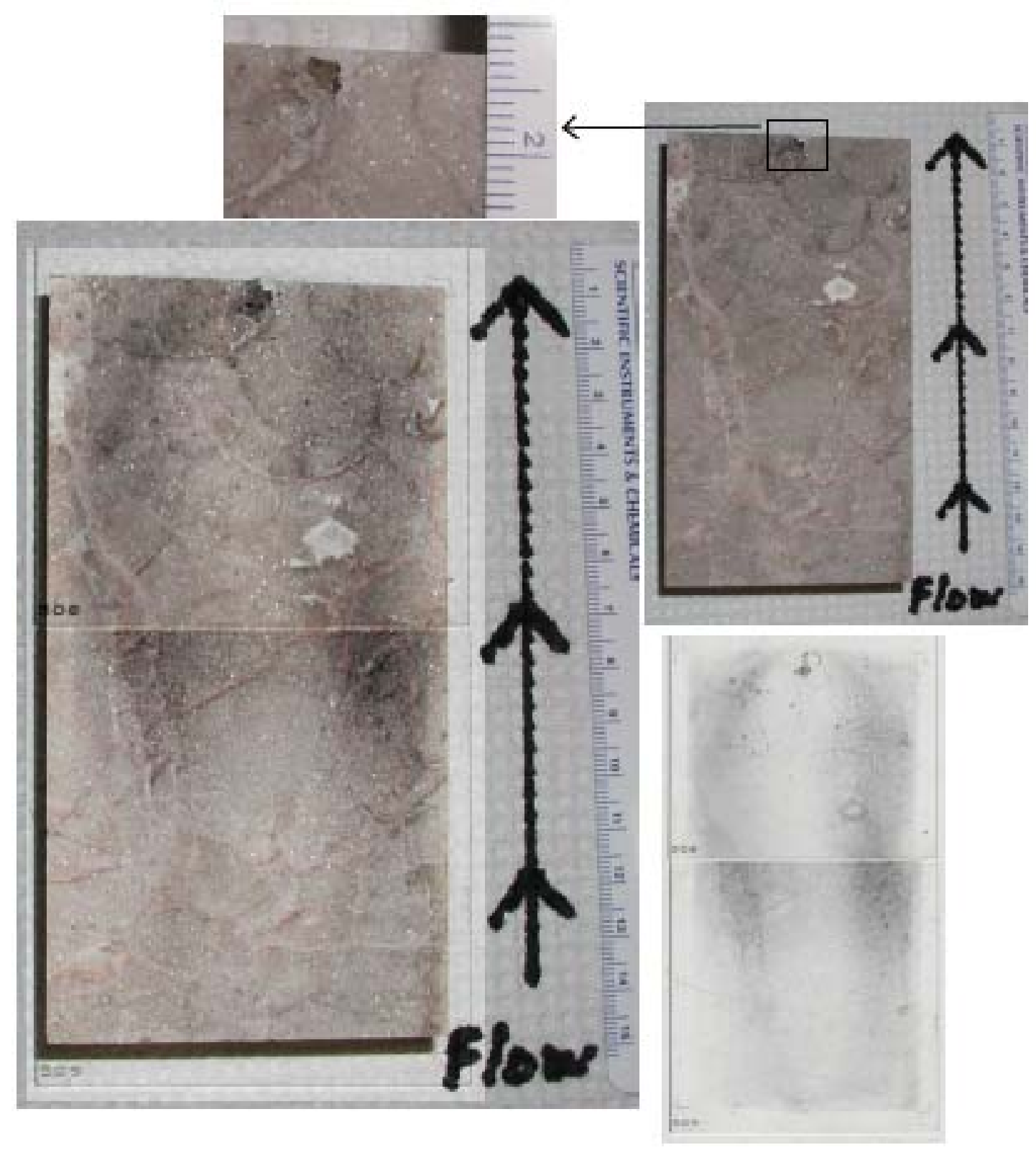

Figure 3.5 One-half of LCA-5 core (top right) and developed radiography plates (bottom right). Image of developed film is overlain on the core (left) and the arrow is noting direction of flow during the flowthrough experiment. Dark spots on the radiography plates indicate regions of concentrated alpha activity. Expanded inset of LCA-5 core outlet is shown in top left position. 


\subsubsection{LCA-6}

Alpha tracks were observed throughout the core indicating a wide distribution of alpha activity. The appearance of $\alpha$-tracks at the outlet is consistent with the observation of alpha emitting radionuclides in the effluent during the flowthrough experiment. However, the density of $\alpha$ tracks at the outlet of the core was visibly lower than several other regions.

There are three noteworthy regions of concentrated alpha activity on the core (Figure 3.6). Section A shows a strong correlation between a small fracture running along the left side of the core and concentrated alpha activity. The fracture is relatively thin and shallow, allowing the short-range alpha particles to reach the radiography plate. Section B corresponds to another small fracture that appeared to sequester ${ }^{238} \mathrm{Pu}$. The alpha tracks in region $\mathrm{B}$ are darker, relative to the other alpha tracks, indicating more concentrated alpha activity. Similar to LCA-5, low-power microscopic observations revealed the presence of both white material and synthetic fibers. The "Y" shaped feature of alpha activity within region B exactly corresponds to the distribution of the white material within that region, but are only observable under magnification. When small amounts of the white material were collected and placed in acid; little or no strong effervescence was observed. It suggests that a significant fraction of this material is colloidal silica. Therefore, similar to the observation made for LCA-5, there is a correlation between the presence of the white material and alpha activity and it is suggestive of colloid filtration.

The yellow and blue synthetic fibers observed on LCA-5 were also observed under low-power magnification of LCA-6. A large grouping of the fibers associated with the white secondary precipitates and/or colloids is shown in Figure 3.7. Several fibers were observed throughout the core, but the image in Figure 3.7 shows the highest concentration of fibers observed at one point. As with LCA-5, intertwinement of the fibers with the white material indicates that the fibers were introduced before or during the experiment. Furthermore, the association of alpha-activity with the white material in both cores, and the lack of association with the synthetic fibers, indicates that the white material controls the distribution of alpha emitting radionuclides on both core surfaces, while the synthetic fibers have little or no influence.

Region C (Figure 3.6) contains some red solid phases which are presumably iron oxides or iron oxide coatings on the host matrix. This region has a high concentration of alpha activity. An expanded image of the core surface in region $\mathrm{C}$ (Figure 3.8) shows the region is not flat. The interstitial space between the core surface and the radiography film may attenuate alpha particles. Therefore, if additional activity was present within the occlusion, it would not have been detected using the alpha radioactivity technique employed in these experiments. No alpha activity was observed associated with the reddish mineral phases in the lower right corner of the core. This may be due to preferential flow in the center of the fracture resulting from the pinhole opening at the core inlet. 


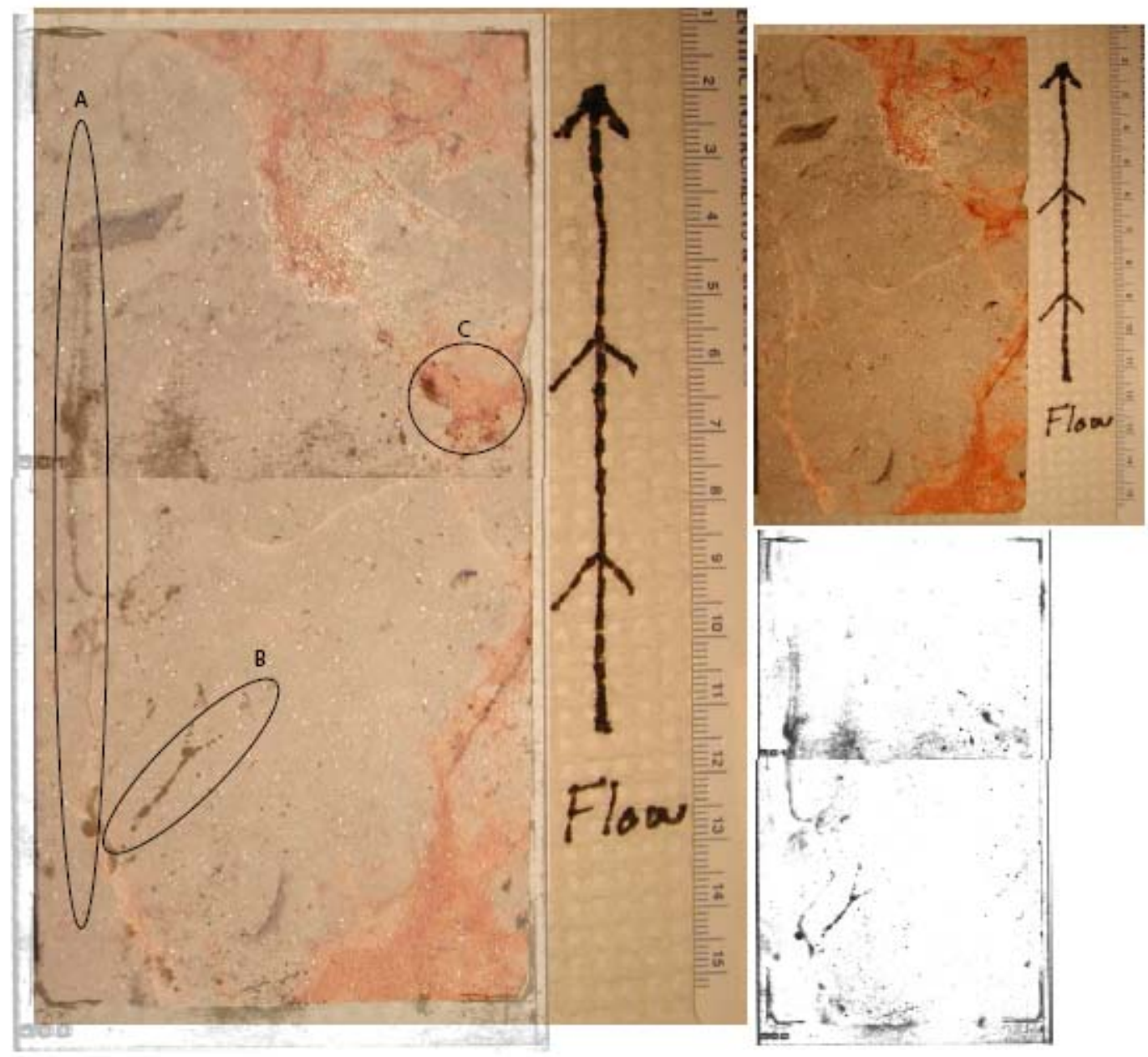

Figure 3.6 One-half of LCA-6 core (top right) and developed radiography plates (bottom right). Image of developed film is overlain on the core (left) and the arrow is noting direction of flow during the flowthrough experiment. Dark spots on the radiography plates indicate regions of concentrated alpha activity. Areas noted A, B, and C (left) show areas of interest as discussed in the text. 
Digital Images of Core LCA- 6 from

Flow-through colloid transport experiment

Note: Inset squares in approximate position
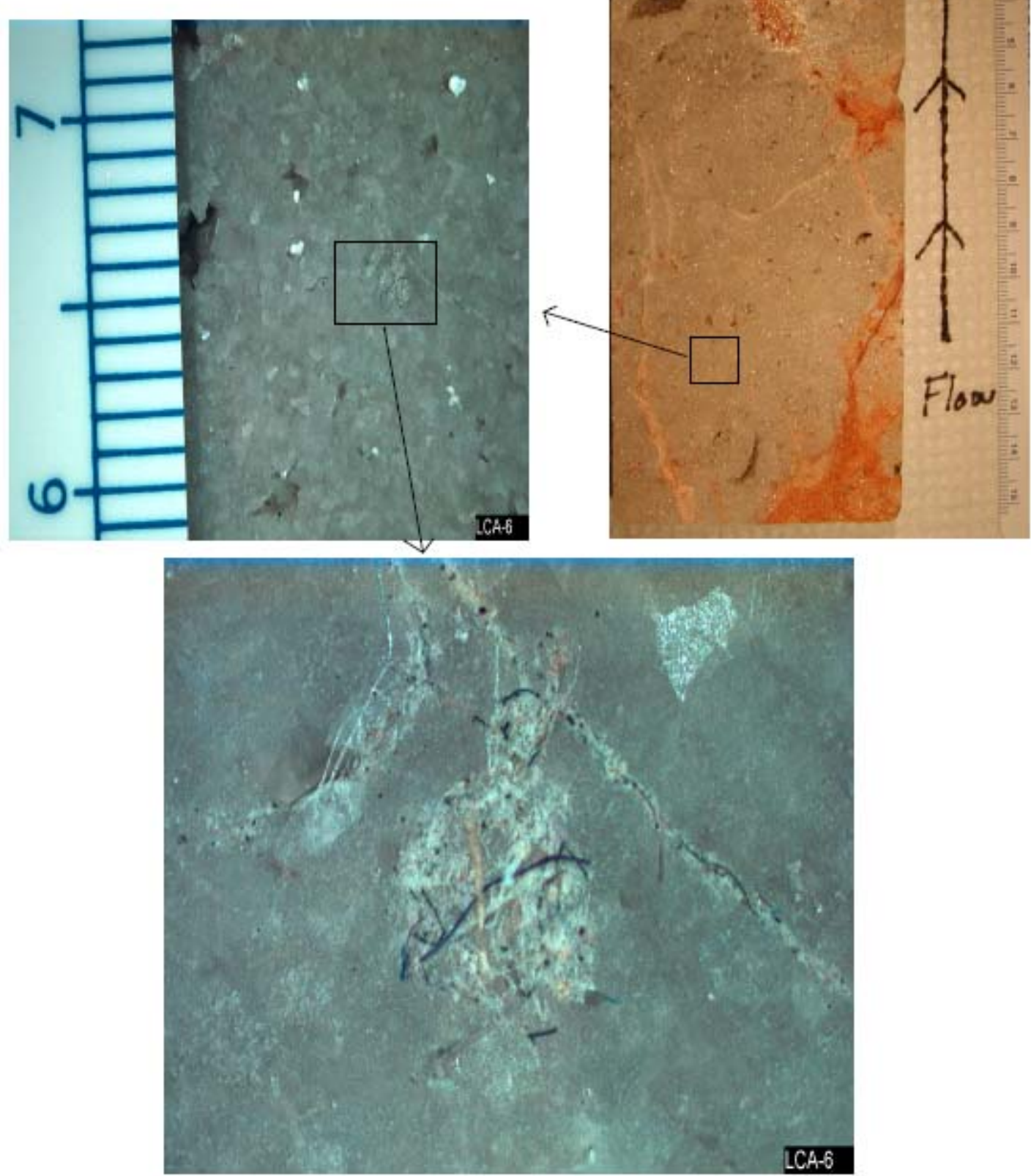

Figure 3.7 Digital image of precipitates/colloids and synthetic fibers observed in region B of Figure 3.6. 


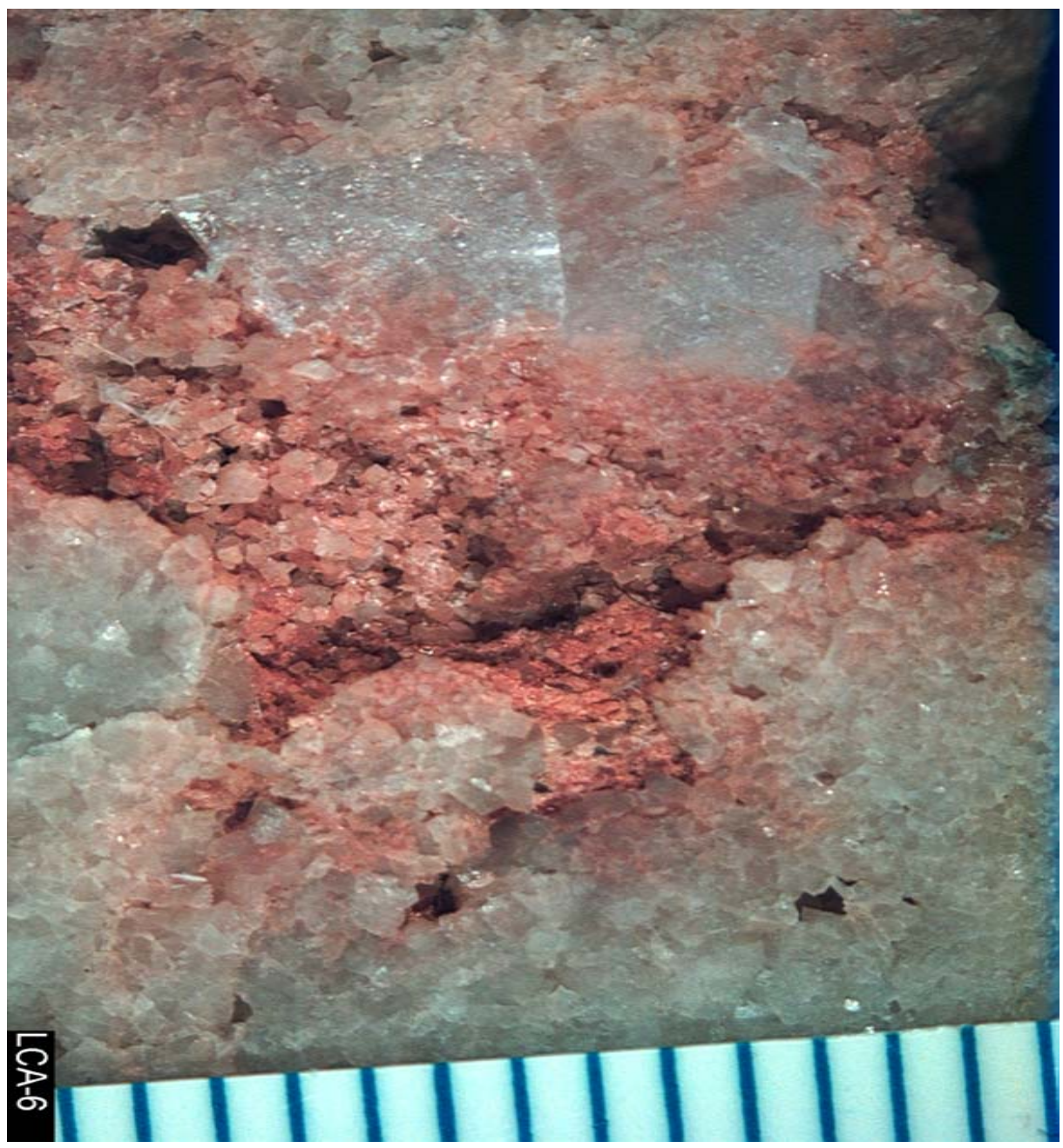

Figure 3.8 Digital image of region $\mathrm{C}$ from Figure 3.6. Scale markings represent $1 \mathrm{~mm}$.

\subsection{Laser Ablation}

For LCA-5, Re breakthrough data are indicative of non-sorbing transport. Consistently, LA/ICPMS data show uniform ${ }^{185}$ Re distribution across the fracture surface at near background levels (Figure 3.9a). A similar distribution pattern was observed for ${ }^{238} \mathrm{U}$, consistent with its nearly quantitative elution from the fractured core. Some higher concentrations in the latter half of the fracture surface reflect residual U(VI). Breakthrough data indicate that only a fraction of the ${ }^{147} \mathrm{Sm}$ and ${ }^{242} \mathrm{Pu}$ are eluted. However, both ${ }^{147} \mathrm{Sm}$ and ${ }^{242} \mathrm{Pu}$ are also uniformly distributed in LCA-5. The absence of a "migration front" is likely due to a combination of transport processes controlling migration of these radionuclides (i.e. colloid-facilitated transport, colloid filtration, matrix diffusion, and matrix sorption. 

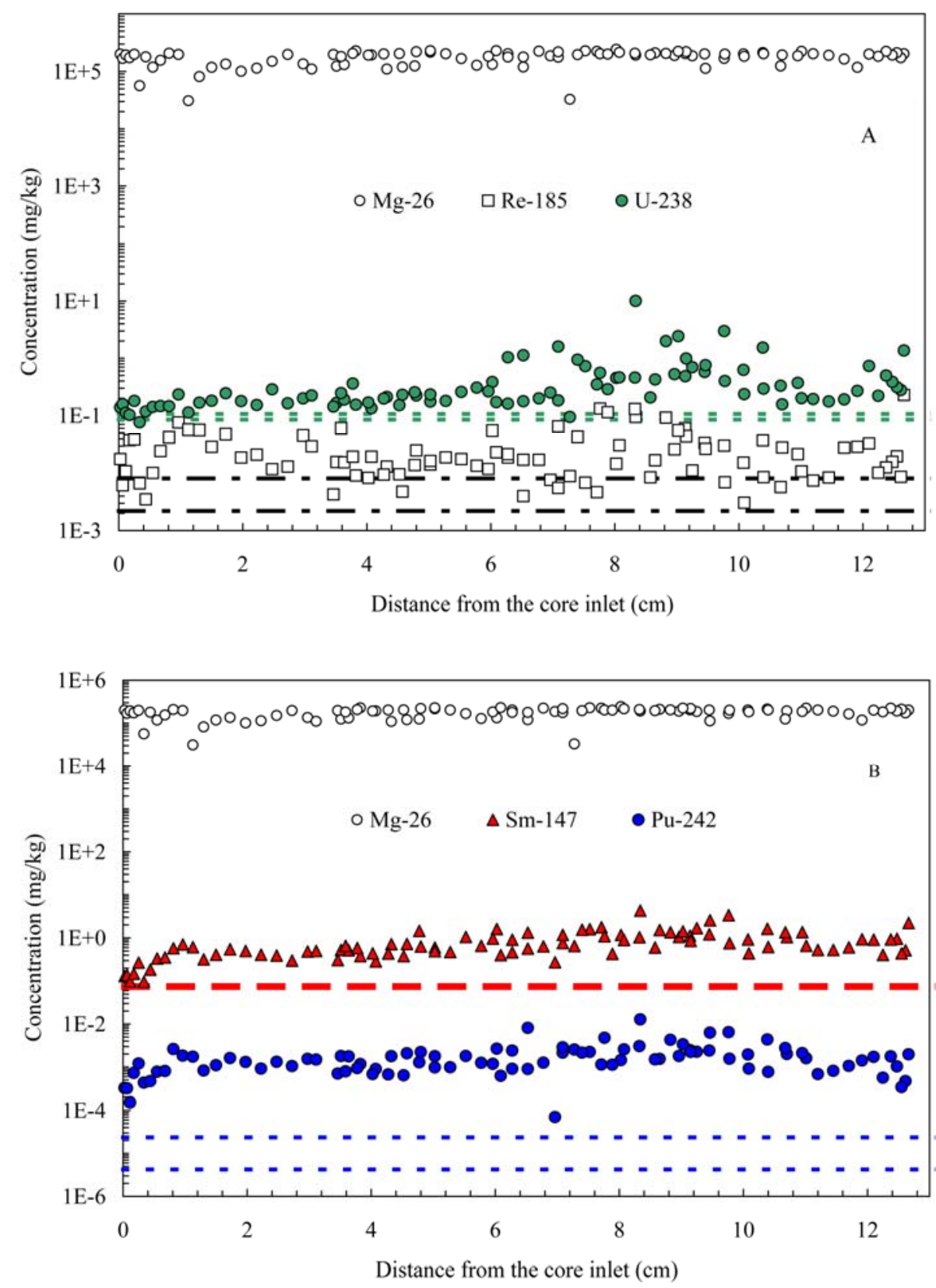

Figure 3.9 Distribution of isotopes obtained from surface profiling in LCA-5 core using LA/ICPMS. Symbols represent data; lines represent background intensity ratios (average \pm standard deviation). The distribution of intrinsic Mg-26 is also shown.

Results from depth profiling confirm that transverse migration had occurred for the applied tracers. Figure 3.10 shows the profiling results obtained at two locations $\sim 2.5 \mathrm{~mm}$ from the core inlet and perpendicular to the fracture surface. Compared to the uniform distribution pattern of ${ }^{26} \mathrm{Mg}$, all the added tracer elements exhibit a higher surface concentration than the locations deep in the rock matrix. This is particularly evident for ${ }^{242} \mathrm{Pu}$, which has a low background level. Concentrations of ${ }^{242} \mathrm{Pu}$ decrease gradually and approach background at $50-100 \mu \mathrm{m}$. 
The LA/ICPMS results from LCA-6 generally reflect the same transport behavior observed in LCA-5. The non-sorbing ${ }^{185} \mathrm{Re}$ was mostly flushed out and little remains on the fracture surface (Figure 3.11). Some ${ }^{238} \mathrm{U}$ appears to have accumulated near the core inlet. However, the concentration is only slightly above background and may be related to the trace iron oxide located near the core inlet. Similar accumulation near the core inlet is observed for ${ }^{147} \mathrm{Sm}$ and ${ }^{242} \mathrm{Pu}$. ${ }^{242} \mathrm{Pu}$ is also observed over the entire length of the core, consistent with the LCA-5 data.

Interestingly, measurement of $\mathrm{Fe}$ and ${ }^{242} \mathrm{Pu}$ simultaneously over a number of locations on the LCA-5 fracture surface confirms the preferential sorption of Pu to iron oxides vs. calcite (Figure 3.12). This was also observed when autoradiography was combined with optical microscopy. Nevertheless, due to the very small quantities of iron oxide in these samples, calcite will likely be the dominant sorber in the carbonate rock matrix. 

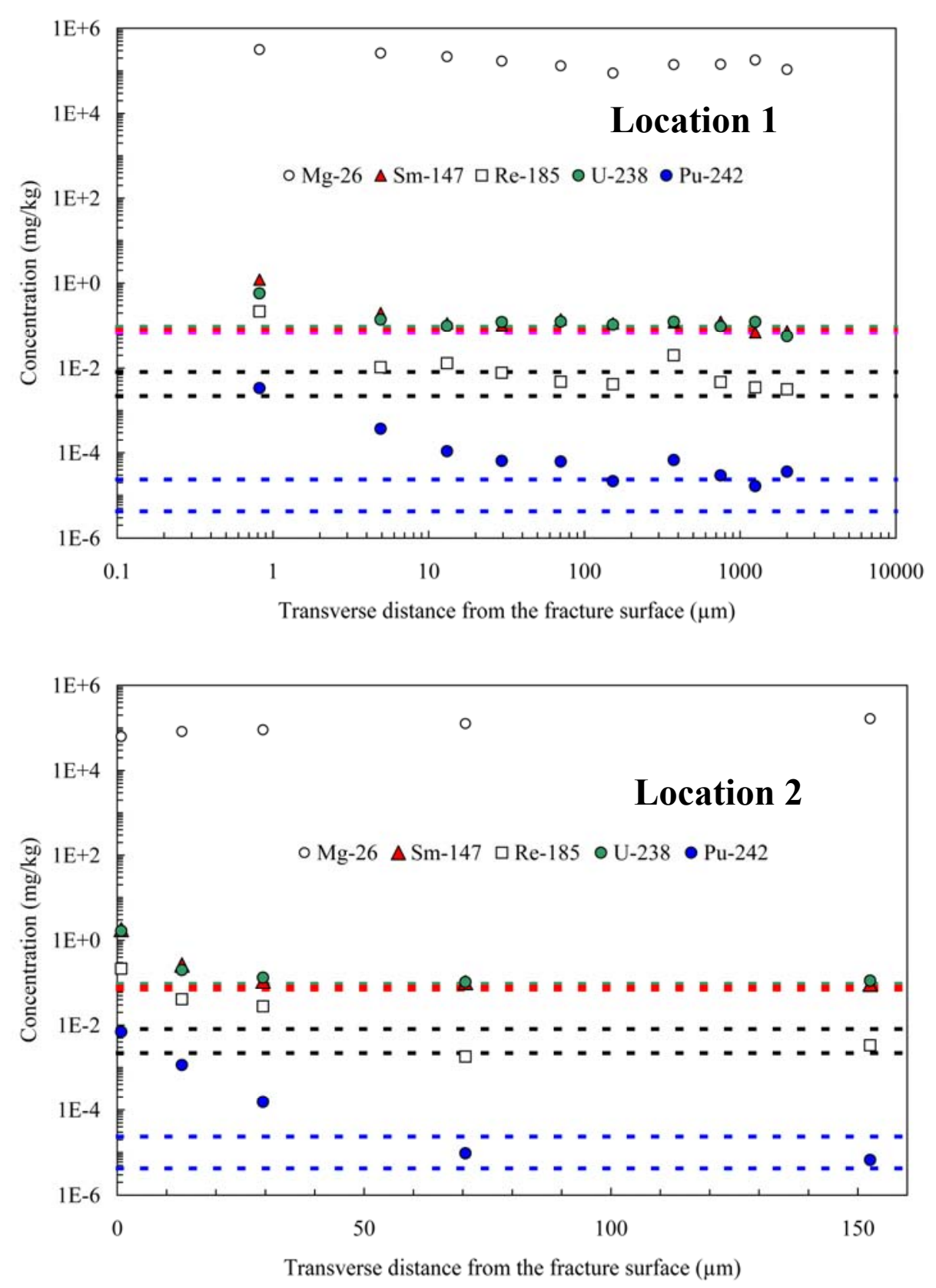

Figure 3.10 Distribution of several isotopes obtained from depth profiling in LCA-5 core sample using LA/ICP-MS at two locations near the core inlet. Symbols represent data; lines represent background intensity ratios (average \pm standard deviation). 

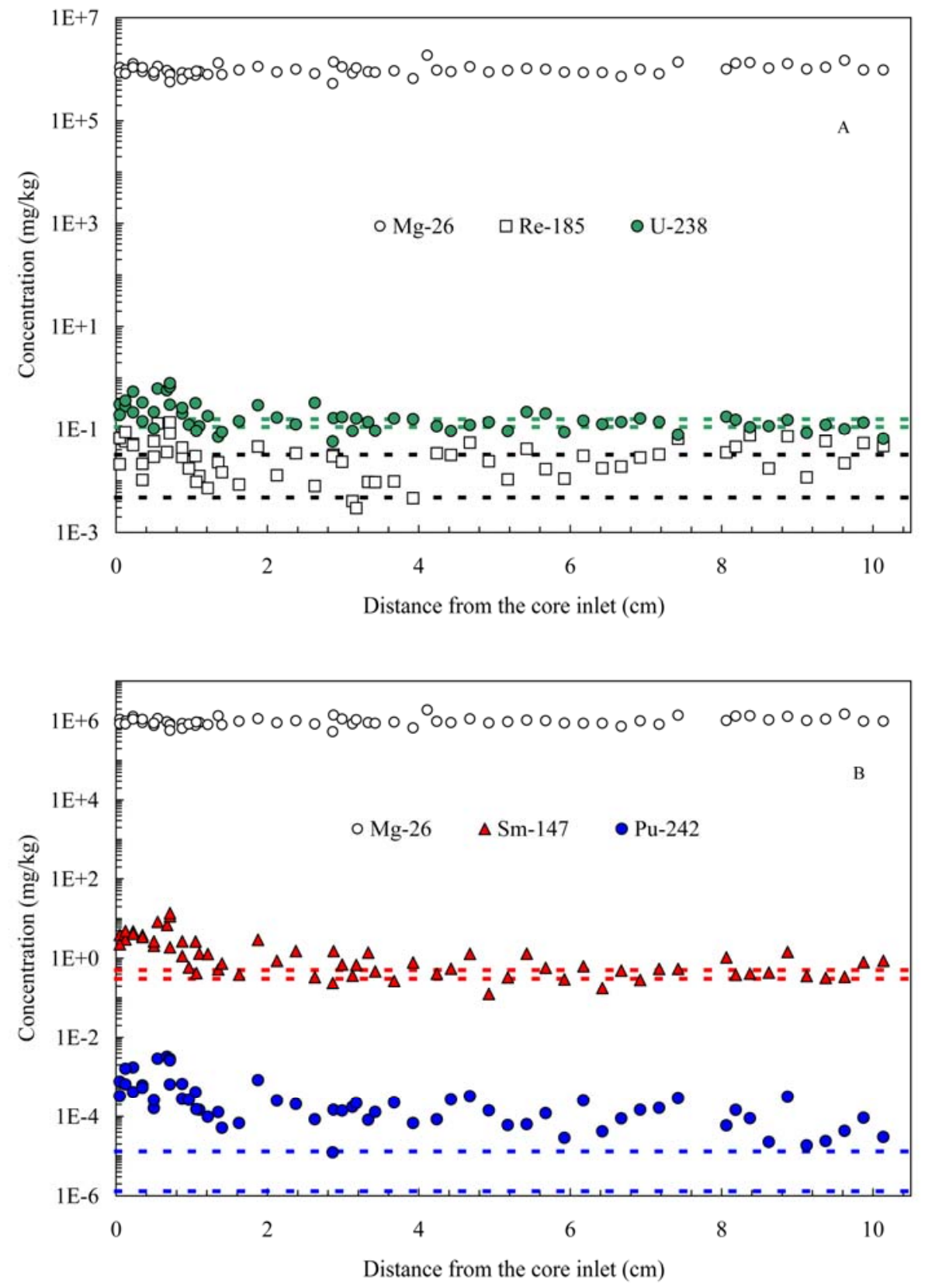

Figure 3.11 Distribution of isotopes obtained from surface profiling in LCA-6 core using LA/ICPMS. Symbols represent data; lines represent background intensity ratios (average \pm standard deviation). 

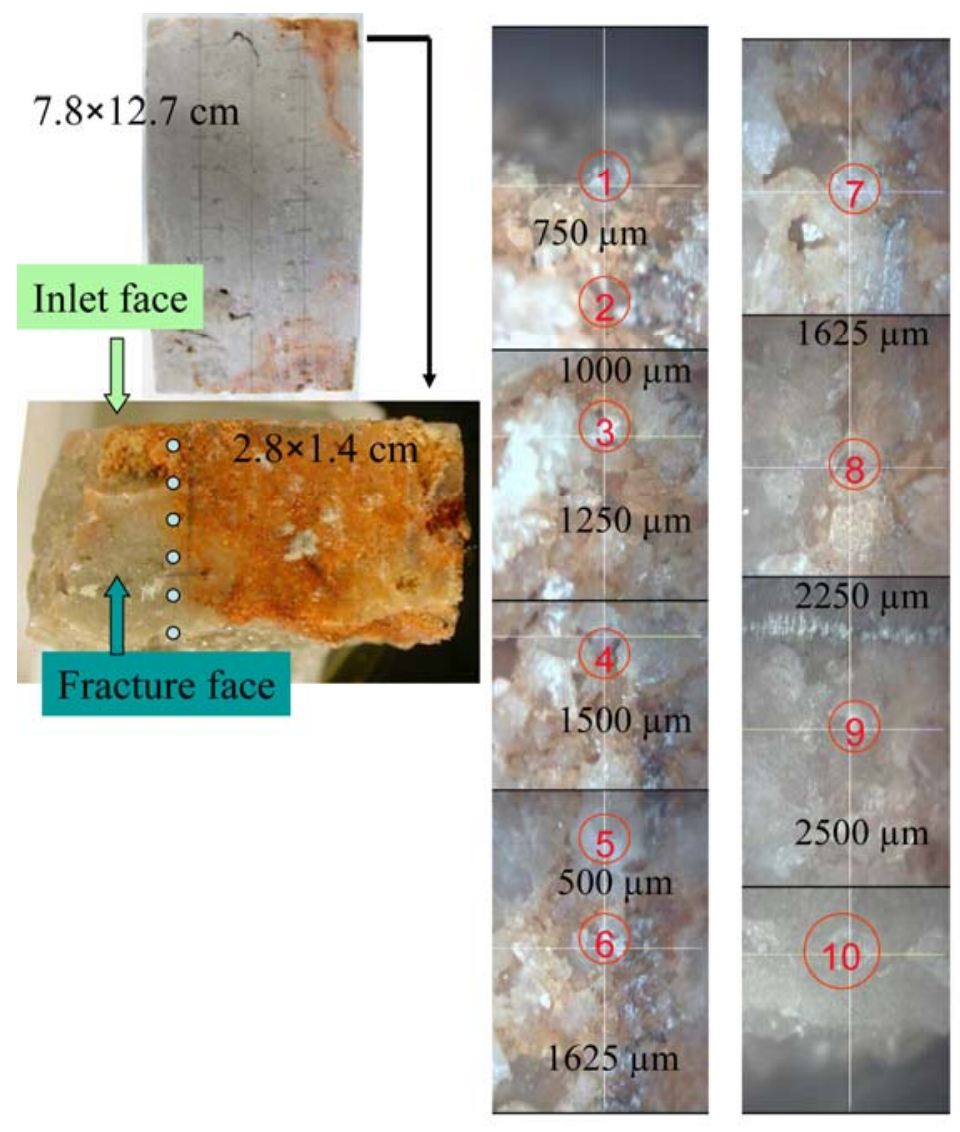

\begin{tabular}{|c|c|c|}
\hline $\begin{array}{c}\text { Sample } \\
\text { spot } \\
\text { (laser } \\
\text { pulse) }\end{array}$ & $\begin{array}{c}\text { Fe conc. } \\
(\mathrm{g} / \mathrm{kg})\end{array}$ & $\begin{array}{c}242 \mathrm{Pu} \\
\text { conc. } \\
(\mathrm{ng} / \mathrm{kg})\end{array}$ \\
\hline $1(20)$ & 13.7 & 750 \\
\hline $2(20)$ & 10.2 & 641 \\
\hline $3(20)$ & 59.4 & 1704 \\
\hline $4(20)$ & 20.8 & 604 \\
\hline $5(20)$ & 1.89 & 161 \\
\hline $6(5)$ & 131.2 & 2871 \\
\hline $7(5)$ & 4.04 & 638 \\
\hline $8(20)$ & 3.57 & 238 \\
\hline $9(20)$ & 0.539 & 146 \\
\hline $10(20)$ & 0.885 & 127 \\
\hline & \multicolumn{3}{|c|}{ Correlation: 0.979} \\
\hline
\end{tabular}

Figure 3.12 Distribution of Fe and Pu on LCA-6 fracture surface using LA/ICP-MS. Strong correlation is indicative of the preferential sorption of $\mathrm{Pu}$ to iron oxide vs. calcite.

\section{REACTIVE TRANSPORT MODELING}

Experiments LCA-5 and LCA-6 were modeled using the CRUNCH code (Steefel and Yabusaki, 1995). CRUNCH can simulate multi-component mass transport in porous/fractured media under non-isothermal conditions, including consideration of zonal variations in mineralogy and fluid chemistry. Aqueous speciation, surface complexation, ion exchange, mineral dissolution/precipitation, and radionuclide decay are all modeled explicitly. Details regarding the CRUNCH code and its use are reported in (Zavarin et al., 2005) and will not be repeated here.

A large number of parameters and data are needed to simulate reactive transport with the CRUNCH code. The water chemistry used in the model was based on the average composition of the effluent (see Appendix). Radionuclide concentrations were taken from Table 2.4. The rock mineralogy was assumed to be pure carbonate. The core characteristics (porosity, core dimensions, aperture) and flow rate $(0.02 \mathrm{~mL} / \mathrm{min})$ were taken from Table 2.1 . The time of the tracer injection pulse was taken from Table 2.5. Aqueous complexation and surface complexation reaction constants and mineral surface area/reactive site density were taken from (Zavarin and Bruton, 2004a; Zavarin and Bruton, 2004b) and (Zavarin et al., 2002). The concentration of colloid $>\mathrm{SiOH}$ and $>\mathrm{AlOH}$ reactive sites was calculated based on the colloid 
mineralogy, load, particle size, and a nominal reactive site density of 2.31 sites $/ \mathrm{nm}^{2}$. However, the surface complexation reaction constants and calcite surface area were adjusted in the model to achieve the best fit to the data. Because all model parameters were held constant during modeling, data fitting parameters could be reduced to parameters describing three processes: (1) sorption to colloids, (2) matrix diffusion, and (3) matrix sorption. Breakthrough of all radionuclides in a single experiment was modeled simultaneously. Matrix diffusion was calibrated to the breakthrough of the non-sorbing tracers. Diffusion coefficients in water for all radionuclides were taken from the literature $\left(25^{\circ} \mathrm{C}\right) .{ }^{3} \mathrm{H}$ and $\mathrm{Re}$ diffusion in water was $2.2 \times 10^{-9}$, $1.5 \times 10^{-9}$, respectively (Kemper, 1986; Mills, 1973; Lide, 2000; Reimus et al., 2002; Hershey et al., 2003). The diffusion of all other radionuclides (U, Pu, and $\mathrm{Sm}$ ) was assumed to be equivalent to the diffusion of Tc in water $\left(1.5 \times 10^{-9} \mathrm{~m}^{2} / \mathrm{s}\right.$ from (Reimus et al., 2002)); it was impractical to try to accurately predict the diffusivity of these radionuclides since multiple aqueous species were predicted to be present in solution and each would diffuse at a different rate. The tortuosity parameter was used to fit the apparent radionuclide diffusion. Dispersivity was set to 0 in our model. When run in the global implicit approach, the CRUNCH code can suffer from significant numerical dispersion. As described in (Zavarin et al., 2005), model results were not sensitive to dispersivity because its effect was masked by numerical dispersion. In any case, dispersion is expected to be low since the fracture geometry is smooth and regular.

Table 4.1 and Figures 4.1 to 4.7 summarize modeling results. Table 4.1 lists the transport parameters varied to fit the breakthrough data (tortuosity $(\tau)$, matrix retardation factor, fraction sorbed to colloids). All other parameters used in the modeling were either measured directly or based on values from the literature (e.g. $\left.D_{0}\right)$.

Table 4.1 Predicted and fitted radionuclide retardation and diffusion parameters for carbonate cores.

\begin{tabular}{|c|c|c|c|c|c|c|}
\hline & ${ }^{3} \mathrm{H}$ & $\mathrm{Re}$ & $\mathrm{U}$ & $\mathrm{Pu}(\mathrm{IV})$ & $\mathrm{Pu}(\mathrm{V})$ & $\mathrm{Sm}$ \\
\hline \multicolumn{7}{|c|}{ LCA-5 } \\
\hline$\tau^{\mathrm{a}}$ & 1 & 1 & 1 & 1 & 1 & 1 \\
\hline Rmatrix & 1 & 1 & $10^{1.7}$ & $10^{7.0}$ & $10^{2.5}$ & $10^{6.9}$ \\
\hline $\begin{array}{l}\text { Percent on } \\
\text { colloids }\end{array}$ & 0 & 0 & 0 & 98 & 0 & 97 \\
\hline \multicolumn{7}{|c|}{ LCA-6 } \\
\hline$\tau$ & 1 & 1 & 1 & 1 & 1 & 1 \\
\hline Rmatrix & 1 & 1 & $10^{0.1}$ & $10^{3.2}$ & $10^{1.1}$ & $10^{7.7}$ \\
\hline $\begin{array}{l}\text { Percent on } \\
\text { colloids }\end{array}$ & 0 & 0 & 0 & 98 & 0 & 99.5 \\
\hline
\end{tabular}

a To achieve a good fit, the porosity of the rock was increased from $1 \%$ to $2 \%$.

The tortuosity, free water diffusivity $\left(\mathrm{D}_{0}\right)$ and porosity parameters are all highly correlated. As a result, only one of the three parameters can be fitted during modeling. The $\mathrm{D}_{0}$ and porosity for each radionuclide and core were taken from the literature and measured directly, respectively. However, based on the fact that the fitted tortuosity was consistently 1.0, we suspect that the actual porosity of the carbonate rock may be somewhat higher than the measured value. In fact, to achieve a good fit to the data, the porosity of LCA-5 was increased from the measured value of $1 \%$ to a fitted value of $2 \%$. 
For both LCA-5 and LCA-6, the breakthrough of non-sorbing ${ }^{3} \mathrm{H}$ and Re could be modeled quite well using the measured fractured core geometry, rock properties, and fluid flow rates and adjusting only the tortuosity and the porosity of LCA-5 (Figure 4.1). The fit to the LCA-5 data was somewhat hampered by the mass balance issues associated with this experiment. Nevertheless, the model fit the data quite well. Importantly, the modeling results indicate that the carbonate core will be accessible to diffusion and will contribute to the retardation of nonsorbing tracers. The modeled distribution of non-sorbing ${ }^{3} \mathrm{H}$ and $\mathrm{Re}$ in the matrix at the end of the LCA-5 flowthrough experiment is plotted in Figure 4.2.
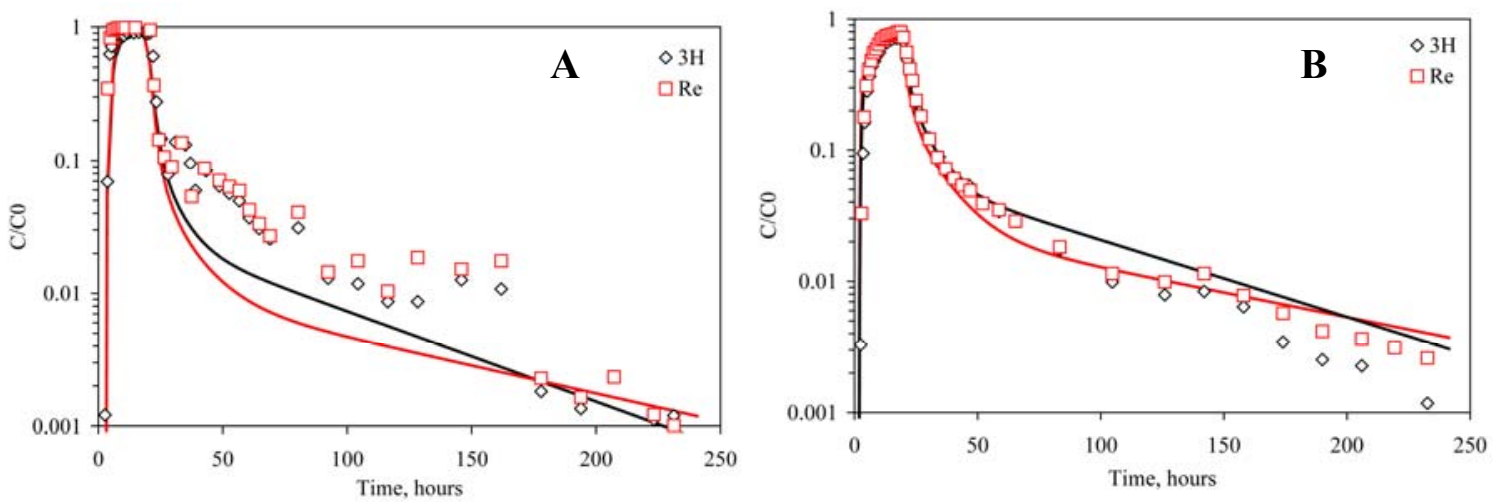

Figure 4.1 Model fits to LCA-5 (A) and LCA-6 (B) non-sorbing tracer elution data.
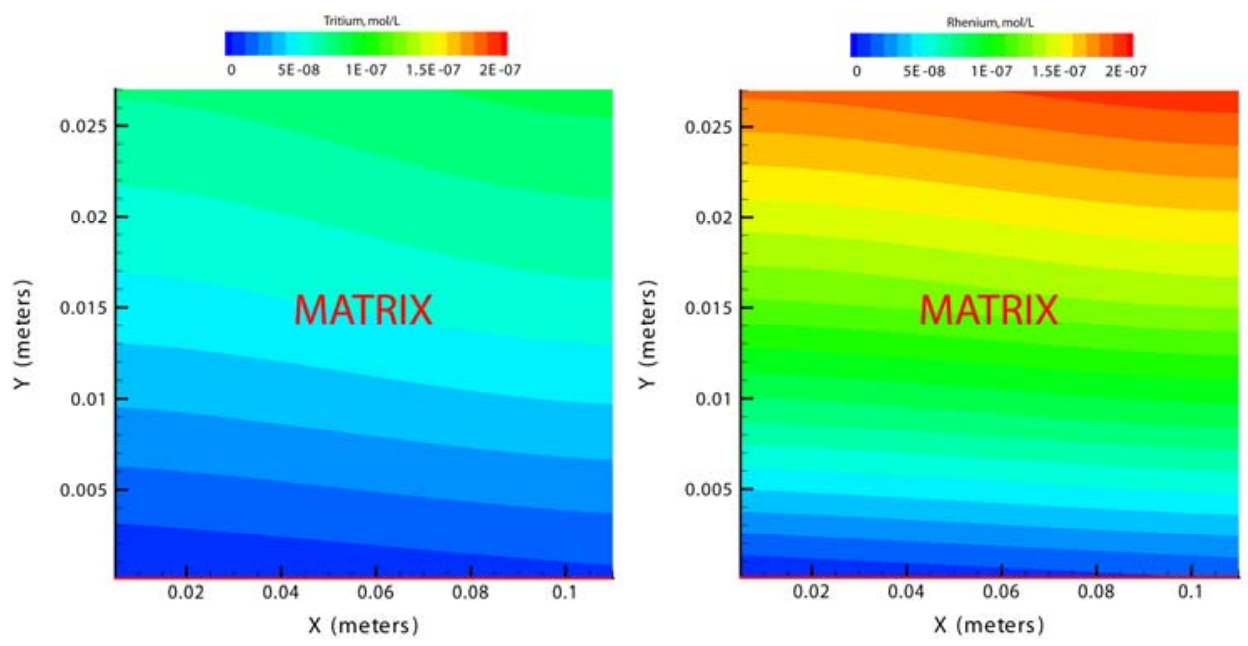

Figure 4.2 LCA-5 model of aqueous tracer radionuclide distribution at end of flowthrough experiment.

Generally, U(VI) sorbs weakly to calcite when in the +6 oxidation state (Zavarin and Bruton, $2004 b)$. This is consistent with the modeled U(VI) retardation values of $50\left(10^{1.7}\right)$ and $1.3\left(10^{0.1}\right)$ for LCA-5 and LCA-6, respectively (Table 4.1). The LCA-5 and LCA-6 fracture breakthrough data could be modeled very well with diffusion and matrix sorption (Figures 4.2). Interestingly, U(VI) sorption in LCA-5 was significantly greater than in LCA-6. The source for the greater retardation is not known but could be address by trace concentrations of iron oxide found in carbonate rock. 

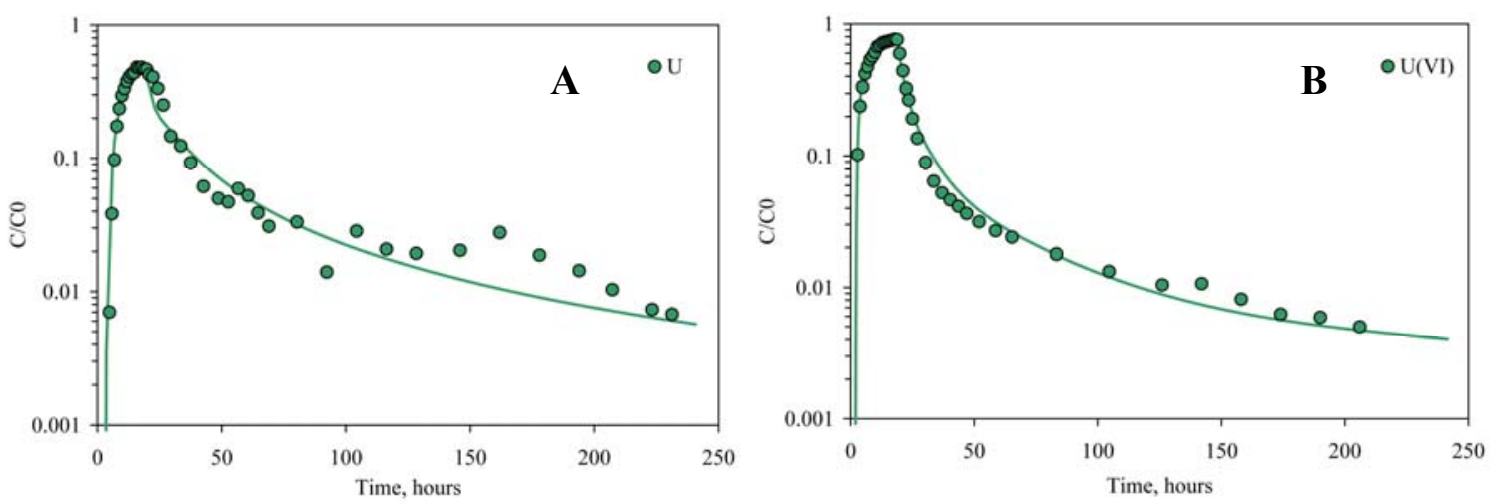

Figure 4.3 Model fits to LCA-5 (A) and LCA-6 (B) U(VI) elution data.

The migration of Sm(III) could not be modeled without accounting for colloid-facilitated transport. Given the very strong affinity of Sm(III) and all trivalent lanthanides and actinides for mineral surfaces, we would expect most of the soluble Sm(III) to be colloid-bound in both fracture transport experiments. To model the data, Sm(III) diffusion into the carbonate matrix was restricted to the non-colloid-bound species. Colloid filtration was not included in this model. A very good fit to the LCA-5 and LCA-6 data could be achieved (Figure 4.4). In both cases, $>95 \%$ of the aqueous $\mathrm{Sm}($ (III) was bound to colloids while the matrix retardation factor was very high $\left(10^{6.9}\right.$ and $\left.10^{7.7}\right)$. The high retardation resulted in predicted Sm deposition into the first $\sim 50 \mu \mathrm{m}$ of the matrix (Figures 4.5). The results are in general agreement with the depth profiling results shown in Figure 3.10 for core LCA-5. The distribution of Sm along the length of the fracture is also qualitatively consistent with LA/ICP-MS data reported in Section 3.
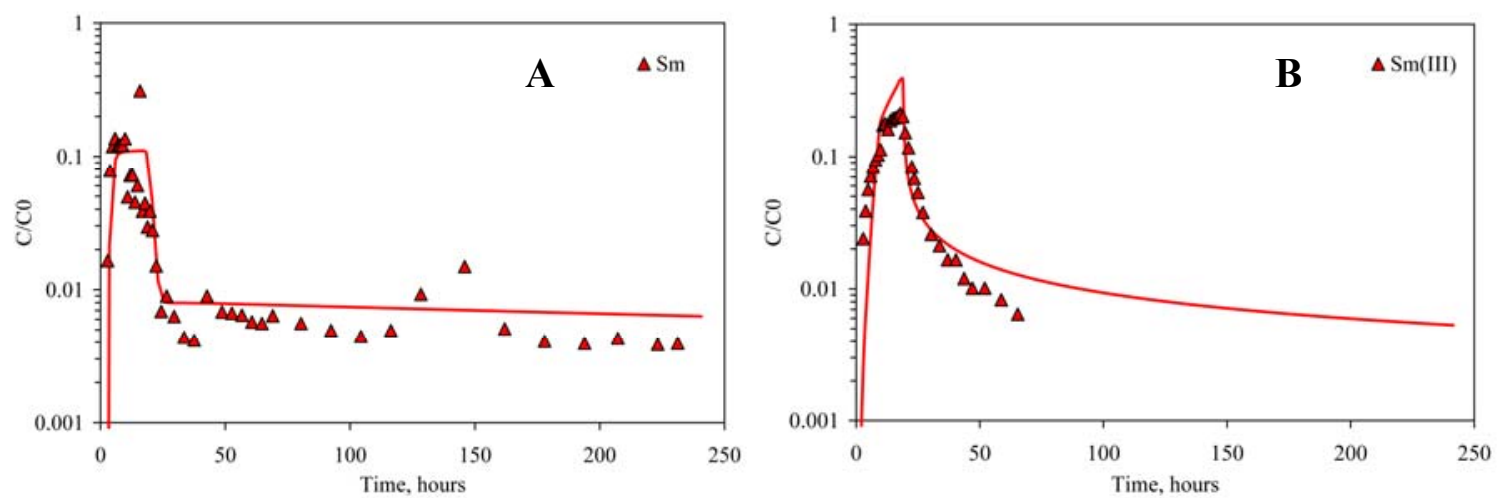

Figure 4.4 Model fits to LCA-5 (A) and LCA-6 (B) Sm(III) elution data. 

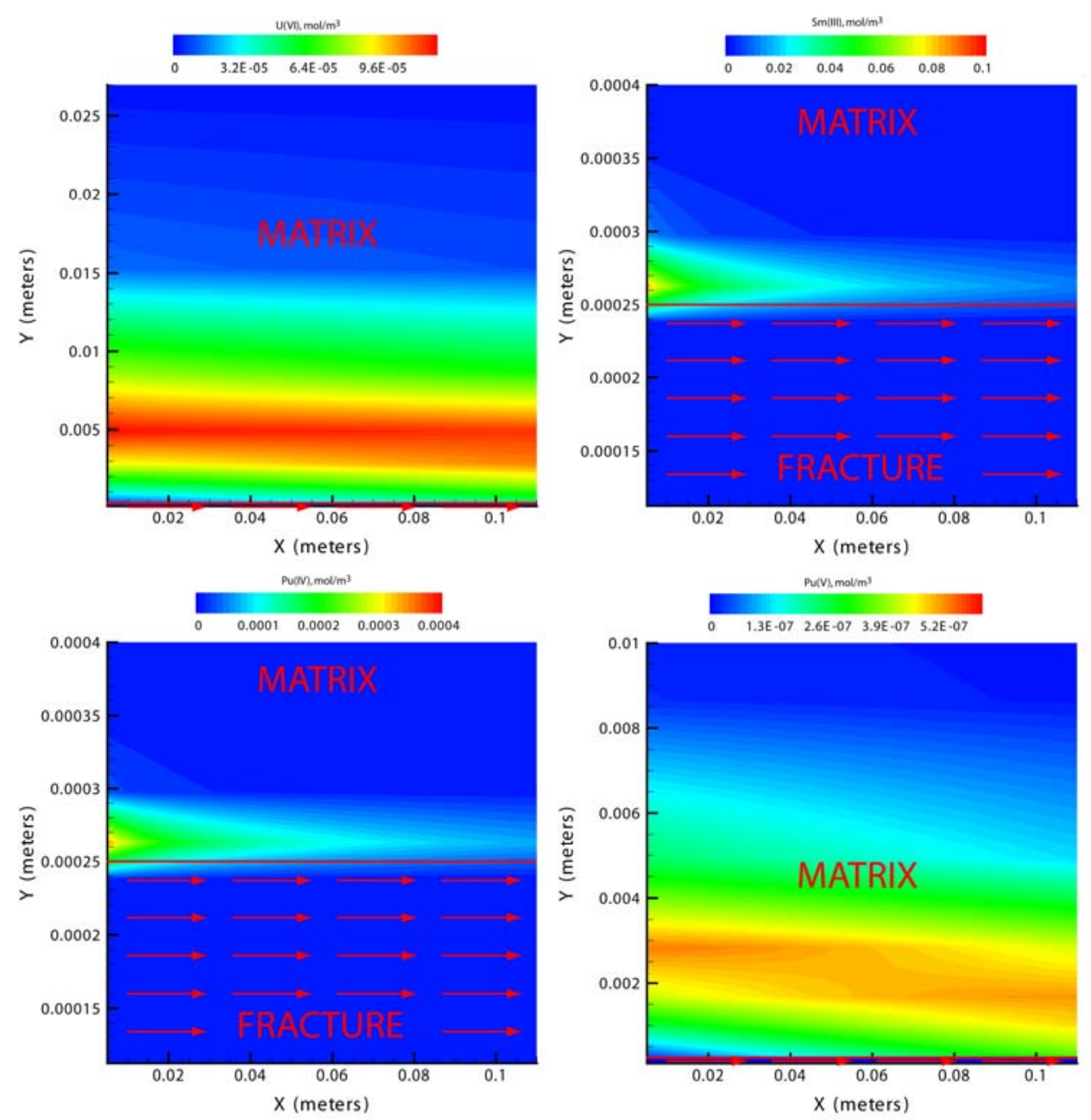

Figure 4.5 LCA-5 model of sorbed radionuclide distribution for $\mathrm{U}, \mathrm{Sm}, \mathrm{Pu}(\mathrm{IV})$, and $\mathrm{Pu}(\mathrm{V})$ at end of flowthrough experiment.

Modeling the migration of $\mathrm{Pu}$ is complicated by the fact that multiple oxidation states with differing sorption affinities for both the colloidal and matrix minerals exist. To simplify the $\mathrm{Pu}$ transport model, we assumed that the oxidation state of $\mathrm{Pu}$ was constant and equal to the oxidation state of the stock solutions. Thus, ${ }^{238} \mathrm{Pu}$ was composed of $95 \% \mathrm{Pu}(\mathrm{V})$ and $5 \% \mathrm{Pu}(\mathrm{IV})$; ${ }^{242} \mathrm{Pu}$ was composed of $60 \% \mathrm{Pu}(\mathrm{IV})$ and $40 \% \mathrm{Pu}(\mathrm{V})$. In fact, we expect some of the $\mathrm{Pu}(\mathrm{V})$ to be reduced to $\mathrm{Pu}(\mathrm{IV})$ as it sorbs to the colloids or matrix. However, the rate of this reduction reaction is not known. A second assumption was that $\mathrm{Pu}(\mathrm{V})$ will not sorb to aluminosilicate colloids. This is not altogether unreasonable given the much weaker sorption of $\mathrm{Pu}(\mathrm{V})$ compared to $\mathrm{Pu}(\mathrm{IV})$ to these minerals (Zavarin and Bruton, 2004a). Thus, Pu transport was modeled by adjusting $\mathrm{Pu}(\mathrm{IV})$ sorption to colloids, $\mathrm{Pu}(\mathrm{IV})$ sorption to the matrix, and $\mathrm{Pu}(\mathrm{V})$ sorption to the matrix.

Given the simplicity of our model, the resulting fits to the breakthrough data are quite good (Figure 4.6). The initial ${ }^{242} \mathrm{Pu}$ peak in LCA-5 can be attributed to $\mathrm{Pu}(\mathrm{IV}$ ) colloid-facilitated transport. The second ${ }^{242} \mathrm{Pu}$ peak can be attributed to the migration of $\mathrm{Pu}(\mathrm{V})$. The ${ }^{238} \mathrm{Pu}$ breakthrough includes only one peak that is coincident with the second ${ }^{242} \mathrm{Pu}$ peak. Interestingly, the difference in ${ }^{238} \mathrm{Pu}$ and ${ }^{242} \mathrm{Pu}$ transport could be accounted for by the difference in $\mathrm{Pu}$ 
oxidation state. The relatively poor fit in the tailing of both ${ }^{242} \mathrm{Pu}$ and ${ }^{238} \mathrm{Pu}$ is likely due to the slow reduction of $\mathrm{Pu}(\mathrm{V})$ to $\mathrm{Pu}(\mathrm{IV})$ which was not included in the model. Importantly, the deposition of $\mathrm{Pu}(\mathrm{IV})$ primarily in the first $\sim 50 \mu \mathrm{m}$ of the matrix (Figure 4.5 and Figure 4.7 ) is consistent with the ${ }^{242} \mathrm{Pu}$ depth profiling data shown in Section 3 (note that ${ }^{242} \mathrm{Pu}$ is predominantly $\mathrm{Pu}(\mathrm{IV}))$.

Two separate ${ }^{242} \mathrm{Pu}$ breakthrough peaks are not observed in LCA-6. In this case Pu(V) (i.e. ${ }^{238} \mathrm{Pu}$ ) is not retarded sufficiently to shift its breakthrough. Nevertheless, ${ }^{242} \mathrm{Pu}$ breakthrough is significantly greater and can be attributed to the contribution of $\mathrm{Pu}(\mathrm{IV})$ colloid-facilitated transport.
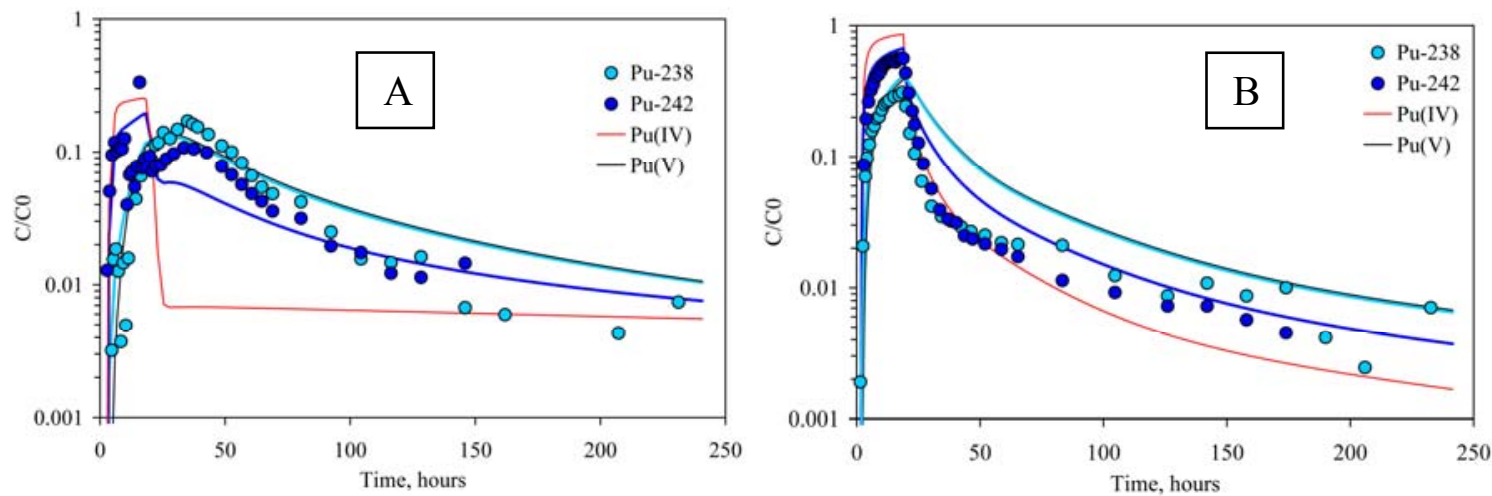

Figure 4.6 Model fits to LCA-5 (A) and LCA-6 (B) Pu elution data. Model results also include transport behavior of $\mathrm{Pu}(\mathrm{IV})$ and $\mathrm{Pu}(\mathrm{V})$. 

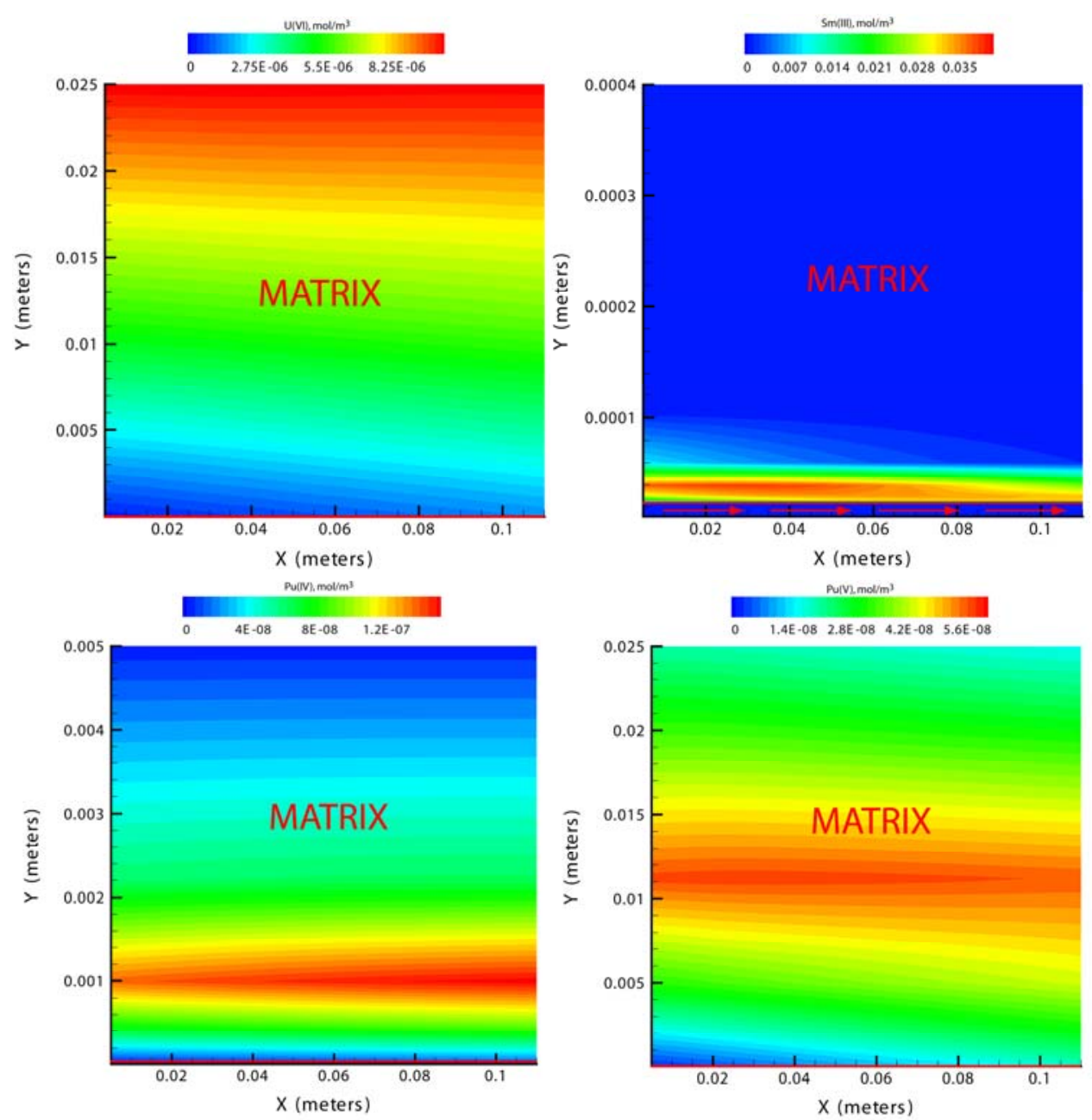

Figure 4.7 LCA-6 model of sorbed radionuclide distribution at end of flowthrough experiment.

\section{CONCLUSIONS AND RECOMMENDATIONS}

Based on the experimental results and modeling described in this report:

- $\quad{ }^{3} \mathrm{H}$ and Re behave as tracers that diffuse into the rock matrix at rates proportional to their diffusivities in water $\left(\operatorname{Re}<^{3} \mathrm{H}\right)$. High predicted tortuosity values may have resulted from underestimates of porosity.

- U breakthrough was retarded only slightly, indicating a low sorption potential of this radionuclide in carbonate rock.

- Sm migration in carbonate fractures was only observed as a result of colloid-facilitated transport. Thus, in the absence of colloids, Sm transport is unlikely. Based on their analogous reaction chemistry, it is likely that the transport of any of the trivalent rare earth radionuclides (as well as the Am(III) and $\mathrm{Cm}$ (III) actinides) will be attributable to colloid-facilitated transport.

- Pu transport in carbonate fractures may occur in the absence of colloids. However, it is likely that this transport is attributable to $\mathrm{Pu}(\mathrm{V})$. In the presence of mineral surfaces, $\mathrm{Pu}$ 
will tend to reduce to $\mathrm{Pu}(\mathrm{IV})$ over time. $\mathrm{Pu}(\mathrm{IV})$ is unlikely to migrate as a free aqueous species in carbonate fractures. However, it can migrate by colloid-facilitated transport.

- The measured and simulated breakthrough curves show good agreement lending some confidence to the identification of the most significant processes, the performance of high quality and controlled experiments, and the interpretation approach and model being appropriate.

\section{ACKNOWLEDGEMENTS}

We would like to acknowledge the assistance of Jerry Magner, USGS, in the selection and collection of core from the USGS core library, Mercury, Nevada.

Funding for this investigation was provided by the Environment Management Operations' Underground Test Area Project at the U.S. Department of Energy, National Nuclear Security Administration, Nevada Field Office. This work was performed under the auspices of the U.S. Department of Energy by Lawrence Livermore National Laboratory under contract number W7405-Eng-48.

\section{REFERENCES}

American Petroleum Institute Recommended Practice (API RP) 27 (1952). Recommended Practice for Determining Permeability of Porous Media. American Petroleum Institute, Dallas, Texas, 3rd Ed.

American Petroleum Institute Recommended Practice (API RP) 40 (1960). Recommended Practice for Core Analysis Procedure. American Petroleum Institute, Dallas, Texas, 1st Ed.

Cartwright, B. G., E. K. Shirk and P. B. Price (1978). "A Nuclear-Track-Recording Polymer of Unique Sensitivity and Resolution." Nuclear Instruments and Methods 153: 457-460.

Ghazi, A. M., S. Shuttleworth, S. J. Angulo and D. H. Pashley (2000). "New applications for laser ablation high resolution ICPMS (LA-HR-ICP-MS): Quantitative measurements of gallium diffusion across human root dentin." J. Anal. At. Spectrom. 15: 1335-1341.

Hershey, R. L., W. Howcroft and P. W. Reimus (2003) Laboratory Experiments to Evaluate Diffusion of 14C into Nevada National Security Site Carbonate Aquifer Matrix, Publication No. 45180, Desert Research Institute, Las Vegas, Nevada.

Kemper, W. D. (1986). Solute Diffusivity. Methods of Soil Analysis, Part 1 - Physical and Mineralogical Methods. A. Klute. Madison, Wisconsin, American Society of Agronomy, Inc. and Soil Science Society of America, Inc.

Kersting, A. B., D. W. Efurd, D. L. Finnegan, D. J. Rokop, D. K. Smith and J. L. Thompson (1999). "Migration of plutonium in ground water at the Nevada Test Site." Nature 397(6714): 56-59.

Kersting, A. B., P. Zhao, M. Zavarin, E. R. Sylwester, Patrick G. Allen, L. Wang, E. J. Nelson and R. W. Williams (2003). Sorption of Pu(IV) on Mineral Colloids. Colloid-Facilitated Transport of Low-solubility Radionuclides: A Field, Experimental, and Modeling Investigation. A. B. Kersting and P. W. Reimus. Livermore, California, Lawrence Livermore National Laboratory: UCRL-ID-149688.

Lide, D. R. (2000). CRC Handbook of Chemistry and Physics. Boca Raton, Florida, CRC Press. 
Mills, R. 1973. Self-Diffusion in Normal and Heavy Water in the Range $1-45^{\circ}$, The Journal of Physical Chemistry, Vol. 77, No. 5, p. 685-688.

Powell, B. A., M. C. Duff, D. I. Kaplan, R. A. Fjeld, M. Newville, D. B. Hunter, P. M. Bertsch, J. T. Coates, P. Eng, M. L. Rivers, S. R. Sutton, I. R. Triay and D. T. Vaniman (2006). "Plutonium oxidation and subsequent reduction by Mn(IV) minerals in Yucca Mountain tuff." Environmental Science \& Technology 40(11): 3508-3514.

Reimus, P. W., S. D. Ware, F. C. Benedict, R. G. Warren, A. Humphrey, A. Adams, B. Wilson and D. Gonzales (2002) Diffusive and Advective Transport of 3H, 14C, and 99Tc in Saturated, Fractured Volcanic Rocks from Pahute Mesa, Nevada, LA-13891-MS, Los Alamos National Laboratory, Los Alamos.

Reimus, P., M. Haga, A. R. Humphrey, D. A. Counce, T. J. Callahan and S. D. Ware (2002). Diffusion Cell and Fracture Transport Experiments to Support Interpretations of the Bullion Forced Gradient Experiment, LA-UR-02-6884, Los Alamos National Laboratory, Los Alamos, New Mexico.

Reimus, P., G. Pohll, T. Mihevc, J. Chapman, M. Haga, B. Lyles, S. Kosinski, R. Niswonger and P. Sanders (2003). "Testing and parameterizing a conceptual model for solute transport in a fractured granite using multiple tracers in a forced gradient test." Water Resources Research 39(12).

Reimus, P. W. and M. J. Haga (1999). Analysis of tracer responses in the Bullion forced-gradient experiment at Pahute Mesa, Nevada, LA-13615-MS, Los Alamos National Laboratory, Los Alamos, New Mexico.

Russo, R. E., X. L. Mao, O. V. Borisov and H. C. Liu (2000). Laser ablation in atomic spectroscopy. Encyclopedia of Analytical Chemistry: Instrumentation and Applications. R. A. Meyers. Chichster, John Wiley \& Sons Ltd: 9485-9506.

Russo, R. E., X. L. Mao, H. C. Liu, J. Gonzalez and S. S. Mao (2002). "Laser ablation in analytical chemistry - A review." Talanta 57(3): 425-451.

Steefel, C. I. and S. B. Yabusaki (1995) OS3D/GIMRT, Software for modeling multicomponentmultidimensional reactive transport, User manual and programmer's guide Richland, WA, Pacific Northwest National Laboratory.

Stoller-Navarro (2004) Geochem04.mdb and A User's Guide to the Comprehensive Water Quality Database for Groundwater in the Vicinity of the Nevada Test Site Las Vegas, Nevada, DOE-NNSA.

Ware, S. D., A. Abdel-Fattah, M. Ding, P. W. Reimus, C. Sedlacek, M. Haga, E. Garcia and S. Chipera (2005) Radionuclide Sorption and Transport in the Lower Carbonate Aquifer and Tuff Confining Unit of Yucca Flat, Nevada Test Site, draft report, Los Alamos National Laboratory, Los Alamos, New Mexico.

Zavarin, M. and C. J. Bruton (2004a) A Non-Electrostatic Surface Complexation Approach to Modeling Radionuclide Migration at the Nevada Test Site: Aluminosilicates, UCRL-TR208672, Lawrence Livermore National Laboratory, Livermore.

Zavarin, M. and C. J. Bruton (2004b) A Non-Electrostatic Surface Complexation Approach to Modeling Radionuclide Migration at the Nevada Test Site: Iron Oxides and Calcite, UCRL-TR-208673, Lawrence Livermore National Laboratory, Livermore.

Zavarin, M., S. F. Carle and R. M. Maxwell (2004) Upscaling Radionuclide Retardation Linking the Surface Complexation and Ion Exchange Mechanistic Approach to a Linear Kd Approach, UCRL-TR-204713, Lawrence Livermore National Laboratory, Livermore, California. 
Zavarin, M., M. R. Johnson, S. K. Roberts, R. Pletcher, T. P. Rose, A. B. Kersting, G. Eaton, Q. Hu, E. Ramon, J. Walensky and P. Zhao (2005) Radionuclide Transport in Tuff and Carbonate Fractures from Yucca Flat, Nevada Test Site, UCRL-TR-219836, Lawrence Livermore National Laboratory, Livermore, California.

Zavarin, M., S. K. Roberts, P. W. Reimus and M. R. Johnson (2006) Summary of Radionuclide Reactive Transport Experiments in Fractured Tuff and Carbonate Rocks from Yucca Flat, Nevada Test Site, draft report, Lawrence Livermore National Laboratory, Livermore, California.

Zavarin, M., S. K. Roberts, T. P. Rose and D. L. Phinney (2002) Validating Mechanistic Sorption Model Parameters and Processes for Reactive Transport in Alluvium, UCRLID-149728, Lawrence Livermore National Laboratory, Livermore, California.

Zavarin, M., S. K. Roberts, N. Hakem, A. Kersting, and A. M. Sawvel. 2005. Eu(III), Sm(III), Np(V), $\mathrm{Pu}(\mathrm{V})$, and $\mathrm{Pu}(\mathrm{IV})$ sorption to calcite, Radiochimica Acta, 93: 93-102 


\section{APPENDIX}

Table A.1 LCA-5 run parameters.

Well $=$ ER 6-1, core depth $=\mathbf{2 6 0 1 . 7 - 2 6 0 2 . 8}$

Fracture aperture $=500$ microns

LCA-5 core mineralogy $=98.4 \%$ dolomite and $1.6 \%$ calcite

Porosity: $0.967 \%$, Permeability: $1.9 \times 10^{-3} \mathrm{md}$, Bulk density: $2.80 \mathrm{~g} / \mathrm{cm}^{3}$

Sorption solution of $\mathrm{NaHCO}_{3}, \mathrm{Mg}, \mathrm{K}, \mathrm{Ca},{ }^{3} \mathrm{H}, \mathrm{Sm}, \mathrm{Re}, \mathrm{U}, \mathrm{Pu}$

Experiment started on : 21 March 06 08:00

Start pumping sorption solution at: 28 March 06 16:00

Stopped pumping sorption solution at: 29 March 06 07:22

Pump and tubing volume (mL): 2.01

Table A.2 LCA-5 data: Radionuclides and pH.

\begin{tabular}{|c|c|c|c|c|c|c|c|c|}
\hline \multirow[t]{2}{*}{$\begin{array}{c}\text { Sample } \\
\#\end{array}$} & \multirow{2}{*}{$\begin{array}{c}\text { Sampling } \\
\text { Time } \\
\text { days }\end{array}$} & ${ }^{3} \mathbf{H}$ & Pu & Sm & $\operatorname{Re}$ & $\mathbf{U}$ & $\mathbf{P u}$ & \multirow[t]{2}{*}{ pH } \\
\hline & & \multicolumn{2}{|c|}{------- LSC ------- } & - & \multicolumn{3}{|c|}{ 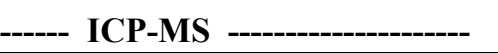 } & \\
\hline 3 & 0.08 & - & - & - & - & $4.58 \times 10-5$ & - & - \\
\hline 5 & 0.11 & $1.21 \times 10^{-3}$ & $-3.88 \times 10^{-4}$ & - & - & - & - & - \\
\hline 6 & 0.12 & - & - & $1.65 \times 10^{-2}$ & - & $7.50 \times 10^{-5}$ & $1.28 \times 10^{-2}$ & 8.39 \\
\hline 8 & 0.15 & $6.93 \times 10^{-2}$ & $2.91 \times 10^{-4}$ & - & - & - & - & - \\
\hline 9 & 0.16 & - & - & $7.81 \times 10^{-2}$ & $3.47 \times 10^{-1}$ & $2.58 \times 10^{-4}$ & $5.05 \times 10^{-2}$ & - \\
\hline 11 & 0.19 & $6.26 \times 10^{-1}$ & $3.20 \times 10^{-3}$ & - & - & - & - & - \\
\hline 12 & 0.20 & - & - & $1.19 \times 10^{-1}$ & $8.28 \times 10^{-1}$ & $7.00 \times 10^{-3}$ & $9.47 \times 10^{-2}$ & - \\
\hline 13 & 0.22 & $7.15 \times 10^{-1}$ & $1.55 \times 10^{-2}$ & - & - & - & - & - \\
\hline 15 & 0.24 & - & - & $1.37 \times 10^{-1}$ & $9.50 \times 10^{-1}$ & $3.83 \times 10^{-2}$ & $1.18 \times 10^{-1}$ & - \\
\hline 16 & 0.26 & $8.35 \times 10^{-1}$ & $1.86 \times 10^{-2}$ & - & - & - & - & 8.29 \\
\hline 18 & 0.28 & - & - & $1.20 \times 10^{-1}$ & $9.60 \times 10^{-1}$ & $9.75 \times 10^{-2}$ & $1.01 \times 10^{-1}$ & - \\
\hline 19 & 0.31 & $8.65 \times 10^{-1}$ & $1.26 \times 10^{-2}$ & - & - & - & - & - \\
\hline 21 & 0.33 & - & - & $1.23 \times 10^{-1}$ & $9.81 \times 10^{-1}$ & $1.74 \times 10^{-1}$ & $1.07 \times 10^{-1}$ & - \\
\hline 22 & 0.35 & $8.89 \times 10^{-1}$ & $3.73 \times 10^{-3}$ & - & - & - & - & - \\
\hline 24 & 0.37 & - & - & $1.22 \times 10^{-1}$ & $9.81 \times 10^{-1}$ & $2.37 \times 10^{-1}$ & $1.05 \times 10^{-1}$ & - \\
\hline 25 & 0.39 & $9.08 \times 10^{-1}$ & $1.46 \times 10^{-2}$ & - & - & - & - & 8.40 \\
\hline 27 & 0.41 & - & - & $1.36 \times 10^{-1}$ & $9.97 \times 10^{-1}$ & $2.96 \times 10^{-1}$ & $1.26 \times 10^{-1}$ & - \\
\hline 28 & 0.43 & $8.62 \times 10^{-1}$ & $4.94 \times 10^{-3}$ & - & - & - & - & - \\
\hline 30 & 0.45 & - & - & $4.95 \times 10^{-2}$ & $9.87 \times 10^{-1}$ & $3.34 \times 10^{-1}$ & $4.00 \times 10^{-2}$ & - \\
\hline 31 & 0.47 & $9.14 \times 10^{-1}$ & $1.58 \times 10^{-2}$ & - & - & - & - & - \\
\hline 33 & 0.49 & - & - & $7.17 \times 10^{-2}$ & 1.01 & $3.78 \times 10^{-1}$ & $6.74 \times 10^{-2}$ & - \\
\hline 36 & 0.53 & - & - & $7.24 \times 10^{-2}$ & 1.00 & $4.10 \times 10^{-1}$ & $7.16 \times 10^{-2}$ & 8.40 \\
\hline 39 & 0.58 & - & - & $4.52 \times 10^{-2}$ & 1.00 & $4.31 \times 10^{-1}$ & $5.47 \times 10^{-2}$ & - \\
\hline 40 & 0.60 & $9.05 \times 10^{-1}$ & $4.42 \times 10^{-2}$ & - & - & - & - & - \\
\hline 42 & 0.62 & - & - & $6.02 \times 10^{-2}$ & $9.87 \times 10^{-1}$ & $4.39 \times 10^{-1}$ & $7.79 \times 10^{-2}$ & - \\
\hline 45 & 0.66 & - & - & $3.10 \times 10^{-1}$ & 1.07 & $4.83 \times 10^{-1}$ & $3.35 \times 10^{-1}$ & - \\
\hline 46 & 0.68 & $9.14 \times 10^{-1}$ & $6.60 \times 10^{-2}$ & - & - & - & - & 8.42 \\
\hline 48 & 0.70 & - & - & $3.87 \times 10^{-2}$ & 1.05 & $4.77 \times 10^{-1}$ & $7.58 \times 10^{-2}$ & - \\
\hline 51 & 0.74 & - & - & $4.44 \times 10^{-2}$ & 1.06 & $4.83 \times 10^{-1}$ & $8.84 \times 10^{-2}$ & - \\
\hline
\end{tabular}


Table A.2 (continued).

\begin{tabular}{|c|c|c|c|c|c|c|c|c|}
\hline \multirow[t]{2}{*}{$\begin{array}{c}\text { Sample } \\
\#\end{array}$} & $\begin{array}{c}\text { Sampling } \\
\text { Time }\end{array}$ & ${ }^{3} \mathbf{H}$ & $\mathbf{P u}$ & Sm & $\operatorname{Re}$ & $\mathbf{U}$ & $\mathbf{P u}$ & \multirow[t]{2}{*}{ pH } \\
\hline & days & \multicolumn{2}{|c|}{ - } & \multicolumn{4}{|c|}{ - - } & \\
\hline 53 & 0.78 & $9.01 \times 10^{-1}$ & $8.19 \times 10^{-2}$ & - & - & - & - & - \\
\hline 54 & 0.78 & - & - & $2.94 \times 10^{-2}$ & 1.04 & $4.68 \times 10^{-1}$ & $7.58 \times 10^{-2}$ & - \\
\hline 56 & 0.82 & $8.92 \times 10^{-1}$ & $9.10 \times 10^{-2}$ & - & - & - & - & - \\
\hline 57 & 0.83 & - & - & $3.87 \times 10^{-2}$ & 1.04 & $4.67 \times 10^{-1}$ & $9.26 \times 10^{-2}$ & - \\
\hline 59 & 0.86 & $9.01 \times 10^{-1}$ & $8.66 \times 10^{-2}$ & - & - & - & - & - \\
\hline 60 & 0.87 & - & - & $2.77 \times 10^{-2}$ & $9.50 \times 10^{-1}$ & $4.25 \times 10^{-1}$ & $7.16 \times 10^{-2}$ & - \\
\hline 62 & 0.92 & $6.06 \times 10^{-1}$ & $1.13 \times 10^{-1}$ & - & - & - & - & 8.46 \\
\hline 63 & 0.93 & - & - & $1.51 \times 10^{-2}$ & $3.67 \times 10^{-1}$ & $4.09 \times 10^{-1}$ & $7.79 \times 10^{-2}$ & - \\
\hline 64 & 0.97 & $2.76 \times 10^{-1}$ & $1.18 \times 10^{-1}$ & - & - & - & - & - \\
\hline 66 & 1.01 & - & - & $6.88 \times 10^{-3}$ & $1.43 \times 10^{-1}$ & $3.35 \times 10^{-1}$ & $8.00 \times 10^{-2}$ & - \\
\hline 67 & 1.06 & $1.46 \times 10^{-1}$ & $1.40 \times 10^{-1}$ & - & - & - & - & - \\
\hline 69 & 1.10 & - & - & $8.96 \times 10^{-3}$ & $1.06 \times 10^{-1}$ & $2.52 \times 10^{-1}$ & $8.84 \times 10^{-2}$ & - \\
\hline 70 & 1.17 & $7.85 \times 10^{-2}$ & $1.26 \times 10^{-1}$ & - & - & - & - & - \\
\hline 72 & 1.23 & - & - & $6.31 \times 10^{-3}$ & $8.97 \times 10^{-2}$ & $1.47 \times 10^{-1}$ & $9.68 \times 10^{-2}$ & - \\
\hline 73 & 1.29 & $1.38 \times 10^{-1}$ & $1.48 \times 10^{-1}$ & - & - & - & - & - \\
\hline 76 & 1.40 & - & - & $4.37 \times 10^{-3}$ & $1.36 \times 10^{-1}$ & $1.24 \times 10^{-1}$ & $1.07 \times 10^{-1}$ & 8.38 \\
\hline 77 & 1.46 & $1.31 \times 10^{-1}$ & $1.71 \times 10^{-1}$ & - & - & - & - & - \\
\hline 79 & 1.54 & $9.55 \times 10^{-2}$ & $1.63 \times 10^{-1}$ & - & - & - & - & - \\
\hline 80 & 1.56 & - & - & $4.16 \times 10^{-3}$ & $5.36 \times 10^{-2}$ & $9.25 \times 10^{-2}$ & $1.05 \times 10^{-1}$ & - \\
\hline 81 & 1.63 & $5.94 \times 10^{-2}$ & $1.55 \times 10^{-1}$ & - & - & - & - & - \\
\hline 84 & 1.78 & - & - & $8.96 \times 10^{-3}$ & $8.75 \times 10^{-2}$ & $6.17 \times 10^{-2}$ & $9.89 \times 10^{-2}$ & - \\
\hline 85 & 1.81 & $8.36 \times 10^{-2}$ & $1.36 \times 10^{-1}$ & - & - & - & - & - \\
\hline 89 & 2.03 & $6.42 \times 10^{-2}$ & $1.11 \times 10^{-1}$ & $6.81 \times 10^{-3}$ & $7.11 \times 10^{-2}$ & $5.01 \times 10^{-2}$ & $7.79 \times 10^{-2}$ & 8.54 \\
\hline 92 & 2.19 & $5.65 \times 10^{-2}$ & $9.96 \times 10^{-2}$ & $6.67 \times 10^{-3}$ & $6.37 \times 10^{-2}$ & $4.71 \times 10^{-2}$ & $6.74 \times 10^{-2}$ & - \\
\hline 95 & 2.36 & $4.97 \times 10^{-2}$ & $8.26 \times 10^{-2}$ & $6.45 \times 10^{-3}$ & $5.94 \times 10^{-2}$ & $5.93 \times 10^{-2}$ & $5.68 \times 10^{-2}$ & - \\
\hline 98 & 2.53 & $3.69 \times 10^{-2}$ & $6.64 \times 10^{-2}$ & $5.73 \times 10^{-3}$ & $4.24 \times 10^{-2}$ & $5.25 \times 10^{-2}$ & $4.84 \times 10^{-2}$ & - \\
\hline 101 & 2.69 & $3.06 \times 10^{-2}$ & $5.44 \times 10^{-2}$ & $5.59 \times 10^{-3}$ & $3.34 \times 10^{-2}$ & $3.89 \times 10^{-2}$ & $4.25 \times 10^{-2}$ & - \\
\hline 104 & 2.88 & $2.56 \times 10^{-2}$ & $4.83 \times 10^{-2}$ & $6.38 \times 10^{-3}$ & $2.71 \times 10^{-2}$ & $3.09 \times 10^{-2}$ & $3.58 \times 10^{-2}$ & 8.48 \\
\hline 110 & 3.35 & $3.11 \times 10^{-2}$ & $4.19 \times 10^{-2}$ & $5.59 \times 10^{-3}$ & $4.08 \times 10^{-2}$ & $3.33 \times 10^{-2}$ & $3.16 \times 10^{-2}$ & - \\
\hline 116 & 3.85 & $1.30 \times 10^{-2}$ & $2.49 \times 10^{-2}$ & $4.95 \times 10^{-3}$ & $1.45 \times 10^{-2}$ & $1.40 \times 10^{-2}$ & $1.96 \times 10^{-2}$ & - \\
\hline 122 & 4.35 & $1.18 \times 10^{-2}$ & $1.56 \times 10^{-2}$ & $4.44 \times 10^{-3}$ & $1.75 \times 10^{-2}$ & $2.85 \times 10^{-2}$ & $1.75 \times 10^{-2}$ & - \\
\hline 128 & 4.85 & $8.66 \times 10^{-3}$ & $1.47 \times 10^{-2}$ & $4.95 \times 10^{-3}$ & $1.03 \times 10^{-2}$ & $2.08 \times 10^{-2}$ & $1.22 \times 10^{-2}$ & - \\
\hline 134 & 5.35 & $8.66 \times 10^{-3}$ & $1.62 \times 10^{-2}$ & $9.25 \times 10^{-3}$ & $1.86 \times 10^{-2}$ & $1.93 \times 10^{-2}$ & $1.14 \times 10^{-2}$ & - \\
\hline 143 & 6.08 & $1.26 \times 10^{-2}$ & $6.73 \times 10^{-3}$ & $1.49 \times 10^{-2}$ & $1.52 \times 10^{-2}$ & $2.04 \times 10^{-2}$ & $1.45 \times 10^{-2}$ & - \\
\hline 149 & 6.75 & $1.08 \times 10^{-2}$ & $5.96 \times 10^{-3}$ & $5.09 \times 10^{-3}$ & $1.75 \times 10^{-2}$ & $2.78 \times 10^{-2}$ & - & - \\
\hline 155 & 7.41 & $1.82 \times 10^{-3}$ & $3.88 \times 10^{-4}$ & $4.09 \times 10^{-3}$ & $2.28 \times 10^{-3}$ & $1.88 \times 10^{-2}$ & - & - \\
\hline 161 & 8.08 & $1.35 \times 10^{-3}$ & $-2.42 \times 10^{-4}$ & $3.94 \times 10^{-3}$ & $1.64 \times 10^{-3}$ & $1.43 \times 10^{-2}$ & - & - \\
\hline 166 & 8.64 & $2.34 \times 10^{-3}$ & $4.31 \times 10^{-3}$ & $4.30 \times 10^{-3}$ & $2.33 \times 10^{-3}$ & $1.03 \times 10^{-2}$ & - & - \\
\hline 172 & 9.30 & $1.12 \times 10^{-3}$ & $-8.72 \times 10^{-4}$ & $3.87 \times 10^{-3}$ & $1.22 \times 10^{-3}$ & $7.33 \times 10^{-3}$ & - & - \\
\hline 175 & 9.64 & $1.20 \times 10^{-3}$ & $7.41 \times 10^{-3}$ & $3.94 \times 10^{-3}$ & $1.01 \times 10^{-3}$ & $6.75 \times 10^{-3}$ & - & - \\
\hline $\mathrm{C}_{0} \mathrm{I}$ & ues* & $3.88 \times 10^{2}$ & $2.06 \times 10^{2}$ & $1.40 \times 10^{2}$ & $1.89 \times 10^{2}$ & $1.20 \times 10^{3}$ & $4.75 \times 10^{-1}$ & - \\
\hline
\end{tabular}

$* \mathrm{C}_{0}$ values for LSC are in counts/ min; $\mathrm{C}_{0}$ values for ICP-MS are in $\mathrm{ng} / \mathrm{mL}$. 
Table A.3 LCA-5 data: Major cations.

\begin{tabular}{|c|c|c|c|c|c|}
\hline Sample \# & $\begin{array}{c}\text { Sampling Time } \\
\text { days }\end{array}$ & $\mathbf{N a}$ & Mg & $\mathbf{K}$ & $\mathbf{C a}$ \\
\hline 3 & 0.13 & $7.39 \times 10^{-1}$ & 1.06 & $7.44 \times 10^{-1}$ & 1.26 \\
\hline 6 & 0.25 & $7.50 \times 10^{-1}$ & $4.99 \times 10^{-2}$ & $1.69 \times 10^{-2}$ & $5.85 \times 10^{-3}$ \\
\hline 9 & 0.38 & $8.55 \times 10^{-1}$ & $9.07 \times 10^{-2}$ & $2.82 \times 10^{-2}$ & $9.76 \times 10^{-3}$ \\
\hline 12 & 0.50 & $9.77 \times 10^{-1}$ & $6.35 \times 10^{-2}$ & $2.25 \times 10^{-2}$ & $6.50 \times 10^{-3}$ \\
\hline 15 & 0.63 & 1.02 & $6.35 \times 10^{-2}$ & $1.69 \times 10^{-2}$ & $6.50 \times 10^{-3}$ \\
\hline 18 & 0.75 & $9.88 \times 10^{-1}$ & $4.54 \times 10^{-2}$ & $1.13 \times 10^{-2}$ & $5.20 \times 10^{-3}$ \\
\hline 21 & 0.88 & $9.89 \times 10^{-1}$ & $8.62 \times 10^{-2}$ & $2.82 \times 10^{-2}$ & $9.76 \times 10^{-3}$ \\
\hline 24 & 1.00 & $9.83 \times 10^{-1}$ & $4.08 \times 10^{-2}$ & $1.13 \times 10^{-2}$ & $2.93 \times 10^{-3}$ \\
\hline 27 & 1.13 & $9.90 \times 10^{-1}$ & $4.99 \times 10^{-2}$ & $1.69 \times 10^{-2}$ & $6.50 \times 10^{-3}$ \\
\hline 30 & 1.25 & $9.87 \times 10^{-1}$ & $8.16 \times 10^{-2}$ & $2.25 \times 10^{-2}$ & $9.76 \times 10^{-3}$ \\
\hline 33 & 1.38 & 1.01 & $6.35 \times 10^{-2}$ & $2.25 \times 10^{-2}$ & $6.50 \times 10^{-3}$ \\
\hline 36 & 1.50 & 1.00 & $3.17 \times 10^{-2}$ & $7.89 \times 10^{-3}$ & $3.90 \times 10^{-3}$ \\
\hline 39 & 1.63 & 1.00 & $9.07 \times 10^{-2}$ & $2.82 \times 10^{-2}$ & $1.30 \times 10^{-2}$ \\
\hline 42 & 1.75 & $9.90 \times 10^{-1}$ & $6.35 \times 10^{-2}$ & $1.69 \times 10^{-2}$ & $6.50 \times 10^{-3}$ \\
\hline 48 & 2.00 & 1.05 & $6.80 \times 10^{-2}$ & $1.69 \times 10^{-2}$ & $9.76 \times 10^{-3}$ \\
\hline 51 & 2.13 & 1.07 & $4.08 \times 10^{-2}$ & $1.13 \times 10^{-2}$ & $5.85 \times 10^{-3}$ \\
\hline 54 & 2.25 & 1.06 & $3.63 \times 10^{-2}$ & $1.69 \times 10^{-2}$ & $5.85 \times 10^{-3}$ \\
\hline 57 & 2.38 & 1.06 & $6.80 \times 10^{-2}$ & $1.69 \times 10^{-2}$ & $5.85 \times 10^{-3}$ \\
\hline 60 & 2.50 & $9.87 \times 10^{-1}$ & $8.62 \times 10^{-2}$ & $2.25 \times 10^{-2}$ & $9.76 \times 10^{-3}$ \\
\hline 63 & 2.63 & $8.61 \times 10^{-1}$ & $3.63 \times 10^{-2}$ & $1.69 \times 10^{-2}$ & $5.53 \times 10^{-3}$ \\
\hline 66 & 2.75 & $7.80 \times 10^{-1}$ & $6.80 \times 10^{-2}$ & $2.82 \times 10^{-2}$ & $9.76 \times 10^{-3}$ \\
\hline 69 & 2.88 & $7.54 \times 10^{-1}$ & $4.08 \times 10^{-2}$ & $1.13 \times 10^{-2}$ & $5.85 \times 10^{-3}$ \\
\hline 72 & 3.00 & $7.57 \times 10^{-1}$ & $3.17 \times 10^{-2}$ & $1.69 \times 10^{-2}$ & $4.55 \times 10^{-3}$ \\
\hline 76 & 3.17 & $7.34 \times 10^{-1}$ & $3.17 \times 10^{-2}$ & $1.01 \times 10^{-2}$ & $3.90 \times 10^{-3}$ \\
\hline 80 & 3.33 & $7.35 \times 10^{-1}$ & $6.35 \times 10^{-2}$ & $2.82 \times 10^{-2}$ & $9.76 \times 10^{-3}$ \\
\hline 84 & 3.50 & $7.48 \times 10^{-1}$ & $4.08 \times 10^{-2}$ & $1.13 \times 10^{-2}$ & $4.88 \times 10^{-3}$ \\
\hline 89 & 3.71 & $7.89 \times 10^{-1}$ & $6.35 \times 10^{-2}$ & $2.82 \times 10^{-2}$ & $9.76 \times 10^{-3}$ \\
\hline 92 & 3.83 & $7.77 \times 10^{-1}$ & $4.08 \times 10^{-2}$ & $1.69 \times 10^{-2}$ & $5.53 \times 10^{-3}$ \\
\hline 95 & 3.96 & $7.67 \times 10^{-1}$ & $4.54 \times 10^{-2}$ & $1.69 \times 10^{-2}$ & $5.53 \times 10^{-3}$ \\
\hline 98 & 4.08 & $7.59 \times 10^{-1}$ & $7.71 \times 10^{-2}$ & $3.38 \times 10^{-2}$ & $9.76 \times 10^{-3}$ \\
\hline 101 & 4.21 & $7.49 \times 10^{-1}$ & $8.16 \times 10^{-2}$ & $3.38 \times 10^{-2}$ & $9.76 \times 10^{-3}$ \\
\hline 104 & 4.33 & $7.41 \times 10^{-1}$ & $2.72 \times 10^{-2}$ & $8.45 \times 10^{-3}$ & $3.25 \times 10^{-3}$ \\
\hline 110 & 4.58 & $7.77 \times 10^{-1}$ & $4.54 \times 10^{-2}$ & $2.25 \times 10^{-2}$ & $6.50 \times 10^{-3}$ \\
\hline 116 & 4.83 & $7.65 \times 10^{-1}$ & $8.16 \times 10^{-2}$ & $3.38 \times 10^{-2}$ & $9.76 \times 10^{-3}$ \\
\hline 122 & 5.08 & $8.18 \times 10^{-1}$ & $6.80 \times 10^{-2}$ & $2.25 \times 10^{-2}$ & $9.76 \times 10^{-3}$ \\
\hline 128 & 5.33 & $7.70 \times 10^{-1}$ & $4.99 \times 10^{-2}$ & $1.69 \times 10^{-2}$ & $6.50 \times 10^{-3}$ \\
\hline 134 & 5.58 & $7.87 \times 10^{-1}$ & $7.26 \times 10^{-2}$ & $3.38 \times 10^{-2}$ & $9.76 \times 10^{-3}$ \\
\hline 143 & 5.96 & $7.81 \times 10^{-1}$ & $5.44 \times 10^{-2}$ & $2.25 \times 10^{-2}$ & $6.50 \times 10^{-3}$ \\
\hline 149 & 6.21 & $7.74 \times 10^{-1}$ & $3.17 \times 10^{-2}$ & $1.69 \times 10^{-2}$ & $5.85 \times 10^{-3}$ \\
\hline 155 & 6.46 & $7.75 \times 10^{-1}$ & $5.44 \times 10^{-2}$ & $2.25 \times 10^{-2}$ & $6.50 \times 10^{-3}$ \\
\hline 161 & 6.71 & $7.82 \times 10^{-1}$ & $4.99 \times 10^{-2}$ & $2.25 \times 10^{-2}$ & $4.88 \times 10^{-3}$ \\
\hline 166 & 6.92 & $9.36 \times 10^{-1}$ & $6.35 \times 10^{-2}$ & $2.25 \times 10^{-2}$ & $9.76 \times 10^{-3}$ \\
\hline 172 & 7.17 & $7.86 \times 10^{-1}$ & $5.44 \times 10^{-2}$ & $2.25 \times 10^{-2}$ & $9.76 \times 10^{-3}$ \\
\hline 175 & 7.29 & $7.68 \times 10^{-1}$ & $4.54 \times 10^{-2}$ & $1.69 \times 10^{-2}$ & $6.18 \times 10^{-3}$ \\
\hline $\mathrm{C}_{0}$ Values & & $9.47 \times 10^{4}$ & $2.21 \times 10^{4}$ & $1.78 \times 10^{4}$ & $3.08 \times 10^{4}$ \\
\hline
\end{tabular}

$* \mathrm{C}_{0}$ values for ICP-MS are in $\mathrm{ng} / \mathrm{mL}$. 
Table A.4 LCA-6 run parameters.

\begin{tabular}{l}
\hline Well $=$ ER 6-1, core depth $=\mathbf{2 6 1 9 . 0 - 2 6 2 0 . 0}$ \\
Fracture aperture $=50$ microns \\
LCA-6 core mineralogy $=100 \%$ dolomite \\
Porosity: $4.894 \%$, Permeability: $6.0 \mathrm{~m} / \mathrm{d}$, Bulk density: $2.70 \mathrm{~g} / \mathrm{cm}^{3}$ \\
Sorption solution of $\mathrm{NaHCO}_{3}, \mathrm{Mg}, \mathrm{K}, \mathrm{Ca},{ }^{3} \mathrm{H}, \mathrm{Sm}, \mathrm{Re}, \mathrm{U}, \mathrm{Pu}$ \\
Experiment started on: $28 \mathrm{June} 0610: 00$ \\
Start pumping sorption solution at: $11 \mathrm{July} 0614: 56$ \\
Stopped pumping sorption solution at: $12 \mathrm{July} 0607: 47$ \\
Pump and tubing volume $(\mathrm{mL}): 2.521 \mathrm{~mL}$ \\
\hline
\end{tabular}

Table A.5 LCA-6 data: Radionuclides and pH.

\begin{tabular}{|c|c|c|c|c|c|c|c|c|}
\hline \multirow[t]{2}{*}{$\begin{array}{c}\text { Sample } \\
\#\end{array}$} & \multirow{2}{*}{$\begin{array}{c}\text { Sampling } \\
\text { Time } \\
\text { days }\end{array}$} & ${ }^{3} \mathbf{H}$ & $\mathbf{P u}$ & Sm & $\operatorname{Re}$ & $\mathbf{U}$ & $\mathbf{P u}$ & \multirow[t]{2}{*}{$\mathbf{p H}$} \\
\hline & & \multicolumn{2}{|c|}{----- LSC - ------- } & $\mathrm{C} / \mathrm{C}_{0}$ & ICP- & IS -----י- & -.------- & \\
\hline 5 & 0.06 & $2.50 \times 10^{-4}$ & $1.90 \times 10^{-3}$ & - & - & - & - & - \\
\hline 8 & 0.10 & $3.28 \times 10^{-3}$ & $2.08 \times 10^{-2}$ & - & - & - & - & 7.73 \\
\hline 9 & 0.12 & - & - & $2.39 \times 10^{-2}$ & $3.28 \times 10^{-2}$ & $1.02 \times 10^{-1}$ & $8.63 \times 10^{-2}$ & - \\
\hline 11 & 0.15 & $9.45 \times 10^{-2}$ & $7.06 \times 10^{-2}$ & - & - & - & - & - \\
\hline 12 & 0.16 & - & - & $3.87 \times 10^{-2}$ & $1.79 \times 10^{-1}$ & $2.39 \times 10^{-1}$ & $1.94 \times 10^{-1}$ & - \\
\hline 13 & 0.17 & $1.63 \times 10^{-1}$ & $9.75 \times 10^{-2}$ & - & - & - & - & - \\
\hline 15 & 0.20 & - & - & $5.62 \times 10^{-2}$ & $3.09 \times 10^{-1}$ & $3.34 \times 10^{-1}$ & $2.63 \times 10^{-1}$ & - \\
\hline 16 & 0.22 & $2.82 \times 10^{-1}$ & $1.24 \times 10^{-1}$ & - & - & - & - & - \\
\hline 18 & 0.24 & - & - & $7.09 \times 10^{-2}$ & $4.12 \times 10^{-1}$ & $4.18 \times 10^{-1}$ & $3.22 \times 10^{-1}$ & - \\
\hline 19 & 0.26 & $3.66 \times 10^{-1}$ & $1.58 \times 10^{-1}$ & - & - & - & - & - \\
\hline 21 & 0.28 & - & - & $8.38 \times 10^{-2}$ & $4.80 \times 10^{-1}$ & $4.74 \times 10^{-1}$ & $3.57 \times 10^{-1}$ & - \\
\hline 22 & 0.30 & $4.36 \times 10^{-1}$ & $1.73 \times 10^{-1}$ & - & - & - & - & - \\
\hline 24 & 0.33 & - & - & $9.48 \times 10^{-2}$ & $5.53 \times 10^{-1}$ & $5.35 \times 10^{-1}$ & $4.06 \times 10^{-1}$ & 7.92 \\
\hline 25 & 0.34 & $4.80 \times 10^{-1}$ & $1.96 \times 10^{-1}$ & - & - & - & - & - \\
\hline 27 & 0.37 & - & - & $1.03 \times 10^{-1}$ & $5.87 \times 10^{-1}$ & $5.68 \times 10^{-1}$ & $4.24 \times 10^{-1}$ & - \\
\hline 28 & 0.38 & $5.26 \times 10^{-1}$ & $2.03 \times 10^{-1}$ & - & - & - & - & - \\
\hline 30 & 0.41 & - & - & $1.13 \times 10^{-1}$ & $6.40 \times 10^{-1}$ & $6.12 \times 10^{-1}$ & $4.53 \times 10^{-1}$ & - \\
\hline 31 & 0.42 & $5.57 \times 10^{-1}$ & $2.29 \times 10^{-1}$ & - & - & - & - & - \\
\hline 33 & 0.45 & - & - & $1.73 \times 10^{-1}$ & $6.97 \times 10^{-1}$ & $6.73 \times 10^{-1}$ & $4.92 \times 10^{-1}$ & - \\
\hline 34 & 0.47 & $6.20 \times 10^{-1}$ & $2.51 \times 10^{-1}$ & - & - & - & - & - \\
\hline 36 & 0.49 & & & $1.79 \times 10^{-1}$ & $7.13 \times 10^{-1}$ & $6.90 \times 10^{-1}$ & $5.12 \times 10^{-1}$ & - \\
\hline 37 & 0.51 & $6.50 \times 10^{-1}$ & $2.62 \times 10^{-1}$ & - & - & - & - & - \\
\hline 39 & 0.53 & - & - & $1.61 \times 10^{-1}$ & $7.44 \times 10^{-1}$ & $7.19 \times 10^{-1}$ & $5.24 \times 10^{-1}$ & - \\
\hline 40 & 0.55 & $6.59 \times 10^{-1}$ & $2.70 \times 10^{-1}$ & - & - & - & - & - \\
\hline 42 & 0.58 & - & - & $1.88 \times 10^{-1}$ & $7.51 \times 10^{-1}$ & $7.31 \times 10^{-1}$ & $5.34 \times 10^{-1}$ & - \\
\hline 45 & 0.62 & & & $1.95 \times 10^{-1}$ & $7.59 \times 10^{-1}$ & $7.37 \times 10^{-1}$ & $5.40 \times 10^{-1}$ & - \\
\hline 46 & 0.63 & $6.98 \times 10^{-1}$ & $2.88 \times 10^{-1}$ & - & - & - & - & - \\
\hline 48 & 0.66 & - & - & $1.98 \times 10^{-1}$ & $7.70 \times 10^{-1}$ & $7.46 \times 10^{-1}$ & $5.28 \times 10^{-1}$ & - \\
\hline 51 & 0.70 & - & - & $2.02 \times 10^{-1}$ & $7.78 \times 10^{-1}$ & $7.54 \times 10^{-1}$ & $5.59 \times 10^{-1}$ & - \\
\hline 52 & 0.72 & $7.09 \times 10^{-1}$ & $2.95 \times 10^{-1}$ & - & - & - & - & - \\
\hline 54 & 0.74 & - & - & $2.13 \times 10^{-1}$ & $7.99 \times 10^{-1}$ & $7.66 \times 10^{-1}$ & $5.61 \times 10^{-1}$ & - \\
\hline 56 & 0.77 & $7.18 \times 10^{-1}$ & $3.10 \times 10^{-1}$ & - & - & - & - & - \\
\hline 57 & 0.78 & - & - & $2.02 \times 10^{-1}$ & $7.97 \times 10^{-1}$ & $7.61 \times 10^{-1}$ & $5.63 \times 10^{-1}$ & - \\
\hline
\end{tabular}


Table A.5 (continued).

\begin{tabular}{|c|c|c|c|c|c|c|c|c|}
\hline \multirow[t]{2}{*}{$\begin{array}{c}\text { Sample } \\
\#\end{array}$} & $\begin{array}{c}\text { Sampling } \\
\text { Time }\end{array}$ & ${ }^{3} \mathbf{H}$ & $\mathbf{P u}$ & Sm & $\operatorname{Re}$ & $\mathbf{U}$ & $\mathbf{P u}$ & \multirow[t]{2}{*}{ pH } \\
\hline & days & \multicolumn{2}{|c|}{------- LSC -------- } & ------------. & \multicolumn{3}{|c|}{ ICP-MS - } & \\
\hline 60 & 0.83 & $6.74 \times 10^{-1}$ & $2.44 \times 10^{-1}$ & $1.52 \times 10^{-1}$ & $7.28 \times 10^{-1}$ & $5.97 \times 10^{-1}$ & $4.36 \times 10^{-1}$ & - \\
\hline 63 & 0.88 & - & - & $1.17 \times 10^{-1}$ & $5.59 \times 10^{-1}$ & $4.41 \times 10^{-1}$ & $3.06 \times 10^{-1}$ & - \\
\hline 64 & 0.90 & $4.86 \times 10^{-1}$ & $1.51 \times 10^{-1}$ & - & - & - & - & - \\
\hline 66 & 0.94 & - & - & $8.38 \times 10^{-2}$ & $4.18 \times 10^{-1}$ & $3.24 \times 10^{-1}$ & $2.24 \times 10^{-1}$ & - \\
\hline 69 & 0.98 & $3.34 \times 10^{-1}$ & $1.06 \times 10^{-1}$ & $6.81 \times 10^{-2}$ & $3.40 \times 10^{-1}$ & $2.67 \times 10^{-1}$ & $1.77 \times 10^{-1}$ & - \\
\hline 72 & 1.04 & - & - & $5.34 \times 10^{-2}$ & $2.39 \times 10^{-1}$ & $1.92 \times 10^{-1}$ & $1.28 \times 10^{-1}$ & - \\
\hline 74 & 1.10 & $1.95 \times 10^{-1}$ & $6.49 \times 10^{-2}$ & - & - & - & - & - \\
\hline 75 & 1.13 & - & - & $3.77 \times 10^{-2}$ & $1.81 \times 10^{-1}$ & $1.36 \times 10^{-1}$ & $8.83 \times 10^{-2}$ & 7.90 \\
\hline 80 & 1.26 & $1.24 \times 10^{-1}$ & $4.18 \times 10^{-2}$ & $2.58 \times 10^{-2}$ & $1.21 \times 10^{-1}$ & $8.92 \times 10^{-2}$ & $5.69 \times 10^{-2}$ & - \\
\hline 85 & 1.40 & - & - & $2.12 \times 10^{-2}$ & $8.79 \times 10^{-2}$ & $6.47 \times 10^{-2}$ & $3.92 \times 10^{-2}$ & - \\
\hline 86 & 1.43 & $8.84 \times 10^{-2}$ & $3.49 \times 10^{-2}$ & - & - & - & - & - \\
\hline 90 & 1.54 & - & - & $1.66 \times 10^{-2}$ & $7.18 \times 10^{-2}$ & $5.26 \times 10^{-2}$ & $3.34 \times 10^{-2}$ & 7.91 \\
\hline 92 & 1.60 & $6.72 \times 10^{-2}$ & $3.22 \times 10^{-2}$ & - & - & - & - & - \\
\hline 95 & 1.68 & - & - & $1.66 \times 10^{-2}$ & $6.03 \times 10^{-2}$ & $4.64 \times 10^{-2}$ & $3.14 \times 10^{-2}$ & 7.87 \\
\hline 98 & 1.76 & $5.76 \times 10^{-2}$ & $2.92 \times 10^{-2}$ & - & - & - & - & - \\
\hline 100 & 1.82 & - & - & $1.20 \times 10^{-2}$ & $5.36 \times 10^{-2}$ & $4.15 \times 10^{-2}$ & $2.49 \times 10^{-2}$ & 7.90 \\
\hline 104 & 1.93 & $5.38 \times 10^{-2}$ & $2.68 \times 10^{-2}$ & - & - & - & - & - \\
\hline 105 & 1.96 & - & - & $1.01 \times 10^{-2}$ & $4.89 \times 10^{-2}$ & $3.65 \times 10^{-2}$ & $2.35 \times 10^{-2}$ & - \\
\hline 110 & 2.17 & $3.98 \times 10^{-2}$ & $2.52 \times 10^{-2}$ & $1.01 \times 10^{-2}$ & $3.90 \times 10^{-2}$ & $3.15 \times 10^{-2}$ & $2.16 \times 10^{-2}$ & - \\
\hline 115 & 2.44 & $3.39 \times 10^{-2}$ & $2.21 \times 10^{-2}$ & $8.28 \times 10^{-3}$ & $3.48 \times 10^{-2}$ & $2.70 \times 10^{-2}$ & $1.96 \times 10^{-2}$ & - \\
\hline 120 & 2.72 & $2.87 \times 10^{-2}$ & $2.14 \times 10^{-2}$ & $6.44 \times 10^{-3}$ & $2.86 \times 10^{-2}$ & $2.41 \times 10^{-2}$ & $1.73 \times 10^{-2}$ & 8.15 \\
\hline 128 & 3.47 & $1.73 \times 10^{-2}$ & $2.11 \times 10^{-2}$ & - & $1.82 \times 10^{-2}$ & $1.79 \times 10^{-2}$ & $1.14 \times 10^{-2}$ & - \\
\hline 136 & 4.36 & $9.87 \times 10^{-3}$ & $1.24 \times 10^{-2}$ & - & $1.14 \times 10^{-2}$ & $1.33 \times 10^{-2}$ & $9.22 \times 10^{-3}$ & 8.17 \\
\hline 144 & 5.25 & $7.90 \times 10^{-3}$ & $8.68 \times 10^{-3}$ & - & $9.88 \times 10^{-3}$ & $1.05 \times 10^{-2}$ & $7.26 \times 10^{-3}$ & 8.24 \\
\hline 150 & 5.92 & $8.38 \times 10^{-3}$ & $1.09 \times 10^{-2}$ & - & $1.14 \times 10^{-2}$ & $1.07 \times 10^{-2}$ & $7.26 \times 10^{-3}$ & - \\
\hline 156 & 6.58 & $6.40 \times 10^{-3}$ & $8.68 \times 10^{-3}$ & - & $7.80 \times 10^{-3}$ & $8.13 \times 10^{-3}$ & $5.69 \times 10^{-3}$ & 8.07 \\
\hline 162 & 7.25 & $3.45 \times 10^{-3}$ & $1.00 \times 10^{-2}$ & - & $5.72 \times 10^{-3}$ & $6.22 \times 10^{-3}$ & $4.51 \times 10^{-3}$ & - \\
\hline 168 & 7.92 & $2.53 \times 10^{-3}$ & $4.16 \times 10^{-3}$ & - & $4.16 \times 10^{-3}$ & $5.89 \times 10^{-3}$ & - & - \\
\hline 174 & 8.58 & $2.27 \times 10^{-3}$ & $2.45 \times 10^{-3}$ & - & $3.64 \times 10^{-3}$ & $4.98 \times 10^{-3}$ & - & 8.13 \\
\hline 179 & 9.14 & $5.46 \times 10^{-4}$ & $-1.25 \times 10^{-3}$ & - & $3.12 \times 10^{-3}$ & - & - & - \\
\hline 184 & 9.69 & $1.18 \times 10^{-3}$ & $7.06 \times 10^{-3}$ & - & $2.60 \times 10^{-3}$ & - & - & 8.06 \\
\hline \multicolumn{2}{|c|}{$\mathrm{C}_{0}$ Values* } & $3.48 \times 10^{2}$ & $2.15 \times 10^{2}$ & $1.09 \times 10^{2}$ & $1.92 \times 10^{2}$ & $1.21 \times 10^{3}$ & $5.10 \times 10^{-1}$ & - \\
\hline
\end{tabular}

$* \mathrm{C}_{0}$ values for LSC are in counts/ min; $\mathrm{C}_{0}$ values for ICP-MS are in $\mathrm{ng} / \mathrm{mL}$. 
Table A.6 LCA-6 data: Major cations.

\begin{tabular}{|c|c|c|c|c|c|}
\hline $\begin{array}{c}\text { Sample } \\
\#\end{array}$ & $\begin{array}{c}\text { Sampling } \\
\text { Time }\end{array}$ & $\mathbf{N a}$ & Mg & $\mathbf{K}$ & $\mathrm{Ca}$ \\
\hline & days & - & C/ & $y_{0}$ & ------ \\
\hline 6 & 0.08 & 0.64 & 1.12 & 0.14 & 1.59 \\
\hline 9 & 0.12 & 0.66 & 1.14 & 0.14 & 1.54 \\
\hline 12 & 0.16 & 0.64 & 1.07 & 0.17 & 1.35 \\
\hline 15 & 0.20 & 0.75 & 1.21 & 0.27 & 1.55 \\
\hline 18 & 0.24 & 0.78 & 1.25 & 0.35 & 1.50 \\
\hline 21 & 0.28 & 0.80 & 1.23 & 0.40 & 1.51 \\
\hline 24 & 0.33 & 0.83 & 1.25 & 0.46 & 1.52 \\
\hline 27 & 0.37 & 0.85 & 1.25 & 0.51 & 1.58 \\
\hline 30 & 0.41 & 0.87 & 1.28 & 0.56 & 1.58 \\
\hline 33 & 0.45 & 0.88 & 1.18 & 0.67 & 1.44 \\
\hline 36 & 0.49 & 0.88 & 1.17 & 0.67 & 1.43 \\
\hline 39 & 0.53 & 0.90 & 1.18 & 0.70 & 1.49 \\
\hline 42 & 0.58 & 0.90 & 1.21 & 0.71 & 1.45 \\
\hline 45 & 0.62 & 0.89 & 1.18 & 0.72 & 1.48 \\
\hline 48 & 0.66 & 0.90 & 1.19 & 0.74 & 1.44 \\
\hline 51 & 0.70 & 0.89 & 1.17 & 0.74 & 1.46 \\
\hline 54 & 0.74 & 0.93 & 1.22 & 0.76 & 1.49 \\
\hline 57 & 0.78 & 0.92 & 1.20 & 0.75 & 1.45 \\
\hline 60 & 0.83 & 0.90 & 1.17 & 0.73 & 1.43 \\
\hline 63 & 0.88 & 0.88 & 1.17 & 0.66 & 1.41 \\
\hline 66 & 0.94 & 0.84 & 1.13 & 0.54 & 1.41 \\
\hline 69 & 0.98 & 0.83 & 1.14 & 0.47 & 1.32 \\
\hline 72 & 1.04 & 0.82 & 1.11 & 0.40 & 1.26 \\
\hline 75 & 1.13 & 0.82 & 1.12 & 0.35 & 1.25 \\
\hline 80 & 1.26 & 0.81 & 1.12 & 0.30 & 1.28 \\
\hline 85 & 1.40 & 0.79 & 1.11 & 0.26 & 1.25 \\
\hline 90 & 1.54 & 0.80 & 1.14 & 0.25 & 1.25 \\
\hline 95 & 1.68 & 0.79 & 1.12 & 0.23 & 1.28 \\
\hline 100 & 1.82 & 0.80 & 1.15 & 0.23 & 1.31 \\
\hline 105 & 1.96 & 0.80 & 1.16 & 0.22 & 1.33 \\
\hline 110 & 2.17 & 0.81 & 1.17 & 0.21 & 1.34 \\
\hline 115 & 2.44 & 0.81 & 1.21 & 0.21 & 1.36 \\
\hline 120 & 2.72 & 0.80 & 1.19 & 0.20 & 1.36 \\
\hline 128 & 3.47 & 0.81 & 1.21 & 0.19 & 1.36 \\
\hline 136 & 4.36 & 0.81 & 1.20 & 0.18 & 1.32 \\
\hline 144 & 5.25 & 0.81 & 1.18 & 0.18 & 1.39 \\
\hline 150 & 5.92 & 0.81 & 1.26 & 0.18 & 1.44 \\
\hline 156 & 6.58 & 0.81 & 1.24 & 0.18 & 1.43 \\
\hline 162 & 7.25 & 0.80 & 1.18 & 0.17 & 1.31 \\
\hline 168 & 7.92 & 0.81 & 1.17 & 0.17 & 1.20 \\
\hline 174 & 8.58 & 0.81 & 1.19 & 0.17 & 1.33 \\
\hline 179 & 9.14 & 0.82 & 1.19 & 0.17 & 1.20 \\
\hline 184 & 9.69 & 0.85 & 1.22 & 0.17 & 1.22 \\
\hline \multicolumn{2}{|c|}{$\mathrm{C}_{0}$ Values * } & $8.45 \times 10^{4}$ & $2.13 \times 10^{4}$ & $8.74 \times 10^{4}$ & $2.15 \times 10^{4}$ \\
\hline
\end{tabular}

$* \mathrm{C}_{0}$ values for cations are in $\mathrm{ng} / \mathrm{mL}$. 


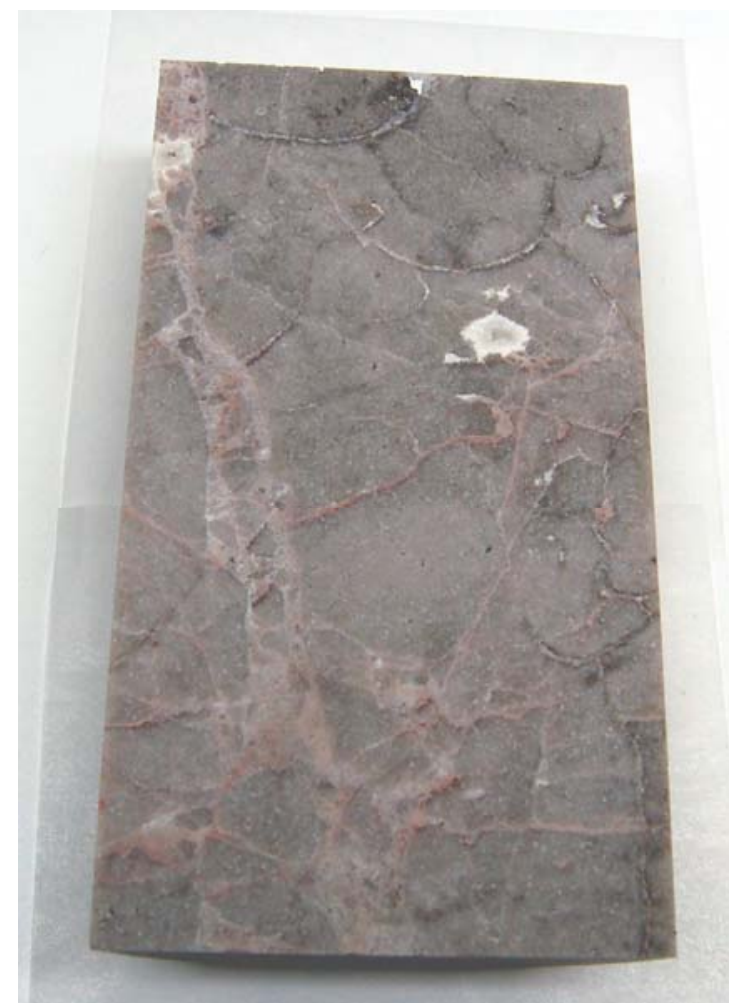

Figure A.1 LCA-5 Synthetic parallel plate fracture.

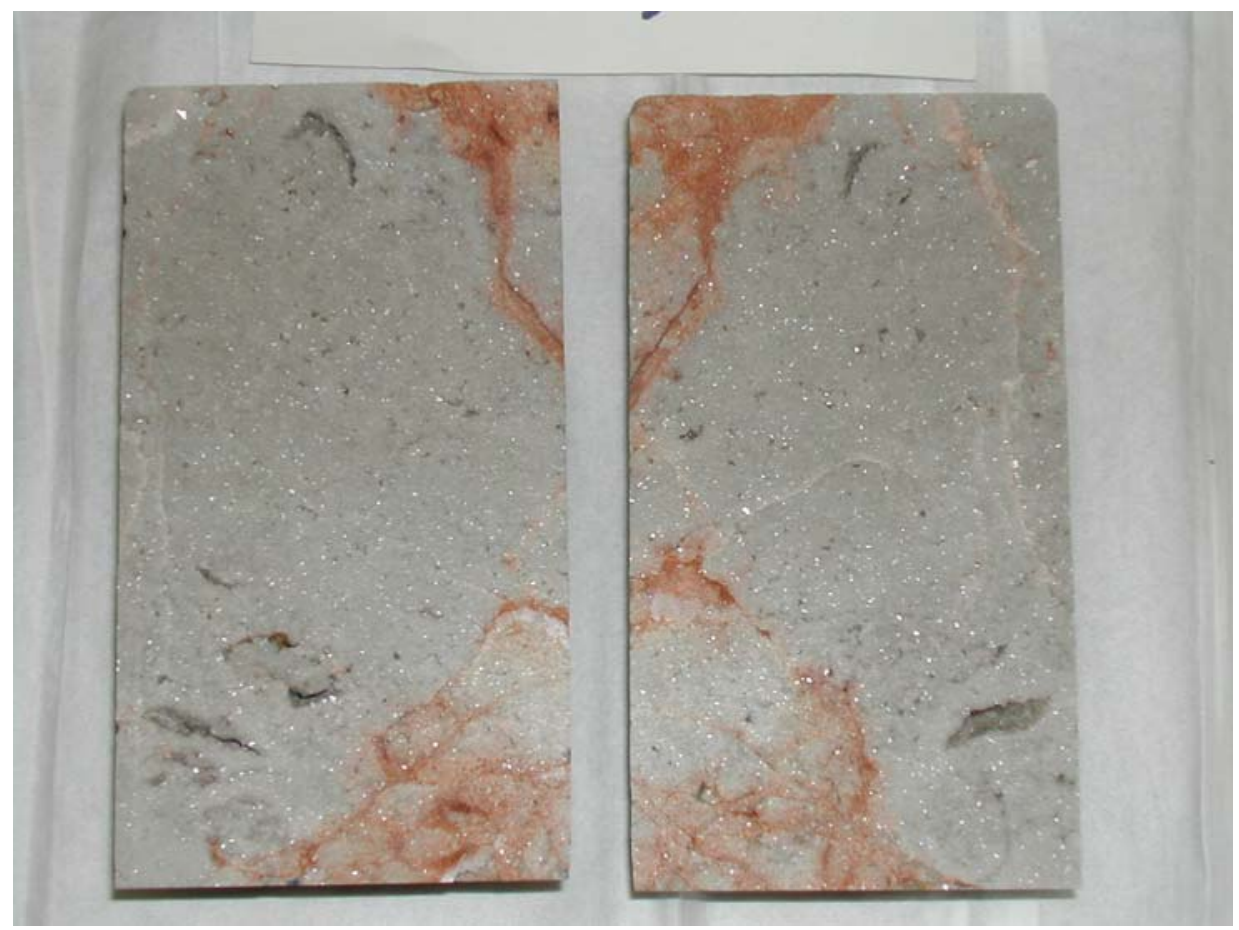

Figure A.2 LCA-6 Synthetic parallel plate fracture. 